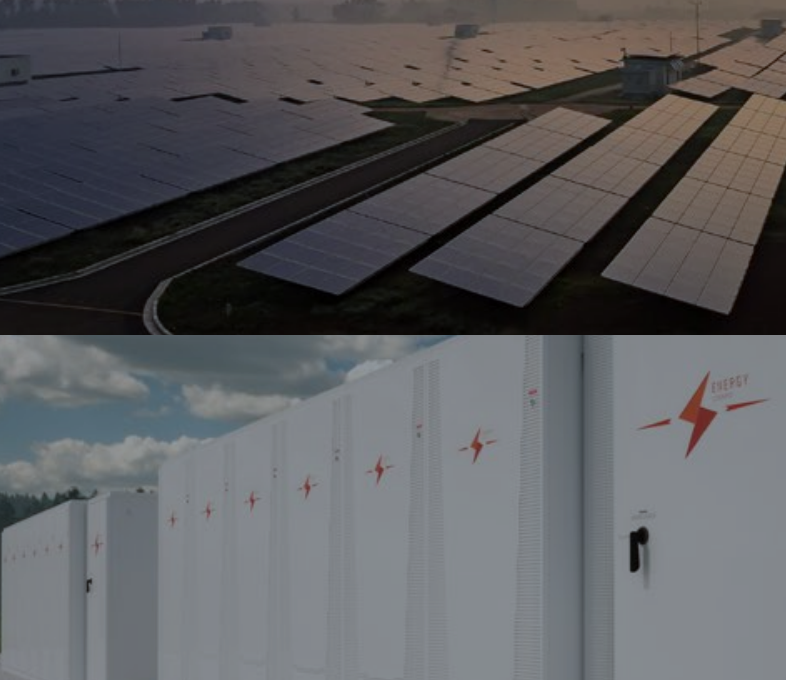

Storage Futures Study Economic Potential of Diurnal Storage in the U.S. Power Sector

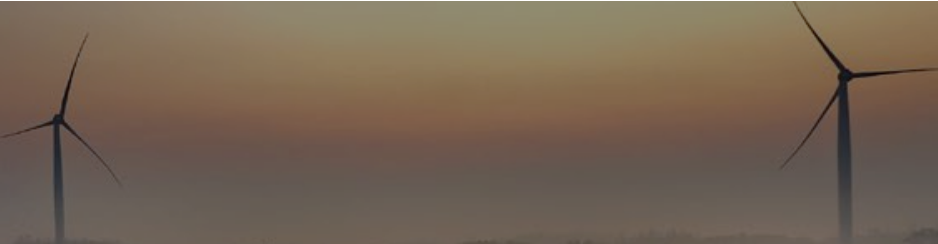




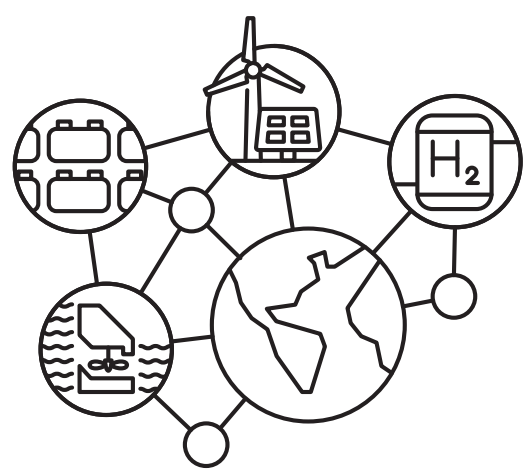

Storage Futures Study

\section{Economic Potential of Diurnal Storage in the U.S. Power Sector}

A. Will Frazier, Wesley Cole, Paul Denholm, Scott Machen, Nathaniel Gates, and Nate Blair 


\section{NOTICE}

This work was authored by the National Renewable Energy Laboratory, operated by Alliance for Sustainable Energy, LLC, for the U.S. Department of Energy (DOE) under Contract No. DE-AC36-08GO28308. Funding provided by U.S. Department of Energy Office of Energy Efficiency and Renewable Energy Solar Energy Technologies Office, U.S. Department of Energy Office of Energy Efficiency and Renewable Energy Wind Energy Technologies Office, U.S. Department of Energy Office of Energy Efficiency and Renewable Energy Water Power Technologies Office and U.S. Department of Energy Office of Energy Efficiency and Renewable Energy Office of Strategic Analysis. The views expressed herein do not necessarily represent the views of the DOE or the U.S. Government.

This report is available at no cost from the National Renewable Energy Laboratory (NREL) at www.nrel.gov/publications.

U.S. Department of Energy (DOE) reports produced after 1991 and a growing number of pre-1991 documents are available free via www.OSTI.gov.

Cover Photos by Dennis Schroeder: (clockwise, left to right) NREL 51934, NREL 45897, NREL 42160, NREL 45891, NREL 48097, NREL 46526.

NREL prints on paper that contains recycled content. 


\section{Preface}

This report is one in a series of the National Renewable Energy Laboratory's Storage Futures Study (SFS) publications. The SFS is a multiyear research project that explores the role and impact of energy storage in the evolution and operation of the U.S. power sector. The SFS is designed to examine the potential impact of energy storage technology advancement on the deployment of utility-scale storage and the adoption of distributed storage, and the implications for future power system infrastructure investment and operations. The research findings and supporting data will be published as a series of publications. The table on the next page lists the planned publications and specific research topics they will examine under the SFS.

This report, the third in the SFS series, performs a set of cost-driven scenarios using the ReEDS model to examine both grid-scale storage deployment as well as relationships between this deployment and variable renewable energy (VRE) penetration. This report assesses the economic potential for utility-scale diurnal storage and the effects that storage capacity additions could have on power system evolution and operations

The SFS series provides data and analysis in support of the U.S. Department of Energy's Energy Storage Grand Challenge, a comprehensive program to accelerate the development, commercialization, and utilization of next-generation energy storage technologies and sustain American global leadership in energy storage. The Energy Storage Grand Challenge employs a use case framework to ensure storage technologies can cost-effectively meet specific needs, and it incorporates a broad range of technologies in several categories: electrochemical, electromechanical, thermal, flexible generation, flexible buildings, and power electronics.

More information, any supporting data associated with this report, links to other reports in the series, and other information about the broader study are available at https://www.nrel.gov/analysis/storage-futures.html. 


\begin{tabular}{|c|c|c|}
\hline Title & Description & Relation to this Report \\
\hline $\begin{array}{l}\text { The Four Phases of } \\
\text { Storage Deployment: } \\
\text { A Framework for the } \\
\text { Expanding Role of } \\
\text { Storage in the U.S. } \\
\text { Power System }\end{array}$ & $\begin{array}{l}\text { Explores the roles and opportunities for } \\
\text { new, cost-competitive stationary energy } \\
\text { storage with a conceptual framework } \\
\text { based on four phases of current and } \\
\text { potential future storage deployment, and } \\
\text { presents a value proposition for energy } \\
\text { storage that could result in cost-effective } \\
\text { deployments reaching hundreds of } \\
\text { gigawatts (GW) of installed capacity }\end{array}$ & $\begin{array}{l}\text { Provides broader context on } \\
\text { the implications of the cost } \\
\text { and performance } \\
\text { characteristics discussed in } \\
\text { this report, including the } \\
\text { specific grid services they } \\
\text { may enable in various phases } \\
\text { of storage deployment. This } \\
\text { framework is supported by } \\
\text { the results of scenarios in this } \\
\text { report. }\end{array}$ \\
\hline
\end{tabular}

\begin{tabular}{l}
\hline Energy Storage \\
Technology Modeling \\
Input Data Report
\end{tabular}

Reviews the current characteristics of a broad range of mechanical, thermal, and electrochemical storage technologies with application to the power sector. Provides current and future projections of cost, performance characteristics, and locational availability of specific commercial technologies already deployed, including lithium-ion battery systems and pumped storage hydropower.
Provides detailed background around the battery and PSH cost and performance values used as inputs to the modeling performed in this report.
Assesses the economic potential for utilityscale diurnal storage and the effects that storage capacity additions could have on power system evolution and operations

\section{Economic Potential of Diurnal Storage in the U.S. Power Sector}

Distributed Storage

Customer Adoption Scenarios
Assesses the customer adoption of distributed diurnal storage for several future scenarios and the implications for the deployment of distributed generation and power system evolution

Grid Operational
Implications of
Widespread Storage
Deployment

Assesses the operation and associated value streams of energy storage for several power system evolution scenarios and explores the implications of seasonal storage on grid operations
This report.

Analyzes distributed storage adoption scenarios to test the various cost trajectories and assumptions in parallel to the grid storage deployments modeled in this report.

Considers the operational implications of storage deployment and grid evolution scenarios to examine and expand on the grid-scale scenario results found with ReEDS in this report

Storage Futures Study: Executive Summary and Synthesis of Findings
Synthesizes and summarizes findings from the entire series and related analyses and reports, and identifies topics for further research
Includes a discussion of all other aspects of the study and provides context for the results of this report 


\section{Acknowledgments}

We would like to acknowledge the contributions of the entire Storage Futures Study team as well as our U.S. Department of Energy (DOE) Office of Strategic Analysis colleagues as core contributors to this document. Those contributors include Chad Augustine, Ben Sigrin, Kevin McCabe, and Ashreeta Prasanna from the National Renewable Energy Laboratory (NREL) and Kara Podkaminer from DOE. We would also acknowledge the feedback and contributions of other NREL staff, including Chad Hunter, Evan Reznicek, Michael Penev, Greg Stark, Vignesh Ramasamy, David Feldman, and Trieu Mai, We also would like to thank the technical review committee for input, including Doug Arent (NREL/Chair), Paul Albertus, Ines Azevedo, Ryan Wiser, Susan Babinec, Aaron Bloom, Chris Namovicz, Arvind Jaggi, Keith Parks, Kiran Kumaraswamy, Granger Morgan, Cara Marcy, Vincent Sprenkle, Oliver Schmidt, David Rosner, John Gavan, and Howard Gruenspecht. Finally, additional thoughts and suggestions came from various technical experts at DOE, including Paul Spitsen, Kathryn Jackson, Neha Rustagi, Marc Melaina, Andrew Dawson, Adria Brooks, Sam Baldwin, Sarah Garman.

This work was authored by the National Renewable Energy Laboratory, operated by Alliance for Sustainable Energy, LLC, for the U.S. Department of Energy (DOE) under Contract No. DEAC36-08GO28308. Funding provided by U.S. Department of Energy Office of Energy Efficiency and Renewable Energy Solar Energy Technologies Office, U.S. Department of Energy Office of Energy Efficiency and Renewable Energy Wind Energy Technologies Office, U.S. Department of Energy Office of Energy Efficiency and Renewable Energy Water Power Technologies Office and U.S. Department of Energy Office of Energy Efficiency and Renewable Energy Office of Strategic Analysis. The views expressed in the article do not necessarily represent the views of the DOE or the U.S. Government. The U.S. Government retains and the publisher, by accepting the article for publication, acknowledges that the U.S. Government retains a nonexclusive, paid-up, irrevocable, worldwide license to publish or reproduce the published form of this work, or allow others to do so, for U.S. Government purposes. 


\section{Executive Summary}

The Storage Futures Study (SFS) is a multiyear research project to explore the role and impact of energy storage in the evolving electricity sector of the United States. The SFS is designed to examine the potential impact of energy storage technology advancement on the deployment of utility-scale storage and the adoption of distributed storage, and the implications for future power system infrastructure investment and operations.

This report models the evolution of diurnal storage ( $<12$ hours) within the U.S. electricity sector from 2020 through 2050 using a least-cost optimization framework across multiple cost scenarios based upon existing policies. In this first comprehensive national U.S. analysis evaluating diurnal storage against other resources, we find that diurnal storage is extremely competitive on an economic basis. We find significant market potential for diurnal energy storage across a variety of scenarios using different cost and performance assumptions for storage, wind, solar photovoltaics (PV), and natural gas. Across all scenarios modelled deployment for energy storage exceeds $125 \mathrm{GW}$ by 2050 , more than a five-fold increase from the current installed storage capacity of $23 \mathrm{GW}$ in 2020 (the majority of which is pumped-hydro). For battery storage, there is at least 3,000 times more battery capacity in 2050 than exists today (Figure ES-1). Depending on cost trajectories and other variables 2050 storage deployment ranges from 130 to $680 \mathrm{GW}$, indicating a rapidly expanding opportunity for diurnal storage in the power sector. These results, based upon technology cost reductions consistent with the 2020 NREL Standard Scenarios paired with updated battery cost projections (Augustine and Blair, 2021), highlight the fundamental drivers of diurnal storage deployment and the increasing competitiveness of storage resources. Across these cost-driven scenarios, variable renewable energy (VRE) reaches penetrations of $43-81 \%$, but does not achieve the deployment needed to meet deep decarbonization goals. Future work will consider scenarios with an accelerated transition to a clean energy grid by 2035 and the resulting impact on storage deployment.

We use expanded modelling capabilities that allow us to differentiate storage resources by duration. In most scenarios, the majority of this storage investments have 4-6 hours of duration, but this distribution varies with assumptions for future natural gas prices and renewable energy cost advancement. Within this economic deployment framework, these results indicate that diurnal storage can likely be sufficient to meet the integration needs of high renewable energy penetrations up to at least $80 \%$. 


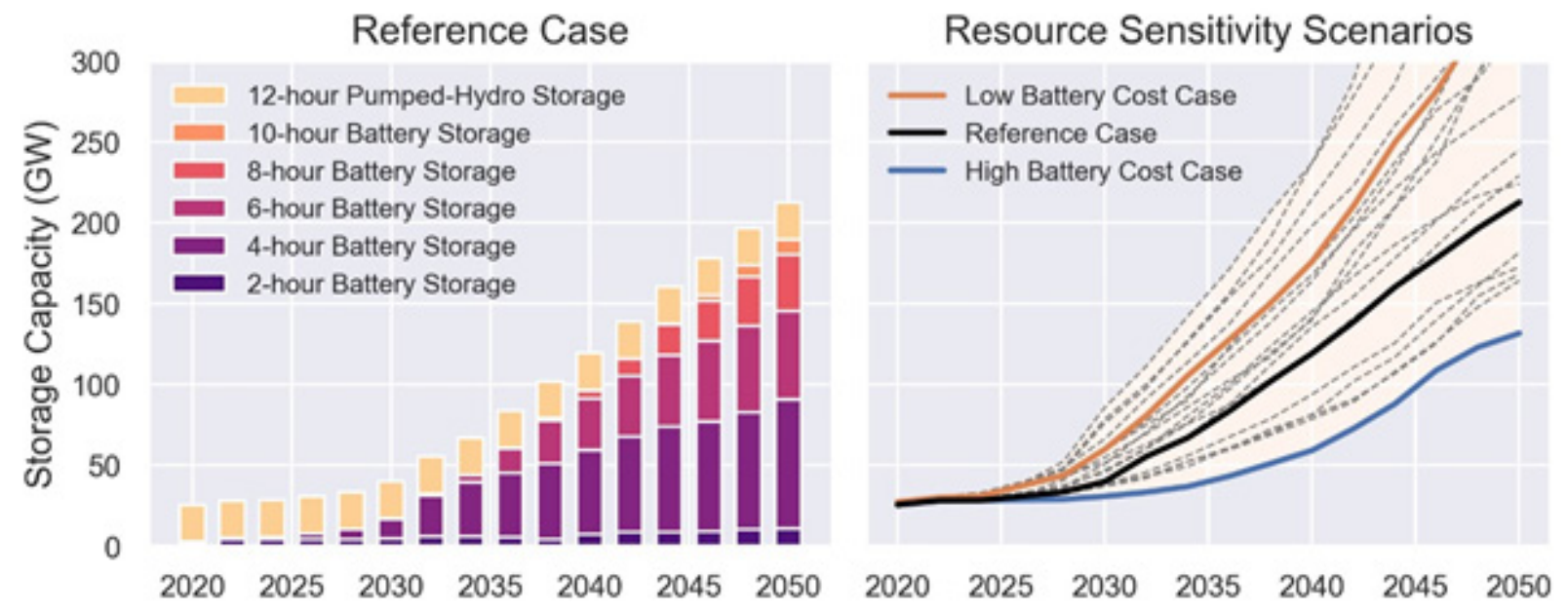

Figure ES-1. National storage capacity in the reference case separated by storage duration (left) and across all scenarios (right)

See Table 1 (Methods: Scenarios and Model Inputs section) for a full list of resource scenarios included here. See Figure A-1 in the appendix for additional details on generation and capacity by technology in each scenario.

While storage can provide many services to the grid, we find that economic storage deployment is driven primarily by the combination of capacity value and energy arbitrage (or time-shifting) value, and that the combination of these value streams is needed for optimal storage deployment to be realized. We also find a strong correlation between PV penetration and storage market potential. More generation from PV leads to narrow net-load peaks in the evenings which increases the market potential of storage capacity value. More generation from PV also creates more volatile energy price profiles which increases the market potential of storage energy timeshifting value.

Collectively, these results demonstrate the phased deployment pathways laid out in the first Storage Futures Study report: The Four Phases of Storage Deployment: A Framework for the Expanding Role of Storage in the U.S. Power System (Denholm et al., 2021). Shorter duration storage is deployed initially and over time longer duration of storage assets deploy on a costeffective basis. This analysis also highlights how far cost-effective diurnal storage alone can move the power sector towards cost-optimal deployment.

Building upon this analysis of economic deployment of diurnal storage future work should examine the relationship between diurnal storage and longer-duration storage resources, especially under highly decarbonized grid conditions outside the scope of this work, such as those approaching 100\% clean energy. In addition, more work is needed to understand the relationship between storage and demand-side flexibility at a national-scale.

Finally, while the focus of this work is on Li-ion batteries because the technology has greater market maturity than other emerging technologies, the results from this study can be generalized to other storage technologies that can meet these cost and performance projections. Collectively, these results speak to the growing opportunity for diurnal storage to provide least-cost solutions in the power system. 


\section{Table of Contents}

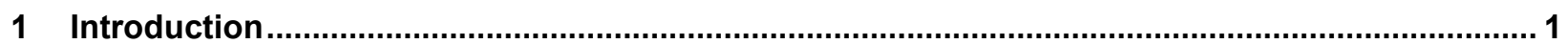

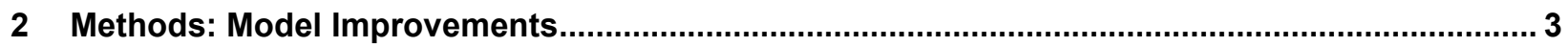

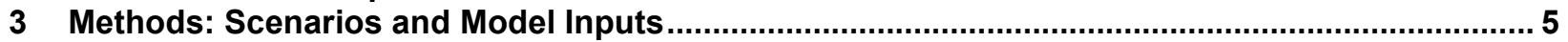

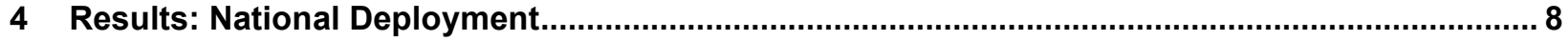

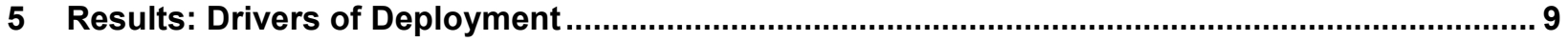

6 Results: Other Interactions and Impact of Storage ............................................................... 15

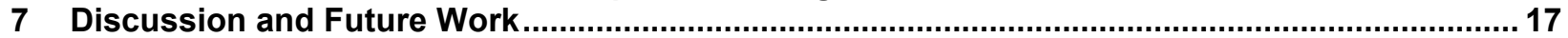

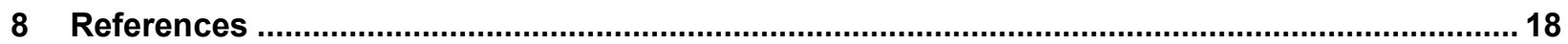

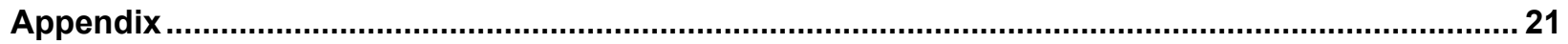

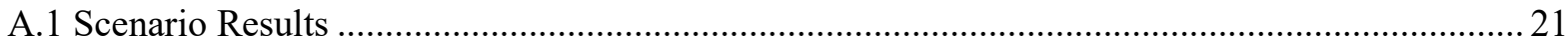

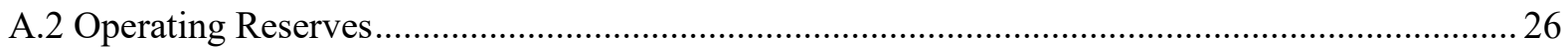

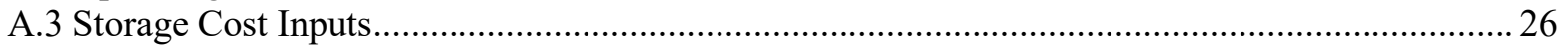

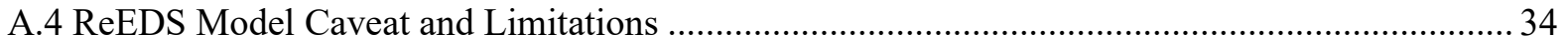

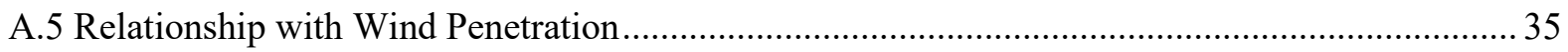

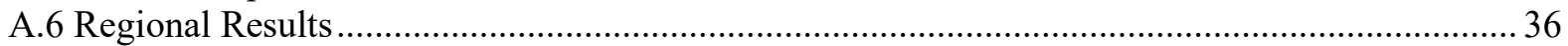




\section{List of Figures}

Figure ES-1. National storage capacity in the reference case separated by storage duration (left) and across all scenarios (right).

Figure 1. National storage capacity in the reference case separated by storage duration (left) and across all

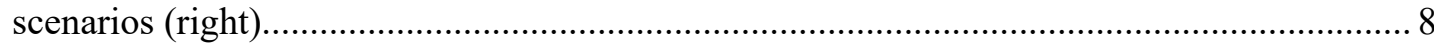

Figure 2. Load and net load in 2050 in California for the Low PV Cost and Low Wind Cost Cases (top); national peaking capacity potential for diurnal storage (up to 12 hours) as a function of PV penetration (bottom left) and national diurnal energy time-shifting potential as a function of PV penetration (bottom right)....

Figure 3. Cumulative battery storage deployment in scenarios with grid services restricted for storage, as indicated by scenario names, with low battery cost (left), reference battery cost (middle) and high battery cost (right).....

Figure 4. 2050 simulated peaking capacity potential for storage as a function of storage penetration and duration (hatched bars), compared to the simulated economic cumulative storage capacity in 2050 in each case (solid bars) .

Figure 5. Cumulative capacity in a subset of scenarios of battery storage (top left), transmission (top right), PV (bottom left), and wind (bottom right) ............................................................ 15

Figure 6. The amount of generation that goes through storage in 2050 across all scenarios at the national and regional levels plotted against PV penetration (left) and wind penetration (right) ......... 16

Figure A-1. Capacity by technology and year in all resource sensitivity scenarios...................................22

Figure A-2. Generation by technology and year in all resource sensitivity scenarios ..............................2 23

Figure A-3. Capacity by technology and year in all storage grid service sensitivity scenarios..................24

Figure A-4. Generation by technology and year in all storage grid service sensitivity scenarios .............. 25

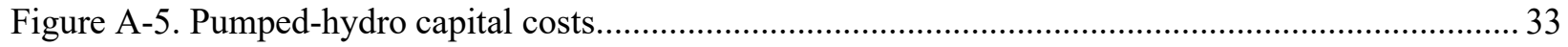

Figure A-6. Load and net load in 2050 in California for the Low PV Cost and Low Wind Cost Cases (top); national peaking capacity potential for diurnal storage (up to 12 hours) as a function of wind penetration (bottom left) and national diurnal energy time-shifting potential as a

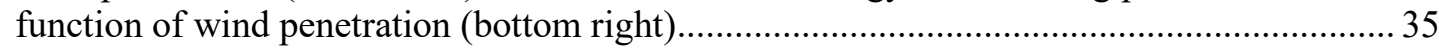

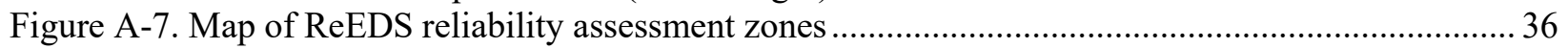

Figure A-8. Cumulative storage capacity by duration and year in each Reliability Assessment Zone (shown in Figure A-7) in the reference case .................................................................... 37

Figure A-9. Economic storage deployment and peaking capacity potential of storage in 2050 in all resource sensitivity scenarios in ERCOT (Figure A-7) ........................................................ 38

Figure A-10. Economic storage deployment and peaking capacity potential of storage in 2050 in all resource sensitivity scenarios in the Great Lakes zone (Figure A-7).................................. 39

Figure A-11. Economic storage deployment and peaking capacity potential of storage in 2050 in all resource sensitivity scenarios in the MISO East zone (Figure A-7) ................................. 40

Figure A-12. Economic storage deployment and peaking capacity potential of storage in 2050 in all resource sensitivity scenarios in the MISO South zone (Figure A-7) ............................... 41

Figure A-13. Economic storage deployment and peaking capacity potential of storage in 2050 in all resource sensitivity scenarios in the MISO West zone (Figure A-7) .................................. 42

Figure A-14. Economic storage deployment and peaking capacity potential of storage in 2050 in all resource sensitivity scenarios in the NPCC New England zone (Figure A-7) ...................... 43

Figure A-15. Economic storage deployment and peaking capacity potential of storage in 2050 in all resource sensitivity scenarios in the NPCC New York zone (Figure A-7) ........................... 44

Figure A-16. Economic storage deployment and peaking capacity potential of storage in 2050 in all resource sensitivity scenarios in the PJM East zone (Figure A-7) ..................................... 45

Figure A-17. Economic storage deployment and peaking capacity potential of storage in 2050 in all resource sensitivity scenarios in the SERC East zone (Figure A-7) ................................... 46 
Figure A-18. Economic storage deployment and peaking capacity potential of storage in 2050 in all resource sensitivity scenarios in the SERC Florida Peninsula zone (Figure A-7) .

Figure A-19. Economic storage deployment and peaking capacity potential of storage in 2050 in all resource sensitivity scenarios in the SERC North zone (Figure A-7).

Figure A-20. Economic storage deployment and peaking capacity potential of storage in 2050 in all resource sensitivity scenarios in the SERC Southeast zone (Figure A-7).....

Figure A-21. Economic storage deployment and peaking capacity potential of storage in 2050 in all resource sensitivity scenarios in the SPP zone (Figure A-7)

Figure A-22. Economic storage deployment and peaking capacity potential of storage in 2050 in all resource sensitivity scenarios in the WECC California zone (Figure A-7)

Figure A-23. Economic storage deployment and peaking capacity potential of storage in 2050 in all resource sensitivity scenarios in the WECC Mountain West zone (Figure A-7) ...................52

Figure A-24. Economic storage deployment and peaking capacity potential of storage in 2050 in all resource sensitivity scenarios in the WECC Pacific Northwest zone (Figure A-7) ............... 53

Figure A-25. Economic storage deployment and peaking capacity potential of storage in 2050 in all resource sensitivity scenarios in the WECC Rocky Mountain zone (Figure A-7) ................. 54

Figure A-26. Economic storage deployment and peaking capacity potential of storage in 2050 in all resource sensitivity scenarios in the WECC Southwest zone (Figure A-7). 55

\section{List of Tables}

Table 1. Resource Sensitivity Scenarios Included in the Study 5

Table 2. Storage Service Restriction Scenarios Used in the Study, Each Performed with High, Reference, and Low Battery Capital Cost Projections

Table A-1. Results for Wind, PV, and Total Renewable Energy Penetration in 2050 Across all Resource

Sensitivity Scenarios 21

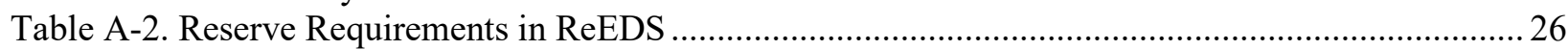

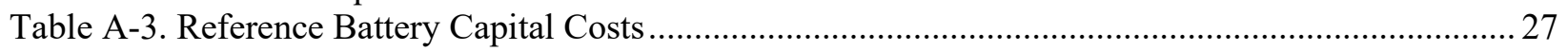

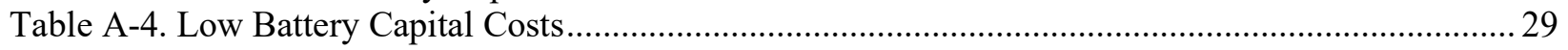

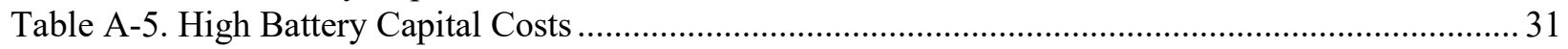




\section{Introduction}

Recent cost declines for many energy storage technologies, notably lithium-ion batteries, and increasing deployment of variable renewable energy (VRE) technologies (predominantly wind and PV) have heightened interest in storage as a grid resource (Brown and Sappington, 2020; Denholm and Margolis, 2016; Duan et al., 2020; Jorgenson et al., 2018). However, the total market potential for storage and the effects that storage capacity could have on power sector evolution and operations remain unclear.

Estimating the market potential for storage is complex (Beuse et al., 2020; Davies et al., 2019). Many grid services that storage provides, including peak shaving, energy time-shifting, and operating reserve provisions, have declining value with storage penetration (Brijs et al., 2019; Denholm et al., 2020). Furthermore, these values are highly dependent on the grid system conditions and can change over time depending on the overall evolution of load, load flexibility, and the mix of generation technologies in the power sector (Hartner and Permoser, 2018; Mallapragada et al., 2020).

Storage devices also have an additional system design consideration that traditional generators do not have, namely the selection of the duration of storage investments. We define duration as the usable energy capacity (in units of watt-hours, Wh) - after accounting for losses and maximum/minimum state-of-charge_-divided by the power capacity (watts, W). Duration is thus measured in hours. A $100 \mathrm{MW}$ system with a 4-hour duration would be capable of storing up to $400 \mathrm{MWh}$ of usable energy. Duration influences the cost of a storage device. A 6-hour 100-MW storage device will cost more than a 4-hour $100 \mathrm{MW}$ storage device because of the additional energy capacity needed in the 6-hour device (Cole and Frazier, 2020). The value of grid services provided by storage also grows with duration, but the cost of this additional energy capacity must be compared to this additional value and assessed on a full system life-cycle basis to determine the optimal duration of a storage investment.

Furthermore, storage is more sensitive to chronology than traditional generators because of this finite duration (Pineda and Morales, 2018). The state-of-charge of a storage device is chronologically linked, and this impacts how it can be used at any given time. And unlike traditional generators, storage does not actually generate electricity, so its operation is entirely dependent on the dispatch of all other grid resources. Properly capturing these chronological considerations in large-scale models that can project market potential is a challenge (Bistline et al., 2020).

The ability of storage to provide peaking capacity is a function of both storage duration and net load shape (Roy et al., 2020), where net load is defined as load minus VRE generation. Initially relatively short durations of storage can reliably serve demand during the highest peaks, but as storage penetration grows the width of the net load peaks widen. Holding storage duration constant, this leads to a declining capacity credit for storage with increasing penetration. However, this decline in capacity credit can be offset by installing storage devices with longer durations but at higher cost. The shape of the net load profile also changes with investments in VRE, and this changes the techno-economic potential of providing peaking capacity from different durations of storage (Frazier et al., 2020). 
Energy time-shifting value comes from storage charging when prices are low and discharging when prices are high, so the duration of storage and shape of the energy price profile determine the possible value of this service. Price profiles can vary widely across spatial regions and change with investments in new generation, transmission, and storage resources. Low-cost generation from $\mathrm{PV}$ and wind drive prices down during periods of high generation. Transmission investments can reduce congestion, which can reduce the frequency and magnitude of price spikes (Wang et al., 2017). Energy time-shifting from storage can raise off-peak prices and lower peak prices, and this leads to declining energy time-shifting value with increased storage penetration and an eventual techno-economic limit where the volatility of price profiles is not large enough to overcome losses from storage (Brijs et al., 2019).

For this work, we add new capabilities to the Regional Energy Deployment System (ReEDS) capacity expansion model to include detailed representation of the grid services provided by diurnal storage. Explicitly considered within the modeling framework are the relationship between these services and storage duration, the declining value of these services with storage penetration, and the evolving techno-economic implications of the changing grid infrastructure. The impacts of chronological operation on all these factors are also considered at an hourly temporal resolution. See the methods section for more details of these modeling improvements. To limit scope, storage with durations shorter than 2 and longer than 12 hours are not considered in this work. In addition, cost and performance inputs resulted in scenarios with up to $80 \%$ nation-wide renewable energy penetration and additional drivers to reach higher penetrations of renewable energy are not considered. The objective of this study is to provide a framework for understanding how diurnal storage deployment is influenced by the evolution of the power grid and how diurnal storage deployment influences the operation and investments of other resources. Though our storage cost projections are based on Li-ion technologies, the results of this work are applicable to any technology that can achieve the cost and performance values used as model inputs. 


\section{Methods: Model Improvements}

We use the ReEDS capacity expansion model, which represents the U.S. power system in 134 regions connected by aggregated transmission corridors, to perform least-cost system wide optimization of power system retirements and investments in generation, transmission, and storage capacity through 2050 (Brown et al., 2020). We optimize investments in the power system in sequential two-year time steps; power system operation is optimized in each biennial time-step with limited temporal resolution.

Because storage operation depends greatly on chronology (Yousif et al., 2019), we add to ReEDS a module outside the optimization that simulates system operation at an hourly chronological resolution. Parameters related to storage — such as curtailment, storage dispatch, capacity credit of VRE and storage, energy time-shifting value, and the relationship between storage, transmission, and curtailment - are determined from the results of this hourly dispatch and used to inform the investment optimizations in the next solve year.

Hourly generation, storage dispatch, transmission, and energy price profiles are obtained by performing a simple least-cost production dispatch using the simulated generation capacity and transmission network from ReEDS. This dispatch is performed in 24-hour blocks for each calendar day and results are stitched together such the inter-day decisions are not considered. We use hourly net load profiles from 2012 load data and time-synchronous wind and PV profiles obtained by multiplying modeled wind and PV capacity by hourly capacity factor profiles from 2012 weather data (Draxl et al., 2015; Sengupta et al., 2018). Start-up costs and minimum generation constraints are not enforced to keep the problem tenable, but the resulting profiles are adjusted later to account for these factors.

Curtailment is determined by comparing the time-series profiles of generation, transmission, and net load. Generation profiles are adjusted based on minimum generation levels obtained from the Transmission Expansion Planning and Policy Committee (TEPCC) database (Frew et al., 2019). Generators that are on but generating below this level are brought up to their minimum generation level. Generators that are on and above their minimum generation level are deemed to have "headroom" and could ramp down to avoid curtailing wind and PV generation. Adjusted generation and net transmission profiles are subtracted from regional net load profiles and any negative values are interpreted as curtailment. These chronological curtailment profiles are aggregated to the coarse temporal resolution used in the ReEDS optimization and enforced there. Marginal curtailment rates are determined by simulating additional VRE generation while considering the time-series profiles of net load and remaining transmission capacity.

The chronological curtailment, transmission, and net load profiles have additional utility in the calculation of the interactions between curtailment, transmission, and storage; by comparing these profiles together, we determine the ability of transmission investments between adjacent regions to reduce curtailment by reducing congestion during hours when there is curtailment. We also perform a simple chronological dispatch of various durations of storage to determine the effects of storage on curtailment. These hourly chronological calculations increase the ability of the model to characterize the value of system flexibility in the form of storage or transmission. 
The regional hourly price profiles are adjusted for start-up costs before storage time-shifting value is calculated. Start-up costs also come from the TEPCC database (Frew et al., 2019). Within each calendar day, if a generator was off at any point then its start-up cost is spread out across each hour weighted by generation. Fractional start-up costs are used, based on the maximum output of that generator for that day. In each hour, the sum of the start-up cost plus the variable operating cost is compared to the energy price in that region for that hour. If there is a generator with an operating-plus-start-cost higher than the energy price for that hour, then the energy price is replaced with the sum of the start-cost and operating cost of the most expensive generator.

Energy time-shifting value is calculated from these adjusted hourly price profiles. We use a profit-maximizing price-taking storage dispatch model to simulate the time-shifting value of energy storage investments (Frew et al., 2019; Sengupta et al., 2018). This value is calculated for each storage duration represented in ReEDS, and this value is added to any storage investment in the optimization during the next solve year. The method uses perfect foresight of prices, so to account for this we reduce the duration of storage by one hour, effectively requiring that all storage devices maintain an hour's worth of energy capacity in case of unforeseen events (Viola et al., 2014).

Capacity credit for wind, PV, and storage is calculated using 7 years of time-synchronous weather and load data (Cole et al., 2020b). Capacity credit is calculated for each season and a constraint in ReEDS requires that firm capacity exceed demand plus a planning reserve margin in each season (NERC (North American Electric Reliability Corporation), 2020). Wind and PV firm capacity is determined by the reduction in load in the highest 10 load hours to the net load in the highest 10 net load hours (Frew et al., 2017). Storage peaking capacity potential is determined using a simplified time-series storage dispatch method and the capacity credit of storage resources is optimized within the model as described by Frazier et al., 2020. Storage peaking capacity potential is also calculated with a 1-hour reduction of storage duration, e.g. 4hour storage gets credit for the peak reduction potential 3-hour storage would have with perfect foresight.

For caveats and limitations associated with using the ReEDS model, see Section A.4 in the appendix. 


\section{Methods: Scenarios and Model Inputs}

We use two sets of scenarios for this work. This first set of scenarios includes several different cost and price assumptions for wind, PV, natural gas, and transmission, and combines those assumptions with different projections of future battery costs to comprise a broad space of future power system conditions and identify the system conditions that influence storage adoption. The second set of scenarios restrict the services that storage can provide. These scenarios are structured to determine which services are the strongest drivers of energy storage deployment and are also performed with various battery cost projections for each to capture the relationship between service values and battery costs. These service restriction scenarios are not intended to represent real cases, but instead are used to identify key drivers of storage value. However, there may be market or other restrictions on service provision, so these scenarios do help identify the importance of monetization and compensation for various services to ensure a cost-optimal deployment of resources.

The resource sensitivity scenarios in this study focus on storage, wind, PV, natural gas, and transmission. These resource sensitivities were selected specifically because they account for most of the investments in the reference case. More, or less, investments of these resources change the dynamics of the grid composition and thus influence the cost-competitiveness of energy storage. A total of 18 sensitivity scenarios, plus the reference case, are included in this study. The full set of these resource scenarios is shown in Table 1.

Table 1. Resource Sensitivity Scenarios Included in the Study

\begin{tabular}{|l|l|}
\hline Resource Sensitivity & Battery Cost Projections \\
\hline Reference & $\begin{array}{l}\text { High Battery Costs } \\
\text { Reference Battery Costs } \\
\text { Low Battery Costs }\end{array}$ \\
\hline Low PV Costs & $\begin{array}{l}\text { Reference Battery Costs } \\
\text { Low Battery Costs }\end{array}$ \\
\hline High PV Costs & Reference Battery Costs \\
\hline Low Wind Costs & Reference Battery Costs \\
Low Battery Costs
\end{tabular}




\begin{tabular}{|l|l|}
\hline Resource Sensitivity & Battery Cost Projections \\
\hline Low Wind and Low PV Costs & $\begin{array}{l}\text { Reference Battery Costs } \\
\text { Low Battery Costs }\end{array}$ \\
\hline High Wind and High PV Costs & $\begin{array}{l}\text { Reference Battery Costs } \\
\text { Low Battery Costs }\end{array}$ \\
\hline High Transmission Costs & $\begin{array}{l}\text { Reference Battery Costs } \\
\text { Low Battery Costs }\end{array}$ \\
\hline
\end{tabular}

All model inputs are consistent with NREL's 2020 Standard Scenarios (Cole et al., 2020a), except for battery storage cost projections, which are taken from Augustine and Blair (Augustine and Blair, forthcoming) (see Tables A-3 through A-5 in the appendix). Pumped-hydro costs come from the Hydropower Vision Study (DOE, 2016) (see Figure A-5 in the appendix) and do not capture recent advancements or the potential for shorter durations of pumped-hydro to be deployed at lower costs.

Performance characteristics for battery storage and other technologies are taken from NREL's 2020 Annual Technology Baseline (NREL (National Renewable Energy Laboratory), 2020). Note that the power and energy components of battery storage are reported after any adjustments for losses maximum/minimum state-of-charge. For example, a $100 \mathrm{MW}$ 4-hour storage device in this study has a nameplate energy capacity of $400 \mathrm{MWh}$, but in reality, it has a higher physical energy capacity to account for storage losses or minimum state-of-charge requirements.

The second set of scenarios used in this study — which restrict the ability of storage to provide services to the grid-is given in Table 2.

Table 2. Storage Service Restriction Scenarios Used in the Study, Each Performed with High, Reference, and Low Battery Capital Cost Projections

\begin{tabular}{|l|l|}
\hline Grid Service Restriction & Battery Cost Projections \\
\hline Storage Cannot Provide Capacity Credit & $\begin{array}{l}\text { High Battery Costs } \\
\text { Reference Battery Costs } \\
\text { Low Battery Costs }\end{array}$ \\
\hline Storage Cannot Perform Energy Time-Shifting & $\begin{array}{l}\text { High Battery Costs } \\
\text { Reference Battery Costs } \\
\text { Low Battery Costs }\end{array}$ \\
\hline Storage Cannot Provide Operating Reserves & $\begin{array}{l}\text { High Battery Costs } \\
\text { Reference Battery Costs } \\
\text { Low Battery Costs }\end{array}$ \\
\hline
\end{tabular}


In the scenario where storage cannot provide capacity credit, the peaking capacity potential of storage is set to zero for all storage durations. ReEDS is still free to build storage and determine the optimal dispatch profile of storage within the model's coarse temporal resolution, but this change prevents storage from contributing to the planning reserve margin in any region. As such, the model must procure sufficient capacity from other resources.

In the scenario where storage cannot perform energy time-shifting, storage is ignored in the hourly production dispatch model that determines curtailment, time-shifting value, and VREstorage interactions. Because storage is ignored in this hourly model, curtailment is calculated without the effects of energy time-shifting from storage. The time-shifting value for storage determined from the hourly price profiles is set to zero so this value is ignored for any storage investment decisions. All VRE-storage interactions that describe the ability of storage to reduce curtailment are also ignored. Storage is allowed to dispatch in ReEDS during high load hours and charge during low load hours, as is required for storage providing firm capacity, but it is not allowed to reduce curtailment by charging and receives no value from this time-shifting.

In the scenario where storage cannot provide operating reserves, the fraction of storage devices' capacities that can be used to provide ancillary services is set to zero (see section A.2 in the appendix for more details on the operating reserves). All other grid services that storage can provide are included as normal except for the specified service in each scenario. 


\section{Results: National Deployment}

Battery storage deployment grows significantly through 2050 across all scenarios we examine. Figure 1 shows deployment by duration in the Reference Case (left) and the cumulative storage deployment in all scenarios (right). There are $213 \mathrm{GW}(1,318 \mathrm{GWh})$ of storage by 2050 in the Reference Case, accounting for $17 \%$ of the total planning reserve margin requirement. There are $132 \mathrm{GW}(702 \mathrm{GWh})$ and $380 \mathrm{GW}(1,783 \mathrm{GWh})$ in the High and Low Battery Cost Cases, respectively. Across all scenarios, cumulative storage capacity in 2050 ranges from 132-679 GW (702-3242 GWh) and annual deployment of battery storage ranges from 1-30 GW in 2030 to 7$77 \mathrm{GW}$ in 2050. These scenarios reach VRE penetrations of 35\%-74\% in 2050 (overall renewable energy penetration of 43\%-81\%). See Table A-1 in the appendix for results from each scenario and Table 1 in Methods for a full list of these scenarios.

In 2020, there are $23 \mathrm{GW}$ of pumped-hydro storage capacity in the United States, all of which is assumed to have a duration of 12 hours. Although new pumped-hydro storage is included in the suite of technologies assessed by the model, only new battery storage is deployed by the model across the scenarios we examine. Across all scenarios the majority of new storage deployment is 4-6 hours in duration, and the capital cost assumptions for new 12-hour pumped-hydro are higher than for 4-6 hour battery storage (DOE, 2016). In addition, as noted in the ReEDS Model Caveats and Limitations (appendix A.4), longer duration resources not considered in this work might compete with diurnal storage.

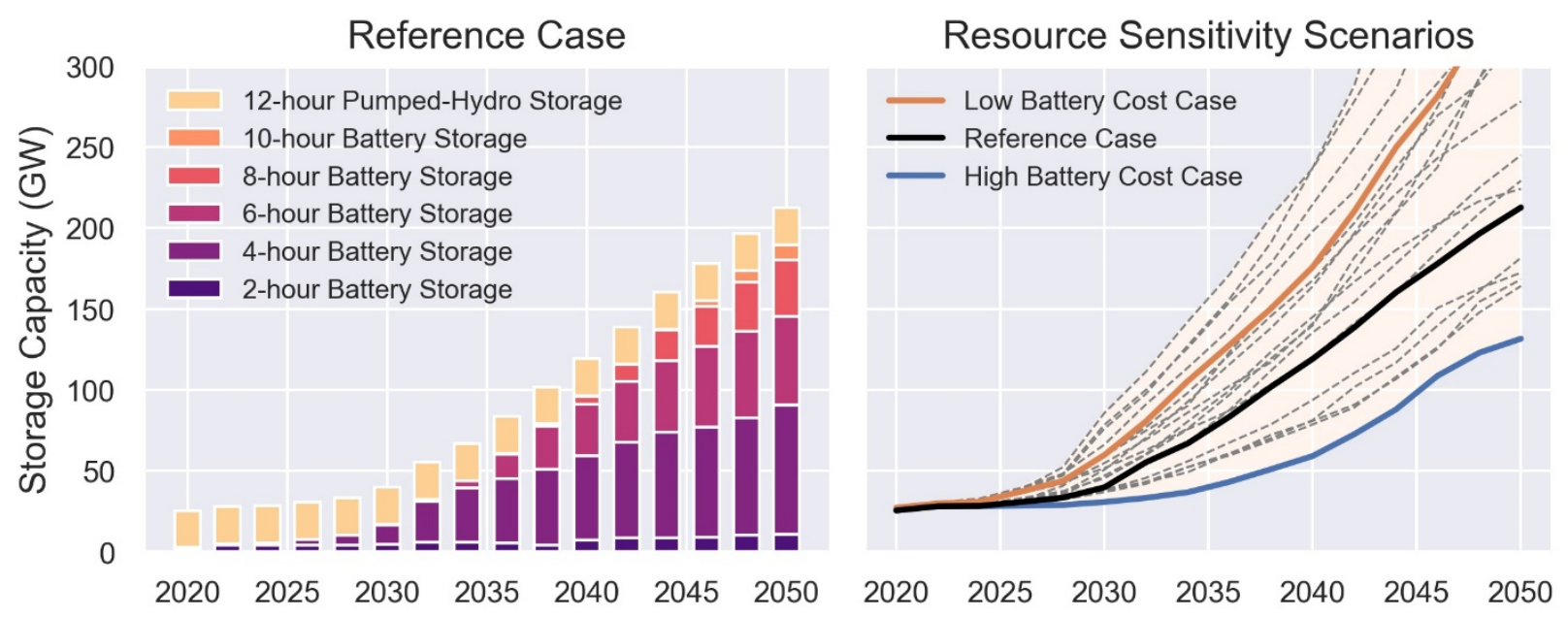

Figure 1. National storage capacity in the reference case separated by storage duration (left) and across all scenarios (right)

See Table 1 (Methods: Scenarios and Model Inputs section) for a full list of resource scenarios included here. See Figures A-1 and A-2 in the appendix for additional details on generation and capacity by technology in each scenario.

New storage deployment is initially from shorter-duration storage (up to 4 hours) and then progresses to longer durations as deployment grows. Longer-duration storage is more expensive, which aligns with the model's preference for shorter durations. In all cases, the first $\sim 100-150$ GW of storage deployment aligns well with storage deployment phases 1 and 2 laid out in Denholm et al. (2021), with the vast majority deployed in phase 2 aimed at providing peaking capacity. 


\section{Results: Drivers of Deployment}

To explore the drivers of storage deployment, we consider the techno-economic potential of storage services, the value of those services, and the costs of storage. The potentials are technoeconomic because they depend on both technical factors (e.g., storage efficiency, load shape) and economic factors (e.g., amount of PV deployed, which generator is on the margin). The ReEDS model considers the ability of storage to independently provide three services - capacity, energy time-shifting, and operating reserves - and co-optimizes storage duration and deployment of storage alongside investments in generation and transmission.

The techno-economic potential of storage services represents the upper bound on the amount of the service storage can provide but does not capture the cost of storage or value of these services. For operating reserves, this is simply the total amount of reserves required by the system. For capacity and energy time-shifting, the potential is more complicated to assess and depends greatly on the net load profile, which is impacted by the amount and timing of wind and PV generation.

$\mathrm{PV}$ generation in particular has a significant impact on storage techno-economic potential, as illustrated in Figure 2. The top panel illustrates an example how PV narrows the net peak demand periods, comparing load in California with the net load in the Low PV Cost Case (63\% annual PV penetration) and the Low Wind Cost Case (40\% annual PV penetration) in 2050 (see Methods section for details on load assumptions). This narrowing of the peak and increased difference between minimum and maximum net load increases the overall techno-economic potential of storage. The bottom left panel in Figure 2 shows the national potential of diurnal storage (storage with 12 or fewer hours of duration) to provide peaking capacity in the United States in each year of each scenario, plotted as a function of the PV penetration. This peaking potential for diurnal storage is calculated using the net load profile shape and storage round-trip efficiency as described by Frazier et al. (2020) The national peaking potential of storage doubles relative to 2020 levels at about $35 \%$ PV penetration.

The energy time-shifting value stream for storage is also sensitive to PV penetration. The increased difference between minimum and maximum net load also increases the potential of storage to provide energy time-shifting. The bottom right panel in Figure 2 shows the national annual techno-economic potential for diurnal energy time-shifting in each year of each scenario plotted as a function of PV penetration. This techno-economic potential is based on the optimal hourly dispatch of generation and transmission with unlimited storage available to flatten daily price profiles to within the round-trip efficiency of storage. As with peaking capacity, there is a strong relationship between the potential of storage to provide energy time-shifting and PV penetration. This potential is also sensitive to fuel price assumptions because higher/lower fuel prices increase/decrease the spread in prices. 

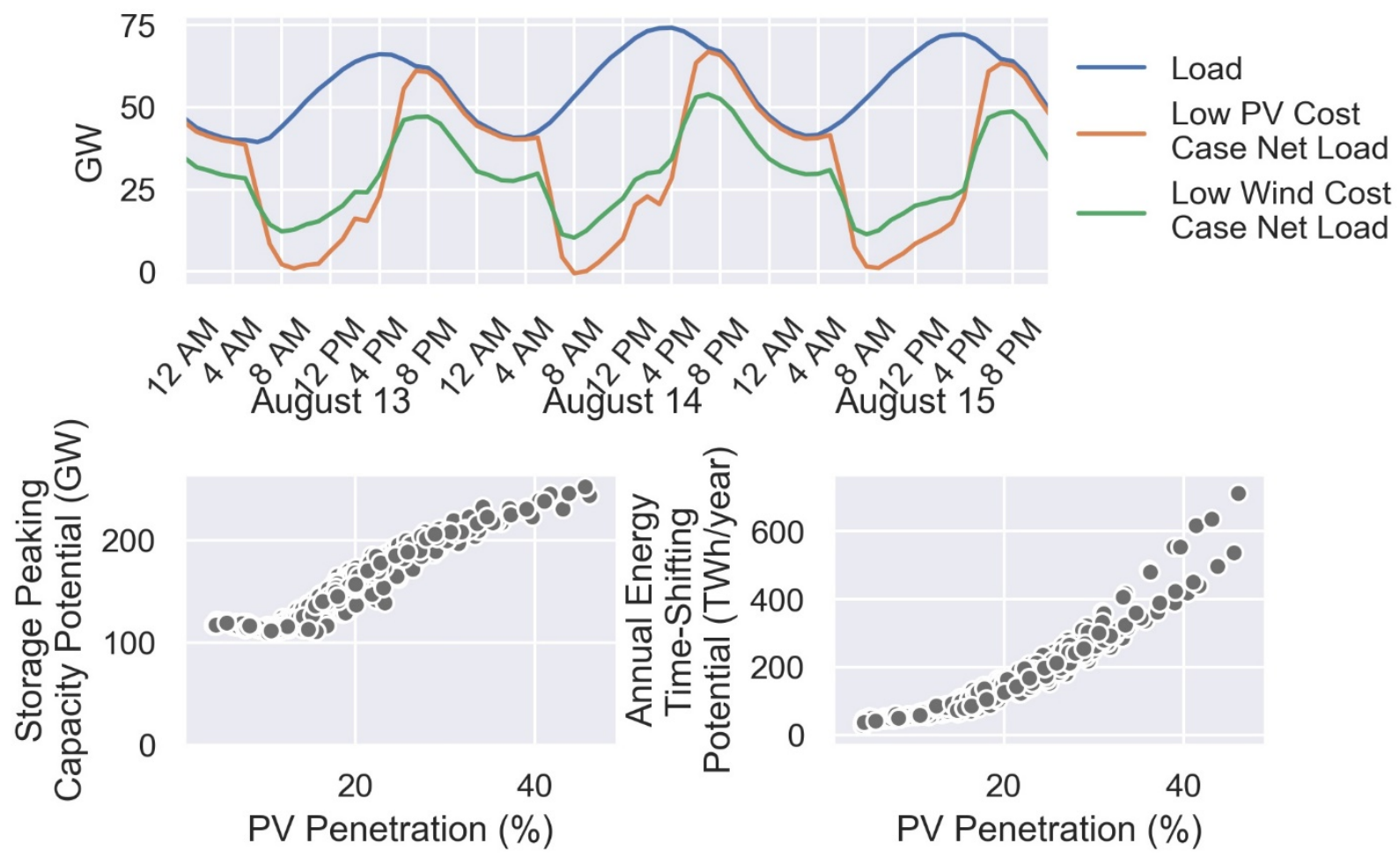

Figure 2. Load and net load in 2050 in California for the Low PV Cost and Low Wind Cost Cases (top); national peaking capacity potential for diurnal storage (up to 12 hours) as a function of PV penetration (bottom left) and national diurnal energy time-shifting potential as a function of PV penetration (bottom right)

The bottom figures show all years in all scenarios (i.e., there is one point for each year in each scenario). See Figure A-6 in the appendix for wind results.

The impact of wind or natural gas deployment on the peaking and energy time-shifting potential occurs primarily via competition with PV. High wind cost or high natural gas prices increase the relative competitiveness of $\mathrm{PV}$, and increased $\mathrm{PV}$ deployment leads to greater potential for storage. The converse is also true.

These storage potentials can be compared to modeled economic deployments that consider the value of the services provided and costs of storage. The model determines value of each service endogenously, considering factors such as the capital and operating cost of alternative resources. In all cases, the value of firm capacity is low from the present through 2030, because throughout that period the capacity of the power system in many regions exceeds the planning reserve margin constraint enforced in the model (Murphy et al., 2020; NERC (North American Electric Reliability Corporation), 2020; Reimers et al., 2019). Over time, the value of peaking capacity increases as load grows and existing generators retire. The value of energy time-shifting also typically grows, particularly as increased PV penetration sharpens the net load profiles.

The model allows storage to provide multiple services, and because high energy prices are correlated with high net loads, these services often overlap temporally such that both energy and capacity services can be performed simultaneously (Sioshansi et al., 2014). Their combined value is often needed for storage to be a cost-optimal resource. To understand the contribution of various services to the overall value of storage, we restrict storage from providing certain 
services; the results are provided in Figure 3. For each projection of future battery costs used in this study (Augustine and Blair, forthcoming), we restrict storage from providing one of its three services - capacity, energy time-shifting, and operating reserves - in the model. For example, in the scenario where storage cannot provide energy time-shifting, storage is only allowed to provide firm capacity and operating reserves and therefore is only deployed if the value of those services is sufficient to recover the cost of the storage. See the methods section for further details on the modifications in these scenarios.

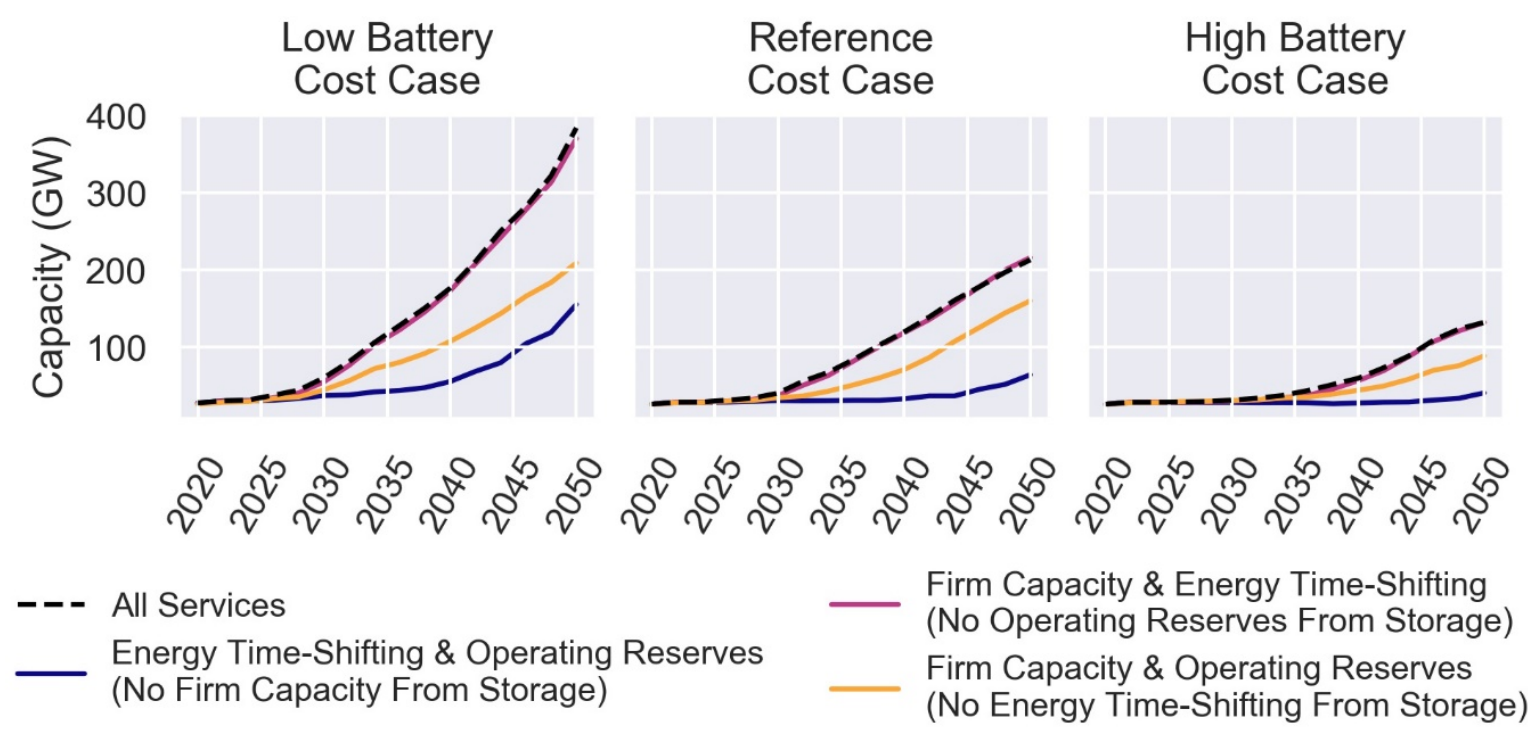

Figure 3. Cumulative battery storage deployment in scenarios with grid services restricted for storage, as indicated by scenario names, with low battery cost (left), reference battery cost (middle) and high battery cost (right)

See Figures A-3 and A-4 in the appendix for additional details of generation and capacity in these scenarios.

Restricting either firm capacity or energy time-shifting leads to substantially less storage deployment across the three battery cost projections used. The ability to provide firm capacity is the most significant driver of storage deployment, but provision of multiple services is key to reaching the full deployment potential. Operating reserves do not drive the deployment of storage within this analysis because of the limited overall market potential for this service and our minimum of 2-hour storage representation in the model, which does not consider the role of shorter-duration storage that has historically been deployed to provide reserves. See Table A-2 in the appendix for details of reserve requirements in ReEDS.

Early storage deployment is also influenced by drivers beyond technology cost and performance, including state mandates for new storage capacity and policies that incentivize VRE and thereby increase the value of energy time-shifting. For example, in regions where renewable energy credit prices are high, the value of installing storage that can reduce renewable energy curtailment is also high.

Figure 4 provides additional insights regarding the techno-economic potential and service value of storage that drive overall economic deployment. The hatched bar shows the national storage peaking potential in 2050, broken out by duration for each scenario. Variations in the storage peaking potential between the scenarios is due to factors illustrated in Figure 2, largely PV 
deployment. The storage peaking potential also shows the requirement of increasingly longer durations as more storage is added, because of the wider net load peaks (Frazier et al., 2020).

The solid bars in Figure 4 show modeled deployment for each scenario. In most of the cases with reference battery costs, the model builds storage with total capacity and durations close to the peaking potential. Once the peaking potential is met the capacity credit of storage drops, and the value of additional storage (providing mostly time-shifting) is less than the additional cost.

Alternatively, the scenarios that use low battery cost assumptions have storage deployment that exceeds the peaking potential for storage. This indicates that reduced capital costs for storage allow storage to be cost-competitive when most of its value coming from energy time-shiftingincluding its ability to store energy that would otherwise be curtailed and shift it to a later timesupplemented by some firm capacity value at a reduced capacity credit. These cases produce the highest levels of storage deployment. The High Natural Gas (NG) Price Case (using reference battery costs) is also a case where the larger price differentials (due to the higher gas prices) allow for additional storage deployments beyond the peaking potential.

The High Battery Cost Case is the only case where the model deploys significantly less than the peaking potential. In this scenario, storage is cost-optimal up to about 6 hours in duration, but longer durations of storage are largely more expensive than alternative options. 


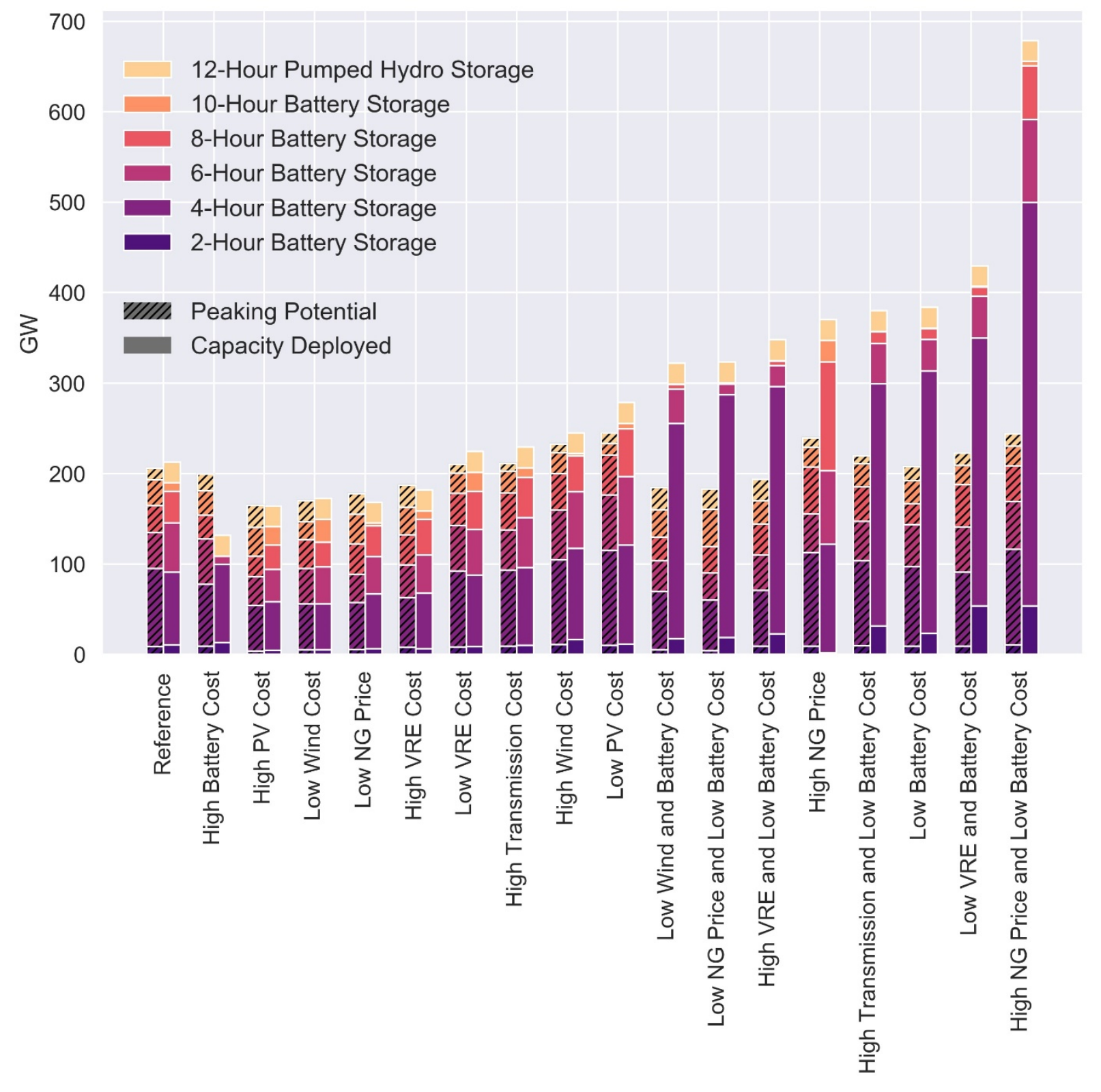

Figure 4. 2050 simulated peaking capacity potential for storage as a function of storage penetration and duration (hatched bars), compared to the simulated economic cumulative storage capacity in 2050 in each case (solid bars)

See Figures A-9 through A-26 in the appendix for regional results.

Figure 4 also illustrates the sensitivity of storage duration to various factors. As seen in Figure 1, shorter-duration storage is deployed first, and most battery storage is deployed with the minimum duration required to get full capacity credit. However, if the value of energy timeshifting is sufficiently high relative to storage costs, it can shift the optimal duration of storage deployment away from the minimum duration required to provide peaking capacity. In the lowcost storage cases, the model chooses to build capacity with less duration than is required for meeting peak demand. The additional power capacity relative to energy capacity deployed helps 
avoid curtailment more than additional energy capacity would be due to the concentration of PV generation during the mid-day hours.

In the High NG Price Case (with reference storage costs), the model deploys some storage with longer durations than are needed to provide peaking capacity. Because of high fuel costs, the cost of additional energy capacity in this scenario is less than the value associated with the additional energy time-shifting.

These results show a few options of how the third phase of storage deployment described in Denholm et al. (2021) after most of the peaking capacity potential of 2-6 hour storage is saturated. The optimal duration of storage after that point may continue to be the minimum duration needed to provide peaking capacity - as in the Reference Case - or it could be as short as 4 hours (Low Battery Cost Case) or as long as 8 hours (High NG Price Case). 


\section{Results: Other Interactions and Impact of Storage}

The diurnal pattern of PV generation produces the strongest interaction with storage in the modeled scenarios, but storage also interacts with other resources in the power sector, including wind and transmission.

Figure 5 shows the cumulative capacity of storage, transmission, PV, and wind (both onshore and offshore) in a subset of scenarios. The Low PV Cost Case results in much greater PV deployment, which increases the techno-economic potential of storage as observed earlier (see Figure 2) and also effectively reduces the cost of storage in terms of reduced duration required to get full capacity credit. This leads to significantly more storage deployment relative to the Reference Case.
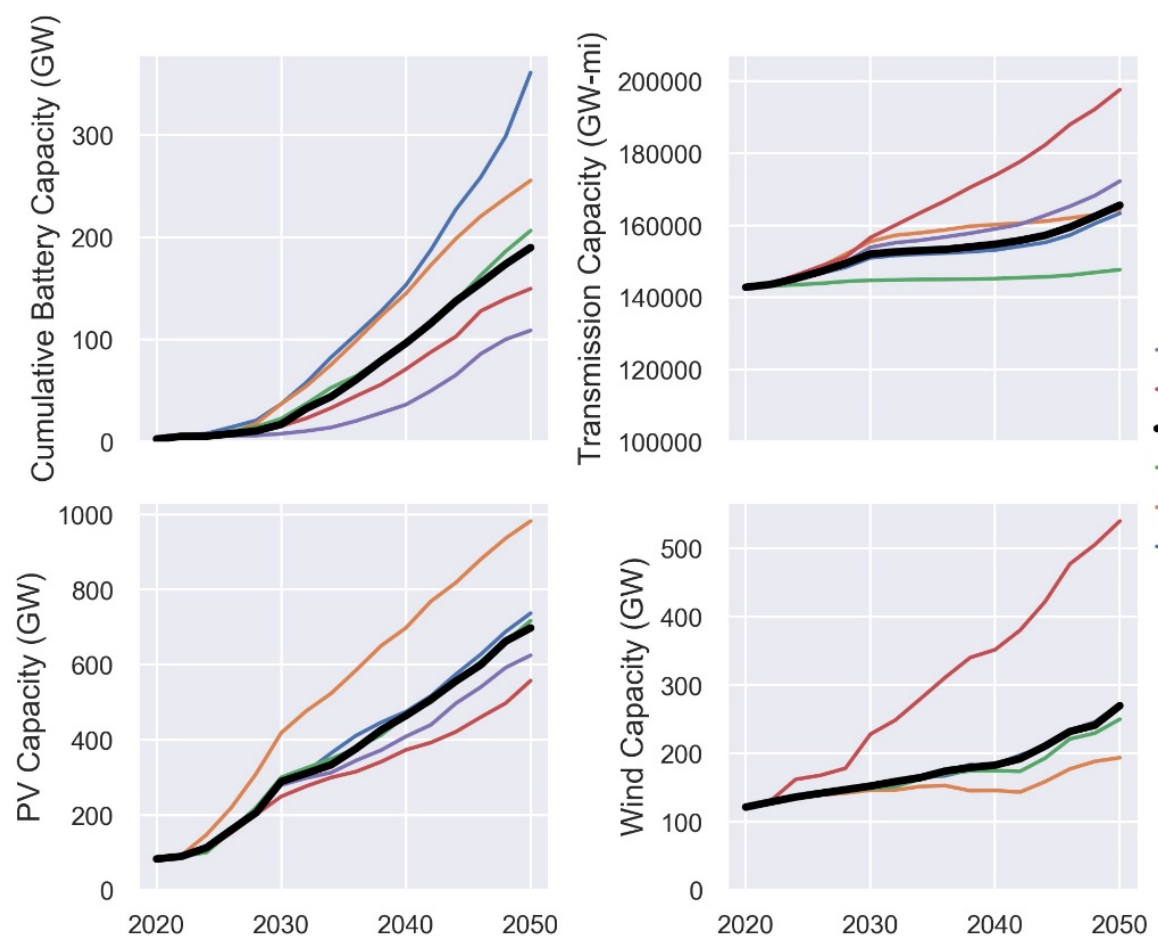

Figure 5. Cumulative capacity in a subset of scenarios of battery storage (top left), transmission (top right), PV (bottom left), and wind (bottom right)

Transmission and storage show limited interaction in the modeled scenarios, with the most significant correlation being between transmission and wind. Both transmission and storage provide flexibility to the power grid, one by shifting energy in space and the other shifting it in time. Modeling results demonstrate that wind benefits more from spatial flexibility, while PV benefits more from temporal flexibility. Transmission is positively correlated with wind capacity, but additional wind does not incentivize additional storage, as wind frequently does not change the net load shape in a way that increases storage peaking capacity potential.

The synergies of diurnal storage and wind are relatively small compared to PV. The Low Wind Cost Case has significantly more wind deployment than the reference case, and this offsets some PV deployment. Because of the strong correlation between storage potential and PV penetration, 
the decrease in PV deployment in this scenario leads to a decrease in storage investments relative to the reference case because lower PV penetrations mean lower techno-economic potentials for storage (Figure 4).

The role of storage and its synergies with PV relative to wind can also be observed by examining the amount of energy cycled through storage. Figure 6 shows, both nationally and regionally for each scenario in 2050, the percent of total generation that is used to charge storage plotted against the PV and wind penetration. The amount of generation used to charge storage in 2050 nationally is $7 \%$ in the Reference Case and ranges from $4 \%$ in the High PV Cost Case to $19 \%$ in the High NG Price and Low Battery Cost Case. While large amounts of wind and PV are deployed across these scenarios as part of the least-cost solution, the diurnal generation profile from PV enables further storage deployment. Under scenarios of high wind deployment, wind reaches high penetrations without significant storage deployment.
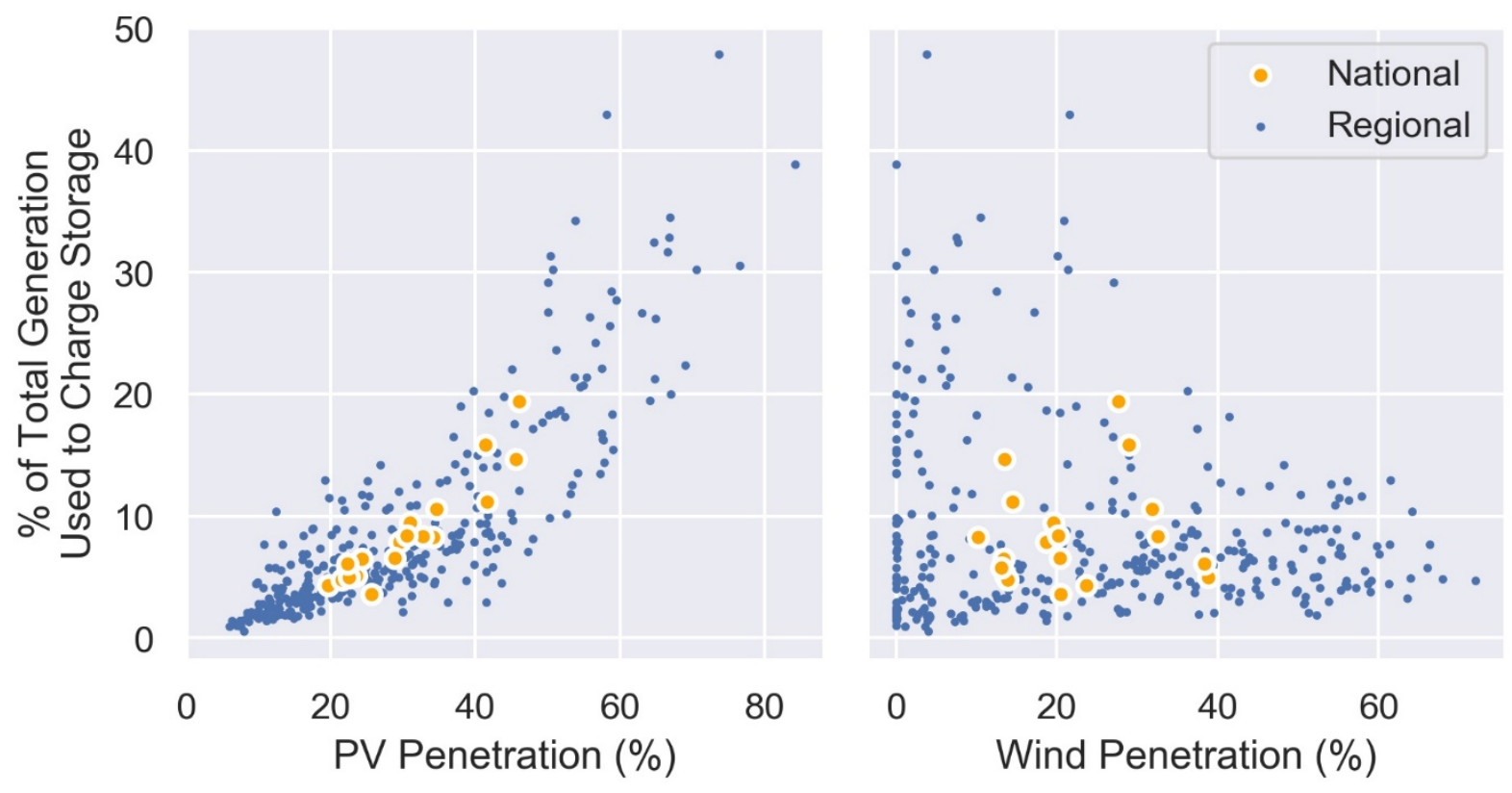

Figure 6. The amount of generation that goes through storage in 2050 across all scenarios at the national and regional levels plotted against PV penetration (left) and wind penetration (right) 


\section{Discussion and Future Work}

This analysis demonstrates that energy storage has the potential to become a significant contributor to system capacity, with new installations reaching $132 \mathrm{GW}$ by 2050 even with our most conservative storage assumptions. While cost and performance metrics in this study focus on Li-ion batteries because the technology has greater market maturity today than other emerging technologies, results from this study can be generalized to other storage technologies that meet the cost and performance projections assumed. Most of this storage deployment occurs after 2030, but alternative near- to mid-term economic conditions or policy changes, retirements of existing peaking capacity, or higher planning reserve margins to address reliability and resilience concerns could drive earlier deployment of storage. Storage growth could also be altered by competitive resources, such as demand response or transmission access to other lowercost storage (e.g. existing Canadian hydro storage), or increased electrification that could increase peaking and overall electric power demand.

Storage deployment in this study is driven by a combination of capacity and energy value. Optimal storage deployment is sensitive to the relationship between these value streams and the cost of storage. In most scenarios, storage deployment is optimized with respect to its potential capacity value and its energy value is supplemental. However, we find alternate scenarios (e.g., those with low battery costs or high natural gas prices) where the value of energy time-shifting relative to storage costs is sufficiently high to incentivize the optimization of storage with respect to its energy value and its capacity value is supplemental.

Storage market potential is strongly tied to the growth in PV. The diurnal pattern of PV and its impact on net load increases the potential for storage and effectively decreases the costs of storage by allowing shorter durations to be a competitive source of peaking capacity. This impact drives our modeling results, which typically build 6 hours or less of duration for most of the installed capacity and make storage much more complementary with PV than wind.

Future work should examine the relationship between diurnal storage (which is the focus of this work) and longer-duration storage resources, especially under highly decarbonized grid conditions outside the scope of this work, such as those approaching $100 \%$ renewable or clean energy. Additionally, more work is needed to understand the relationship between storage and demand-side flexibility at a national-scale.

For caveats and limitations associated with the results of this study, see section 4 in the appendix. 


\section{References}

Augustine, C., Blair, N., forthcoming. Storage Futures Study: Storage Technology Modeling Input Data Report (NREL/TP- 5700-78694). National Renewable Energy Laboratory, Golden, CO.).

Beuse, M., Steffen, B., Schmidt, T.S., 2020. Projecting the Competition between Energy-Storage Technologies in the Electricity Sector. Joule 4, 2162-2184.

https://doi.org/10.1016/j.joule.2020.07.017

Bistline, J., Cole, W., Damato, G., DeCarolis, J., Frazier, W., Linga, V., Marcy, C., Namovicz, C., Podkaminer, K., Sims, R., Sukunta, M., Young, D., 2020. Energy storage in long-term system models: a review of considerations, best practices, and research needs 24 .

Brijs, T., Geth, F., De Jonghe, C., Belmans, R., 2019. Quantifying electricity storage arbitrage opportunities in short-term electricity markets in the CWE region. Journal of Energy Storage 25, 100899. https://doi.org/10.1016/j.est.2019.100899

Brown, D.P., Sappington, D.E.M., 2020. Motivating the optimal procurement and deployment of electric storage as a transmission asset. Energy Policy 138, 15.

Brown, M., Cole, W., Eurek, K., Becker, J., Bielen, D., Chernyakhovskiy, I., Cohen, S., Frazier, W., Gagnon, P., Gates, N., Greer, D., Gudladona, S.S., Ho, J., Jadun, P., Lamb, K., Mai, T., Mowers, M., Murphy, C., Rose, A., Schleifer, A., Steinberg, D., Sun, Y., Vincent, N., Zhou, E., Zwerling, M., 2020. Regional Energy Deployment System (ReEDS) Model Documentation: Version 2019. NREL/TP-6A20-74111 140.

Cole, W., Corcoran, S., Gates, N., Mai, T., Das, P., 2020a. 2020 Standard Scenarios Report: A U.S. Electricity Sector Outlook. NREL/TP-6A20-77442 51.

Cole, W., Eurek, K.P., Vincent, N.M., Mai, T.T., Brinkman, G.L., Mowers, M., 2018. Operating Reserves in Long-Term Planning Models (No. NREL/PR-6A20-71148). National Renewable Energy Laboratory, Golden, CO. https://doi.org/10.2172/1455165

Cole, W., Frazier, A.W., 2020. Cost Projections for Utility-Scale Battery Storage: 2020 Update. Technical Report NREL/TP-6A20-75385 21.

Cole, W., Greer, D., Ho, J., Margolis, R., 2020b. Considerations for maintaining resource adequacy of electricity systems with high penetrations of PV and storage. Applied Energy 279, 115795. https://doi.org/10.1016/j.apenergy.2020.115795

Davies, D.M., Verde, M.G., Mnyshenko, O., Chen, Y.R., Rajeev, R., Meng, Y.S., Elliott, G., 2019. Combined economic and technological evaluation of battery energy storage for grid applications. Nature Energy 4, 42-50. https://doi.org/10.1038/s41560-018-0290-1

Denholm, P., Cole, W., Frazier, A.W., Podkaminer, K., Blair, N., 2021. The Four Phases of Storage Deployment: A Framework for the Expanding Role of Storage in the U.S. Power System 56. 
Denholm, P., Margolis, R., 2016. Energy Storage Requirements for Achieving 50\% Solar Photovoltaic Energy Penetration in California. Renewable Energy 45.

Denholm, P., Nunemaker, J., Gagnon, P., Cole, W., 2020. The potential for battery energy storage to provide peaking capacity in the United States. Renewable Energy 151, 1269-1277.

Denholm, P.L., Sun, Y., Mai, T.T., 2019. An Introduction to Grid Services: Concepts, Technical Requirements, and Provision from Wind (No. NREL/TP-6A20-72578). National Renewable Energy Laboratory, Golden, CO. https://doi.org/10.2172/1493402

DOE, 2016. Hydropower Vision: A New Chapter for America's 1st Renewable Electricity Source" (No. Technical Report DOE/GO-102016-4869). U.S. Department of Energy, Washington, D.C.

Draxl, C., Hodge, B.-M., Clifton, A., 2015. Overview and Meteorological Validation of the Wind Integration National Dataset Toolkit. NREL/TP-5000-61740.

Duan, J., van Kooten, G.C., Liu, X., 2020. Renewable electricity grids, battery storage and missing money. Resources, Conservation, \& Recycling 161, 12.

Frazier, A.W., Cole, W., Denholm, P., Greer, D., Gagnon, P., 2020. Assessing the potential of battery storage as a peaking capacity resource in the United States. Applied Energy 275, 12.

Frew, B., Cole, W., Denholm, P., Frazier, W., Vincent, N., Margolis, R., 2019. Sunny with a Chance of Curtailment: Operating the US Grid with Very High Levels of Solar Photovoltaics. iScience 21, 436-447. https://doi.org/10.1016/ j.isci.2019.10.017

Frew, B., Cole, W., Sun, Y., Richards, J., Mai, T., 2017. 8760-Based Method for Representing Variable Generation Capacity Value in Capacity Expansion Models: Preprint. NREL/CP-6A2068869 .

Hartner, M., Permoser, A., 2018. Through the valley: The impact of PV penetration levels on price volatility and resulting revenues for storage plants. Renewable Energy 115, 1184-1195. https://doi.org/10.1016/j.renene.2017.09.036

Jorgenson, J., Denholm, P., Mai, T., 2018. Analyzing storage for wind integration in a transmission-constrained power system. Applied Energy 228, 122-129. https://doi.org/10.1016/j.apenergy.2018.06.046

Mallapragada, D.S., Sepulveda, N.A., Jenkins, J.D., 2020. Long-run system value of battery energy storage in future grids with increasing wind and solar generation. Applied Energy 275, 13.

Murphy, S., Lavin, L., Apt, J., 2020. Resource adequacy implications of temperature-dependent electric generator availability. Applied Energy 262, 14.

NERC (North American Electric Reliability Corporation), 2020. 2020 Summer Reliability Assessment. 
NREL (National Renewable Energy Laboratory), 2020. 2020 Annual Technology Baseline.

Pineda, S., Morales, J.M., 2018. Chronological Time-Period Clustering for Optimal Capacity Expansion Planning With Storage. IEEE Transactions on Power Systems 33, 7162-7170. https://doi.org/10.1109/TPWRS.2018.2842093

Reimers, A., Cole, W., Frew, B., 2019. The impact of planning reserve margins in long-term planning models of the electricity sector. Energy Policy 125, 1-8.

Roy, S., Sinha, P., Shah, S.I., 2020. Assessing the Techno-Economics and Environmental Attributes of Utility-Scale PV with Battery Energy Storage Systems (PVS) Compared to Conventional Gas Peakers for Providing Firm Capacity in California. Energies 24.

Sengupta, M., Xie, Y., Lopez, A., Habte, A., Maclaurin, G., Shelby, J., 2018. The National Solar Radiation Data Base (NSRDB). Renewable and Sustainable Energy Reviews 89, 51-60.

Sioshansi, R., Madaeni, S., Denholm, P., 2014. A Dynamic Programming Approach to Estimate the Capacity Value of Energy Storage. IEEE TRANSACTIONS ON POWER SYSTEMS 29, 395-403.

Viola, I.M., Harrison, G.P., Dunbar, A., Tagliaferri, F., 2014. The impact of electricity price forecast accuracy on the optimality of storage revenue, in: 3rd Renewable Power Generation Conference (RPG 2014). Presented at the 3rd Renewable Power Generation Conference (RPG 2014), Institution of Engineering and Technology, Naples, Italy, pp. 8.17-8.17. https://doi.org/10.1049/cp.2014.0902

Wang, Y., Dvorkin, Y., Fernandez-Blanco, R., Xu, B., Kirschen, D.S., 2017. Impact of local transmission congestion on energy storage arbitrage opportunities, in: 2017 IEEE Power \& Energy Society General Meeting. Presented at the 2017 IEEE Power \& Energy Society General Meeting (PESGM), IEEE, Chicago, IL, pp. 1-5. https://doi.org/10.1109/PESGM.2017.8274471

Yousif, M., Ai, Q., Wattoo, W.A., Jiang, Z., Hao, R., Gao, Y., 2019. Least cost combinations of solar power, wind power, and energy storage system for powering large-scale grid. Journal of Power Sources 412, 710-716. https://doi.org/10.1016/j.jpowsour.2018.11.084 


\section{Appendix}

\section{A.1 Scenario Results}

This section includes additional scenario results. Figure and table captions describe the details of those results.

Table A-1. Results for Wind, PV, and Total Renewable Energy Penetration in 2050 Across all Resource Sensitivity Scenarios ${ }^{\mathrm{a}}$

\begin{tabular}{|l|c|c|c|c|c|c|}
\hline Scenario & $\begin{array}{c}\text { \% Wind } \\
\text { gen }\end{array}$ & $\begin{array}{c}\text { \% PV } \\
\text { gen }\end{array}$ & $\begin{array}{c}\text { \% RE } \\
\text { gen }\end{array}$ & $\begin{array}{c}\text { Storage } \\
\text { (GW) }\end{array}$ & $\begin{array}{c}\text { Storage } \\
\text { (GWh) }\end{array}$ & $\begin{array}{c}\text { Storage } \\
\text { duration } \\
\text { (hours) }\end{array}$ \\
\hline High NG Price & 28.9 & 41.4 & 77.2 & 370 & 2445 & 6.6 \\
\hline $\begin{array}{l}\text { High NG Price \& Low Battery } \\
\text { Cost }\end{array}$ & 27.7 & 46.0 & 80.8 & 679 & 3242 & 4.8 \\
\hline High PV Cost & 23.6 & 19.7 & 50.8 & 164 & 1132 & 6.9 \\
\hline High VRE Cost & 13.6 & 23.5 & 45.0 & 181 & 1194 & 6.6 \\
\hline High VRE \& Low Battery Cost & 13.4 & 24.4 & 45.4 & 348 & 1598 & 4.6 \\
\hline High Battery Cost & 20.5 & 25.7 & 53.5 & 132 & 702 & 5.3 \\
\hline High Transmission Cost & 18.7 & 29.5 & 55.6 & 229 & 1432 & 6.2 \\
\hline $\begin{array}{l}\text { High Transmission Cost \& Low } \\
\text { Battery Cost }\end{array}$ & 19.6 & 30.9 & 57.9 & 380 & 1783 & 4.7 \\
\hline High Wind Cost & 10.2 & 34.1 & 51.6 & 245 & 1431 & 5.8 \\
\hline Low NG Price & 13.9 & 21.5 & 42.6 & 168 & 1081 & 6.4 \\
\hline $\begin{array}{l}\text { Low NG Price \& Low Battery } \\
\text { Cost }\end{array}$ & 13.1 & 22.4 & 42.7 & 323 & 1468 & 4.5 \\
\hline Low PV Cost & 14.5 & 41.7 & 63.1 & 278 & 1672 & 6.0 \\
\hline $\begin{array}{l}\text { Low PV Cost \& Low Battery } \\
\text { Cost }\end{array}$ & 13.5 & 45.6 & 66.1 & 506 & 2343 & 4.6 \\
\hline Low VRE Cost & 32.5 & 32.7 & 72.0 & 224 & 1458 & 6.5 \\
\hline $\begin{array}{l}\text { Low VRE Cost \& Low Battery } \\
\text { Cost }\end{array}$ & 31.9 & 34.6 & 73.5 & 430 & 1932 & 4.5 \\
\hline Low Battery Cost & 20.2 & 30.6 & 58.0 & 384 & 1792 & 4.7 \\
\hline Low Wind Cost & 20.4 & 28.8 & 56.4 & 213 & 1318 & 6.2 \\
\hline Low Wind \& Low Battery Cost & 38.3 & 22.3 & 67.8 & 322 & 1535 & 4.8 \\
\hline Reference Case & & & & & & \\
\hline
\end{tabular}

a Included is the total storage capacity in GW and GWh, with the average storage duration given as well. Note that each scenario starts with 24 GW and 278 GWh of storage (11.6 hours) in 2018. 

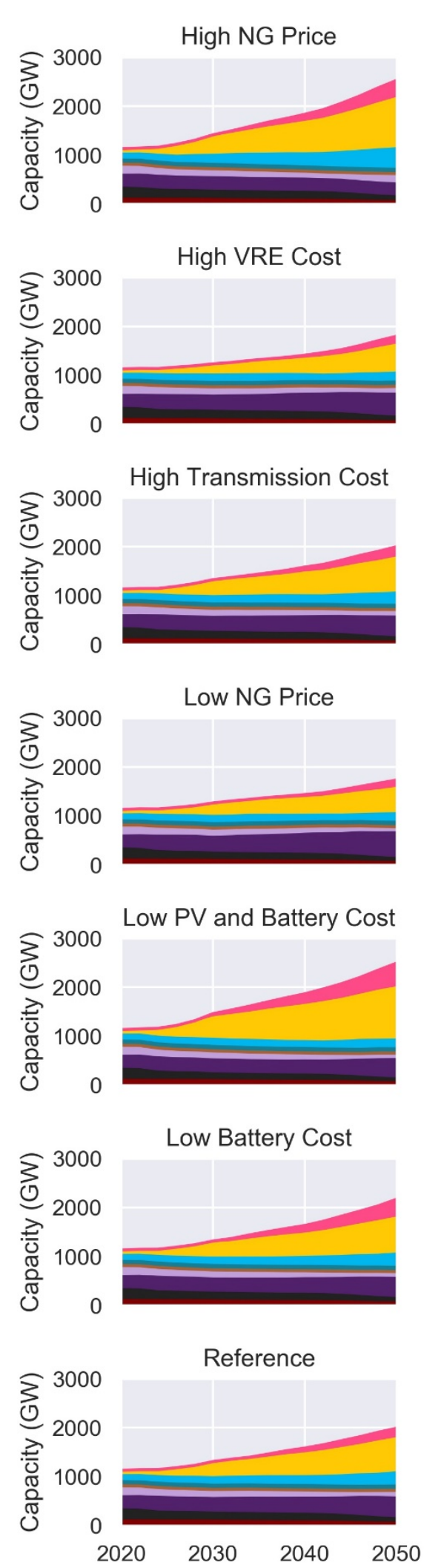

High NG Price and Low Battery Cost

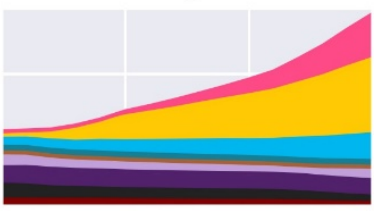

High VRE and Low Battery Cost

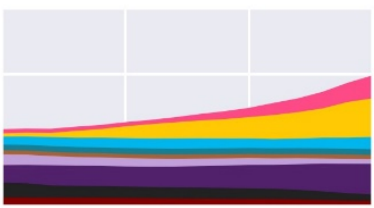

High Transmission and Low Battery Cost

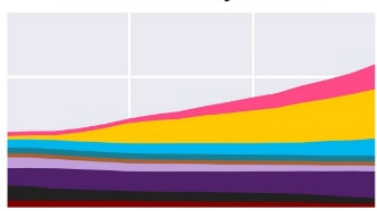

Low NG Price and Low Battery Cost

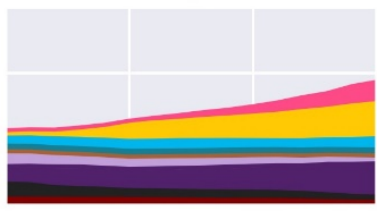

Low VRE Cost

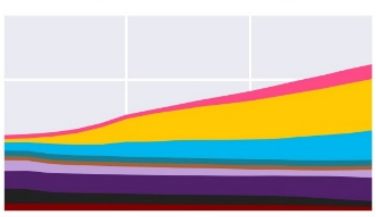

Low Wind Cost

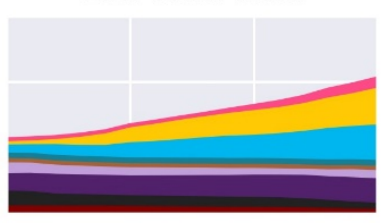

High PV Cost

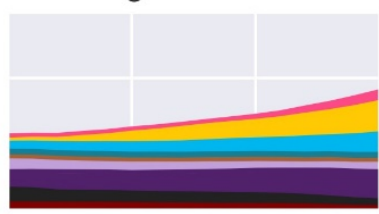

High Battery Cost

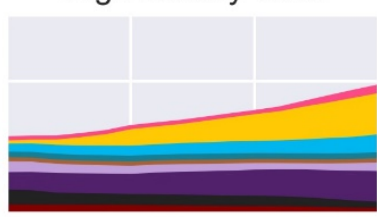

High Wind Cost

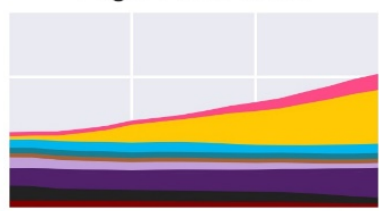

Low PV Cost

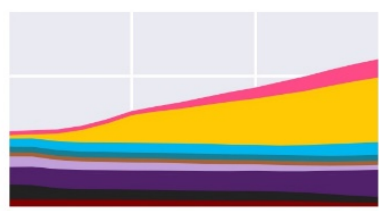

Low VRE and Battery Cost

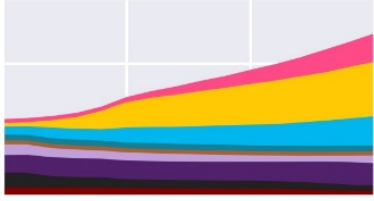

Low Wind and Battery Cost

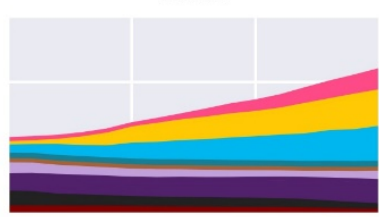

Figure A-1. Capacity by technology and year in all resource sensitivity scenarios 

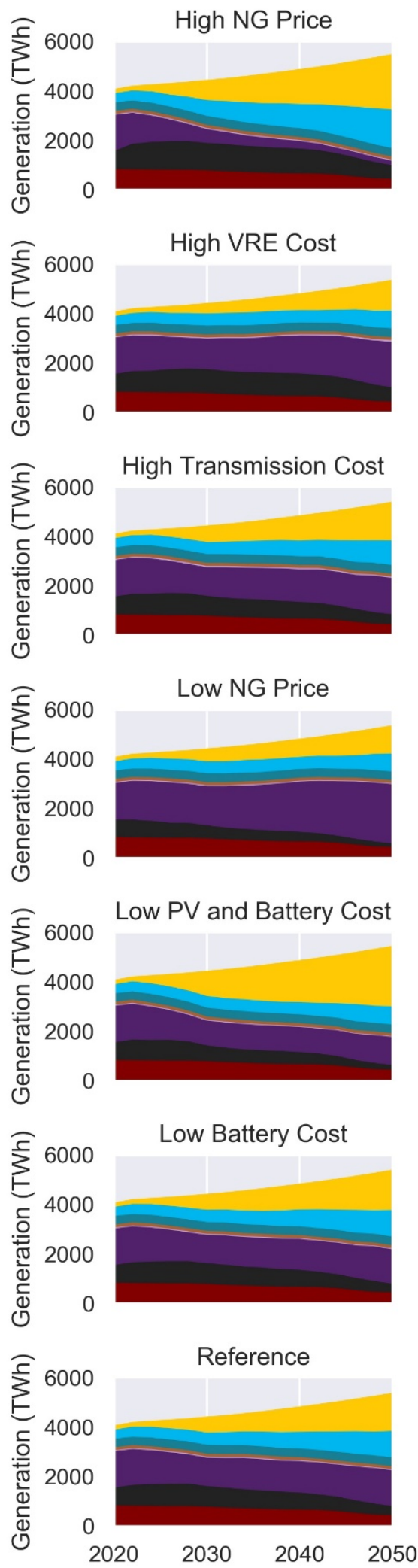

Figure A-2. Generation by technology and year in all resource sensitivity scenarios

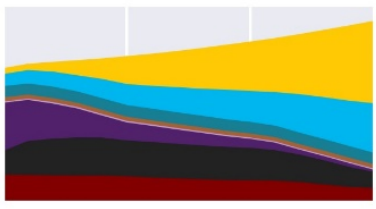

High VRE and Low Battery Cost

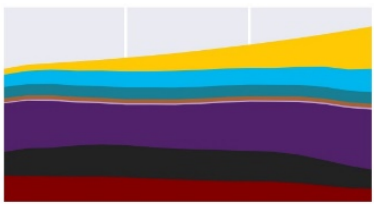

High Transmission and Low Battery Cost

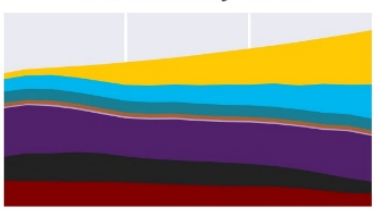

Low NG Price and Low Battery Cost

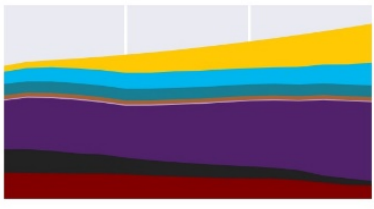

Low VRE Cost

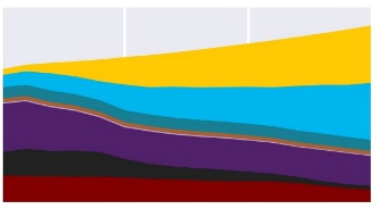

Low Wind Cost

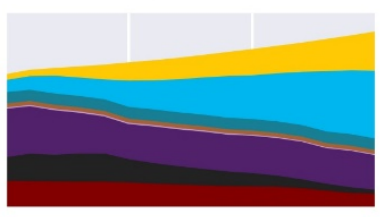

Low VRE and Battery Cost

Low Wind and Battery Cost

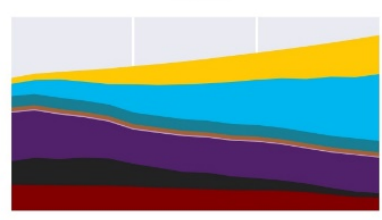

\begin{tabular}{|l|l|l|} 
Solar & Geo/Bio & Coal \\
Wind & NG-CT/OGS \\
Hydro & NG-CC & \\
\hline
\end{tabular}

High PV Cost

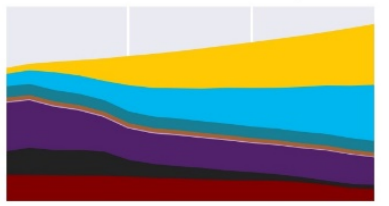




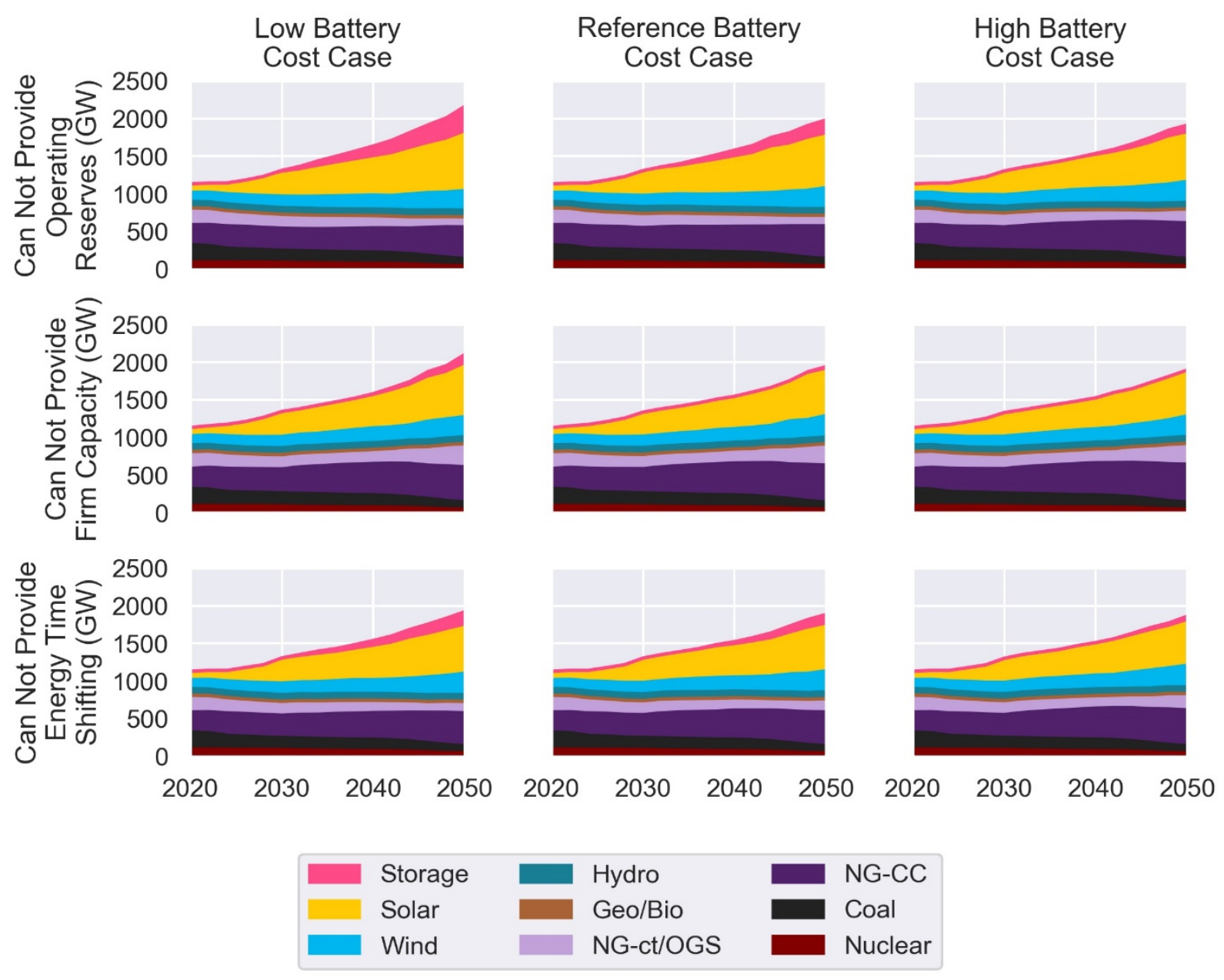

Figure A-3. Capacity by technology and year in all storage grid service sensitivity scenarios 


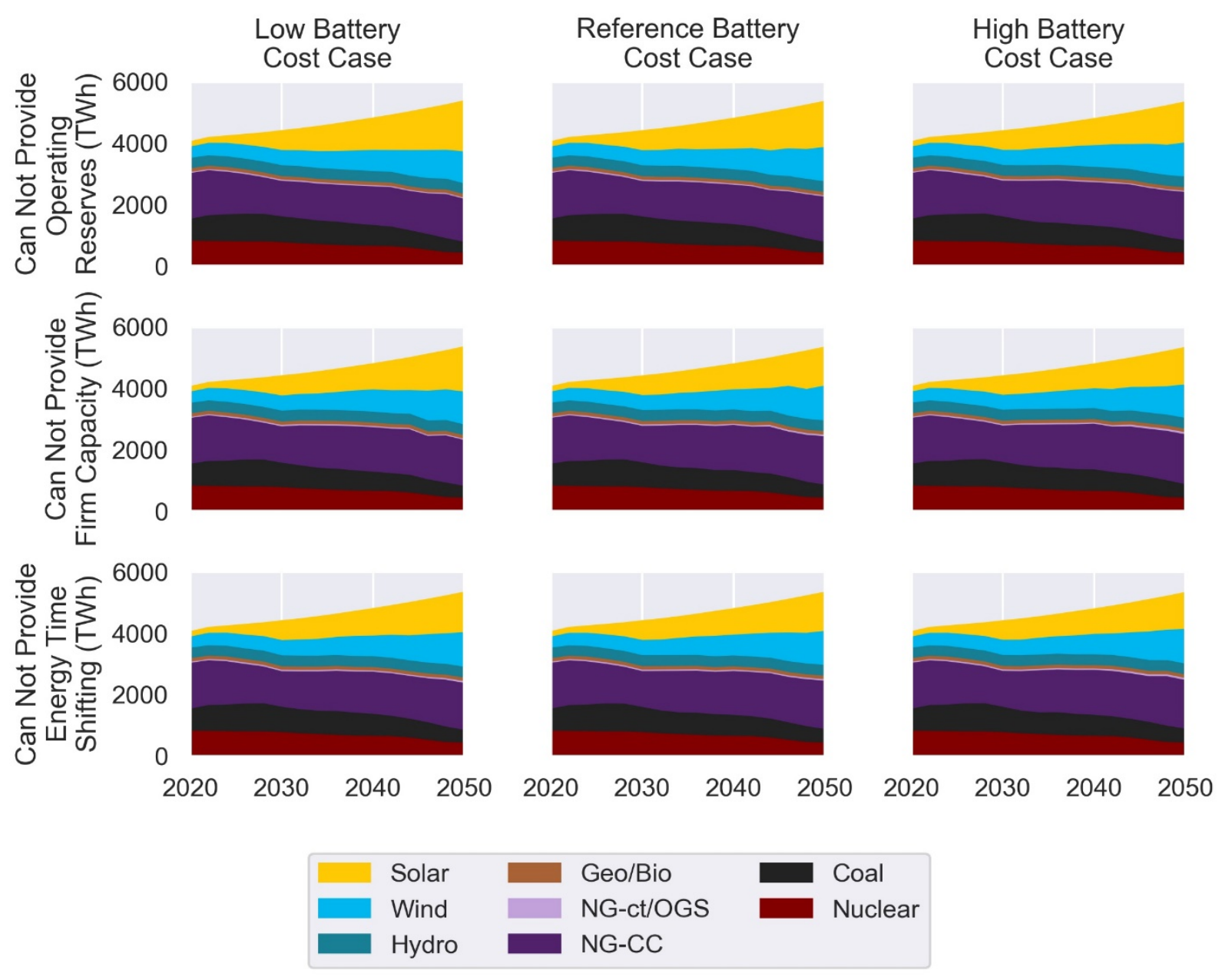

Figure A-4. Generation by technology and year in all storage grid service sensitivity scenarios 


\section{A.2 Operating Reserves}

ReEDS represents three types of operating reserves: regulation, spinning, and flexibility. These reserve types represent the broader range of reserves in current U.S. markets.(Denholm et al., 2019) The reserve types are a function of load, wind generation, and PV capacity as shown in Table A-2. Additional details about the operating reserve implementation are provided by Cole et al. (Cole et al., 2018).

Table A-2. Reserve Requirements in ReEDS

\begin{tabular}{|c|c|c|c|c|}
\hline $\begin{array}{l}\text { Reserve } \\
\text { Type }\end{array}$ & $\begin{array}{l}\text { Load } \\
\text { Requirement }\end{array}$ & Wind Requirement & PV Requirement & Timescale \\
\hline Spinning & $3 \%$ of load & - & - & $10 \mathrm{~min}$ \\
\hline Regulation & $1 \%$ of load & $\begin{array}{l}0.5 \% \text { of wind } \\
\text { generation }\end{array}$ & $\begin{array}{l}0.3 \% \text { of } \mathrm{PV} \text { capacity a during } \\
\text { daytime hours }\end{array}$ & $5 \mathrm{~min}$ \\
\hline Flexibility & - & $\begin{array}{l}10 \% \text { of wind } \\
\text { generation }\end{array}$ & $\begin{array}{l}4 \% \text { of PV capacitya during } \\
\text { daytime hours }\end{array}$ & $60 \mathrm{~min}$ \\
\hline
\end{tabular}

a $\mathrm{PV}$ is based on capacity because PV-induced reserves are most needed during dawn and dusk when generation is low.

\section{A.3 Storage Cost Inputs}

Tables A-3 through A-5 show the battery capital cost assumptions used for this work, which are from Augustine and Blair (2021). ReEDS also includes a fixed operations and maintenance cost equal to $2.5 \%$ of the capital costs. Batteries are assumed to have a lifetime of 15 years and a round-trip efficiency of $85 \%$.

Figure A-5 (reproduced from the ReEDS model documentation (Brown et al., 2020)) shows the PSH supply curve used in ReEDS. All PSH is assumed to have 12 hours of duration. The PSH cost and resource assessment were completed as part of the Hydropower Vision Study(DOE, 2016) which was published in 2016. Since then, much work has been done to improve the assumptions and resource assessments for PSH in the U.S., but that work is not yet ready for inclusion in this study. For example, PSH with durations of less than 12 hours might be lower cost than what is shown in Figure A-5, which might increase the amount of PSH deployed in these scenarios.

Using these battery cost and performance values in this work led to large amounts of battery deployment. If other storage technologies were to achieve the same cost and performance levels as the battery assumptions shown below, we would expect those technologies to be deployed at the levels of battery storage shown in this work. For example, if PSH or flow batteries reach $\$ 150-300 / \mathrm{kWh}$ by 2030 , we would expect those technologies to be deployed at the levels that we showed for battery storage in the scenarios presented here. 
Table A-3. Reference Battery Capital Costs

\begin{tabular}{|c|c|c|c|c|c|c|c|c|c|c|}
\hline \multirow[b]{2}{*}{ Year } & \multicolumn{5}{|c|}{ Future 60-MW BESS Costs (\$/kW) - MID } & \multicolumn{5}{|c|}{ Future 60-MW BESS Costs (\$/kWh) - MID } \\
\hline & 2-hour & 4-hour & 6-hour & 8-hour & 10-hour & 2-hour & 4-hour & 6-hour & 8-hour & 10-hour \\
\hline 2019 & 886 & 1,527 & 2,167 & 2,808 & 3,448 & 443 & 382 & 361 & 351 & 345 \\
\hline 2020 & 851 & 1,438 & 2,026 & 2,614 & 3,202 & 425 & 360 & 338 & 327 & 320 \\
\hline 2021 & 814 & 1,349 & 1,884 & 2,419 & 2,954 & 407 & 337 & 314 & 302 & 295 \\
\hline 2022 & 778 & 1,260 & 1,742 & 2,225 & 2,707 & 389 & 315 & 290 & 278 & 271 \\
\hline 2023 & 742 & 1,171 & 1,601 & 2,030 & 2,460 & 371 & 293 & 267 & 254 & 246 \\
\hline 2024 & 705 & 1,082 & 1,459 & 1,836 & 2,212 & 353 & 271 & 243 & 229 & 221 \\
\hline 2025 & 669 & 993 & 1,317 & 1,641 & 1,965 & 334 & 248 & 219 & 205 & 196 \\
\hline 2026 & 655 & 956 & 1,257 & 1,559 & 1,860 & 327 & 239 & 210 & 195 & 186 \\
\hline 2027 & 638 & 919 & 1,200 & 1,481 & 1,762 & 319 & 230 & 200 & 185 & 176 \\
\hline 2028 & 619 & 882 & 1,145 & 1,408 & 1,670 & 310 & 221 & 191 & 176 & 167 \\
\hline 2029 & 599 & 845 & 1,091 & 1,337 & 1,584 & 299 & 211 & 182 & 167 & 158 \\
\hline 2030 & 577 & 808 & 1,040 & 1,271 & 1,502 & 288 & 202 & 173 & 159 & 150 \\
\hline 2031 & 574 & 798 & 1,022 & 1,245 & 1,469 & 287 & 200 & 170 & 156 & 147 \\
\hline 2032 & 576 & 788 & 1,000 & 1,212 & 1,424 & 288 & 197 & 167 & 152 & 142 \\
\hline 2033 & 576 & 778 & 980 & 1,182 & 1,385 & 288 & 194 & 163 & 148 & 138 \\
\hline 2034 & 574 & 768 & 961 & 1,155 & 1,349 & 287 & 192 & 160 & 144 & 135 \\
\hline 2035 & 572 & 758 & 944 & 1,130 & 1,316 & 286 & 189 & 157 & 141 & 132 \\
\hline 2036 & 568 & 748 & 927 & 1,107 & 1,286 & 284 & 187 & 155 & 138 & 129 \\
\hline 2037 & 564 & 737 & 911 & 1,085 & 1,258 & 282 & 184 & 152 & 136 & 126 \\
\hline 2038 & 559 & 727 & 896 & 1,064 & 1,232 & 280 & 182 & 149 & 133 & 123 \\
\hline 2039 & 554 & 717 & 881 & 1,044 & 1,207 & 277 & 179 & 147 & 130 & 121 \\
\hline 2040 & 548 & 707 & 866 & 1,025 & 1,184 & 274 & 177 & 144 & 128 & 118 \\
\hline 2041 & 542 & 697 & 852 & 1,006 & 1,161 & 271 & 174 & 142 & 126 & 116 \\
\hline 2042 & 536 & 687 & 838 & 988 & 1,139 & 268 & 172 & 140 & 124 & 114 \\
\hline 2043 & 530 & 677 & 824 & 971 & 1,118 & 265 & 169 & 137 & 121 & 112 \\
\hline 2044 & 523 & 667 & 810 & 954 & 1,098 & 262 & 167 & 135 & 119 & 110 \\
\hline
\end{tabular}

$$
27
$$




\begin{tabular}{|c|c|c|c|c|c|c|c|c|c|c|}
\hline \multirow[b]{2}{*}{ Year } & \multicolumn{5}{|c|}{ Future 60-MW BESS Costs (\$/kW) - MID } & \multicolumn{5}{|c|}{ Future 60-MW BESS Costs (\$/kWh) - MID } \\
\hline & 2-hour & 4-hour & 6-hour & 8-hour & 10-hour & 2-hour & 4-hour & 6-hour & 8-hour & 10-hour \\
\hline 2045 & 516 & 657 & 797 & 938 & 1,079 & 258 & 164 & 133 & 117 & 108 \\
\hline 2046 & 509 & 647 & 784 & 922 & 1,060 & 254 & 162 & 131 & 115 & 106 \\
\hline 2047 & 501 & 636 & 772 & 907 & 1,042 & 251 & 159 & 129 & 113 & 104 \\
\hline 2048 & 494 & 626 & 759 & 892 & 1,024 & 247 & 157 & 126 & 111 & 102 \\
\hline 2049 & 486 & 616 & 747 & 877 & 1,007 & 243 & 154 & 124 & 110 & 101 \\
\hline 2050 & 478 & 606 & 734 & 863 & 991 & 239 & 152 & 122 & 108 & 99 \\
\hline
\end{tabular}


Table A-4. Low Battery Capital Costs

\begin{tabular}{|c|c|c|c|c|c|c|c|c|c|c|}
\hline \multirow[b]{2}{*}{ Year } & \multicolumn{5}{|c|}{ Future 60-MW BESS Costs (\$/kW) - LOW } & \multicolumn{5}{|c|}{ Future 60-MW BESS Costs (\$/kWh) - LOW } \\
\hline & 2-hour & 4-hour & 6-hour & 8-hour & 10-hour & 2-hour & 4-hour & 6-hour & 8-hour & 10-hour \\
\hline 2019 & 886 & 1,527 & 2,167 & 2,808 & 3,448 & 443 & 382 & 361 & 351 & 345 \\
\hline 2020 & 690 & 1,189 & 1,688 & 2,187 & 2,686 & 345 & 297 & 281 & 273 & 269 \\
\hline 2021 & 642 & 1,106 & 1,569 & 2,033 & 2,497 & 321 & 276 & 262 & 254 & 250 \\
\hline 2022 & 593 & 1,022 & 1,450 & 1,879 & 2,308 & 297 & 255 & 242 & 235 & 231 \\
\hline 2023 & 545 & 938 & 1,332 & 1,725 & 2,119 & 272 & 235 & 222 & 216 & 212 \\
\hline 2024 & 496 & 854 & 1,213 & 1,571 & 1,930 & 248 & 214 & 202 & 196 & 193 \\
\hline 2025 & 447 & 771 & 1,094 & 1,417 & 1,741 & 224 & 193 & 182 & 177 & 174 \\
\hline 2026 & 423 & 729 & 1,034 & 1,340 & 1,646 & 212 & 182 & 172 & 168 & 165 \\
\hline 2027 & 399 & 687 & 975 & 1,263 & 1,551 & 199 & 172 & 162 & 158 & 155 \\
\hline 2028 & 374 & 645 & 915 & 1,186 & 1,457 & 187 & 161 & 153 & 148 & 146 \\
\hline 2029 & 350 & 603 & 856 & 1,109 & 1,362 & 175 & 151 & 143 & 139 & 136 \\
\hline 2030 & 326 & 561 & 796 & 1,032 & 1,267 & 163 & 140 & 133 & 129 & 127 \\
\hline 2031 & 319 & 550 & 781 & 1,012 & 1,242 & 160 & 138 & 130 & 126 & 124 \\
\hline 2032 & 313 & 539 & 765 & 991 & 1,218 & 157 & 135 & 128 & 124 & 122 \\
\hline 2033 & 307 & 528 & 750 & 971 & 1,193 & 153 & 132 & 125 & 121 & 119 \\
\hline 2034 & 300 & 517 & 734 & 951 & 1,168 & 150 & 129 & 122 & 119 & 117 \\
\hline 2035 & 294 & 506 & 719 & 931 & 1,143 & 147 & 127 & 120 & 116 & 114 \\
\hline 2036 & 288 & 495 & 703 & 911 & 1,118 & 144 & 124 & 117 & 114 & 112 \\
\hline 2037 & 281 & 484 & 687 & 891 & 1,094 & 141 & 121 & 115 & 111 & 109 \\
\hline 2038 & 275 & 473 & 672 & 870 & 1,069 & 137 & 118 & 112 & 109 & 107 \\
\hline 2039 & 268 & 462 & 656 & 850 & 1,044 & 134 & 116 & 109 & 106 & 104 \\
\hline 2040 & 262 & 451 & 641 & 830 & 1,019 & 131 & 113 & 107 & 104 & 102 \\
\hline 2041 & 256 & 440 & 625 & 810 & 994 & 128 & 110 & 104 & 101 & 99 \\
\hline 2042 & 249 & 429 & 609 & 790 & 970 & 125 & 107 & 102 & 99 & 97 \\
\hline 2043 & 243 & 418 & 594 & 769 & 945 & 121 & 105 & 99 & 96 & 94 \\
\hline 2044 & 237 & 407 & 578 & 749 & 920 & 118 & 102 & 96 & 94 & 92 \\
\hline
\end{tabular}

29

This report is available at no cost from the National Renewable Energy Laboratory at www.nrel.gov/publications. 


\begin{tabular}{|c|c|c|c|c|c|c|c|c|c|c|}
\hline & \multicolumn{4}{|c|}{ Future 60-MW BESS Costs (\$/kW) - LOW } & \multicolumn{4}{c|}{ Future 60-MW BESS Costs (\$/kWh) - LOW } \\
\cline { 2 - 13 } Year & 2-hour & 4-hour & $\mathbf{6 - h o u r}$ & $\mathbf{8 - h o u r}$ & $\mathbf{1 0 - h o u r}$ & 2-hour & 4-hour & 6-hour & 8-hour & 10-hour \\
\hline 2045 & 230 & 396 & 563 & 729 & 895 & 115 & 99 & 94 & 91 & 90 \\
\hline 2046 & 224 & 385 & 547 & 709 & 870 & 112 & 96 & 91 & 89 & 87 \\
\hline 2047 & 217 & 374 & 532 & 689 & 846 & 109 & 94 & 89 & 86 & 85 \\
\hline 2048 & 211 & 364 & 516 & 668 & 821 & 106 & 91 & 86 & 84 & 82 \\
\hline 2049 & 205 & 353 & 500 & 648 & 796 & 102 & 88 & 83 & 81 & 80 \\
\hline 2050 & 198 & 342 & 485 & 628 & 771 & 99 & 85 & 81 & 79 & 77 \\
\hline
\end{tabular}


Table A-5. High Battery Capital Costs

\begin{tabular}{|c|c|c|c|c|c|c|c|c|c|c|}
\hline \multirow[b]{2}{*}{ Year } & \multicolumn{5}{|c|}{ Future 60-MW BESS Costs $(\$ / k W)$ - HIGH } & \multicolumn{5}{|c|}{ Future 60-MW BESS Costs (\$/kWh) - HIGH } \\
\hline & 2-hour & 4-hour & 6-hour & 8-hour & 10-hour & 2-hour & 4-hour & 6-hour & 8-hour & 10-hour \\
\hline 2019 & 886 & 1,527 & 2,167 & 2,808 & 3,448 & 443 & 382 & 361 & 351 & 345 \\
\hline 2020 & 863 & 1,487 & 2,111 & 2,734 & 3,358 & 432 & 372 & 352 & 342 & 336 \\
\hline 2021 & 840 & 1,447 & 2,054 & 2,661 & 3,267 & 420 & 362 & 342 & 333 & 327 \\
\hline 2022 & 817 & 1,407 & 1,997 & 2,587 & 3,177 & 408 & 352 & 333 & 323 & 318 \\
\hline 2023 & 794 & 1,367 & 1,940 & 2,513 & 3,087 & 397 & 342 & 323 & 314 & 309 \\
\hline 2024 & 770 & 1,327 & 1,883 & 2,440 & 2,996 & 385 & 332 & 314 & 305 & 300 \\
\hline 2025 & 747 & 1,287 & 1,827 & 2,366 & 2,906 & 374 & 322 & 304 & 296 & 291 \\
\hline 2026 & 730 & 1,257 & 1,784 & 2,311 & 2,838 & 365 & 314 & 297 & 289 & 284 \\
\hline 2027 & 712 & 1,227 & 1,741 & 2,256 & 2,770 & 356 & 307 & 290 & 282 & 277 \\
\hline 2028 & 695 & 1,197 & 1,699 & 2,201 & 2,702 & 347 & 299 & 283 & 275 & 270 \\
\hline 2029 & 677 & 1,167 & 1,656 & 2,145 & 2,635 & 339 & 292 & 276 & 268 & 263 \\
\hline 2030 & 660 & 1,137 & 1,613 & 2,090 & 2,567 & 330 & 284 & 269 & 261 & 257 \\
\hline 2031 & 652 & 1,122 & 1,593 & 2,064 & 2,535 & 326 & 281 & 266 & 258 & 253 \\
\hline 2032 & 643 & 1,108 & 1,573 & 2,038 & 2,503 & 322 & 277 & 262 & 255 & 250 \\
\hline 2033 & 635 & 1,094 & 1,553 & 2,012 & 2,471 & 318 & 273 & 259 & 251 & 247 \\
\hline 2034 & 627 & 1,080 & 1,533 & 1,986 & 2,438 & 313 & 270 & 255 & 248 & 244 \\
\hline 2035 & 619 & 1,066 & 1,512 & 1,959 & 2,406 & 309 & 266 & 252 & 245 & 241 \\
\hline 2036 & 610 & 1,051 & 1,492 & 1,933 & 2,374 & 305 & 263 & 249 & 242 & 237 \\
\hline 2037 & 602 & 1,037 & 1,472 & 1,907 & 2,342 & 301 & 259 & 245 & 238 & 234 \\
\hline 2038 & 594 & 1,023 & 1,452 & 1,881 & 2,310 & 297 & 256 & 242 & 235 & 231 \\
\hline 2039 & 586 & 1,009 & 1,432 & 1,855 & 2,278 & 293 & 252 & 239 & 232 & 228 \\
\hline 2040 & 577 & 995 & 1,412 & 1,829 & 2,246 & 289 & 249 & 235 & 229 & 225 \\
\hline 2041 & 569 & 980 & 1,391 & 1,803 & 2,214 & 285 & 245 & 232 & 225 & 221 \\
\hline 2042 & 561 & 966 & 1,371 & 1,777 & 2,182 & 280 & 242 & 229 & 222 & 218 \\
\hline 2043 & 553 & 952 & 1,351 & 1,750 & 2,150 & 276 & 238 & 225 & 219 & 215 \\
\hline 2044 & 544 & 938 & 1,331 & 1,724 & 2,118 & 272 & 234 & 222 & 216 & 212 \\
\hline
\end{tabular}




\begin{tabular}{|c|c|c|c|c|c|c|c|c|c|c|}
\hline \multirow[b]{2}{*}{ Year } & \multicolumn{5}{|c|}{ Future 60-MW BESS Costs (\$/kW) - HIGH } & \multicolumn{5}{|c|}{ Future 60-MW BESS Costs (\$/kWh) - HIGH } \\
\hline & 2-hour & 4-hour & 6-hour & 8-hour & 10-hour & 2-hour & 4-hour & 6-hour & 8-hour & 10-hour \\
\hline 2045 & 536 & 923 & 1,311 & 1,698 & 2,086 & 268 & 231 & 218 & 212 & 209 \\
\hline 2046 & 528 & 909 & 1,291 & 1,672 & 2,053 & 264 & 227 & 215 & 209 & 205 \\
\hline 2047 & 520 & 895 & 1,270 & 1,646 & 2,021 & 260 & 224 & 212 & 206 & 202 \\
\hline 2048 & 511 & 881 & 1,250 & 1,620 & 1,989 & 256 & 220 & 208 & 202 & 199 \\
\hline 2049 & 503 & 867 & 1,230 & 1,594 & 1,957 & 252 & 217 & 205 & 199 & 196 \\
\hline 2050 & 495 & 852 & 1,210 & 1,568 & 1,925 & 247 & 213 & 202 & 196 & 193 \\
\hline
\end{tabular}




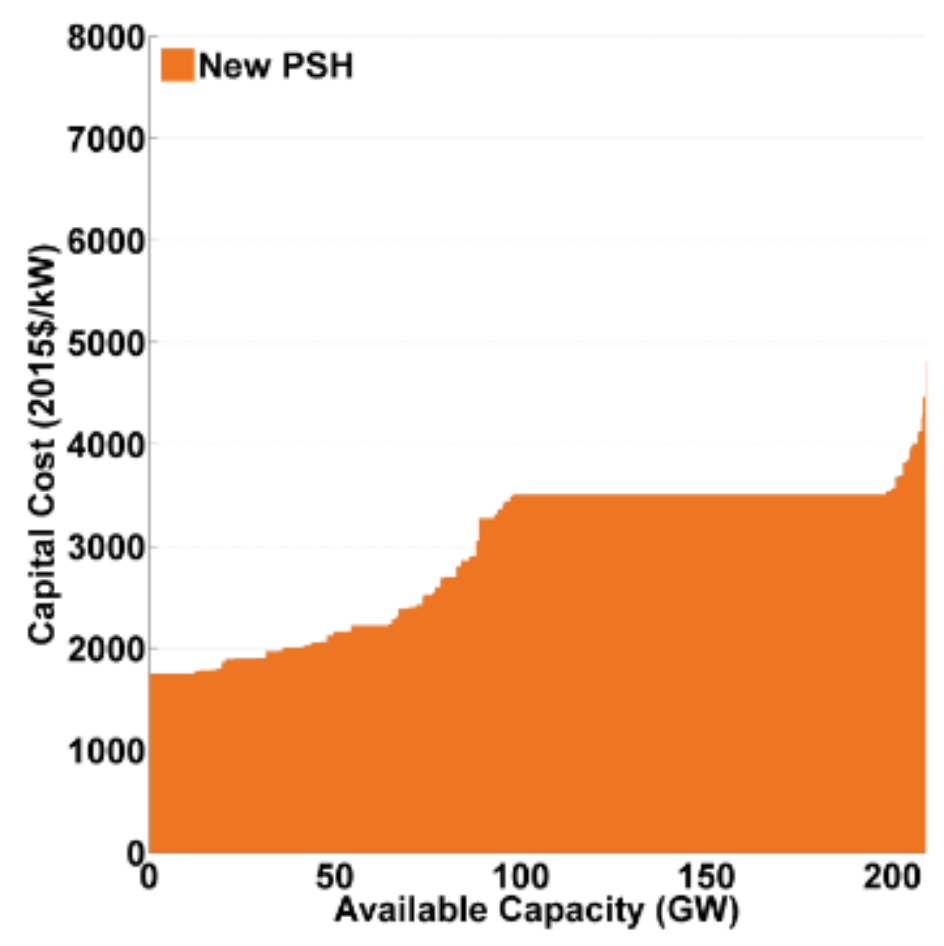

Figure A-5. Pumped-hydro capital costs

These costs are defined regionally and are limited by the potential resource capacity determined in the Hydropower Vision Study(DOE, 2016). 


\section{A.4 ReEDS Model Caveat and Limitations}

The ReEDS model used for this work has several limitations and the results presented here are meant to serve as a framework for understanding the role of storage in the power sector. The storage deployment numbers here are not necessarily specific to lithium-ion batteries per the discussion in the storage cost inputs section of the appendix. Any technology that reaches these cost and performance levels would be competitive resource within the model.

The following elements are important to keep in mind when interpreting the results presented in this work:

- ReEDS is a system-wide, least-cost optimization model. It does not include individual market actors, nor does it represent actual markets. For example, ReEDS assess capacity value and energy value independently in all regions of the country independent of whether or not there are capacity or energy markets in those regions.

- The version of ReEDS used for this work does not include hybrid storage resources. These resources are becoming increasingly common in interconnection queues.

- This work does not include distribution-level or behind-the-meter storage resources.

- Load flexibility is not explicitly modeled in this work, including future flexibility that might come from increased adoption of electric vehicles.

- ReEDS does not represent manufacturing or supply chains for generation and storage resources. If scaling up manufacturing or supply chain to meet the deployment levels shown in this work would create a bottleneck for deployment, that effect would not be captured in these scenarios.

- Durations longer than 12 hours are not considered in this work. Longer duration resources might compete with diurnal storage resources and reduce their market potential.

- Durations shorter than 2 hours are not considered in this work. Shorter duration resources could provide reserves or other services to a greater extent than captured here.

- Other potential drivers of storage deployment, such as voltage support or backup generation, are not examined here.

- Interactions with other sectors are not included. Electrification, or inter-sector coupling such as via hydrogen production and storage, could alter the potential for diurnal storage.

- Transmission representation in ReEDS is limited to aggregate transmission corridors sending power between regions (see Figures A-9 through A-26). Additional transmission investments are represented simply as increasing the amount of capacity that can be sent between regions, and they do not consider citing permits or other issues.

- Based upon the cost and performance inputs, we do not analyze grid conditions exceeding $80 \%$ nation-wide VRE penetration in this study. The combined roles of diurnal storage, seasonal storage, transmission expansion, and other sources of grid flexibility in such scenarios are very complex and are outside the scope of this work. 


\section{A.5 Relationship with Wind Penetration}

Figure A-6 reproduces Figure 2 from the main body (page 10) but plots the values against wind penetration instead of $\mathrm{PV}$ penetration. The relationship between the peaking capacity potential and energy time-shifting potential with wind penetration are far less clear than they are for PV penetration.
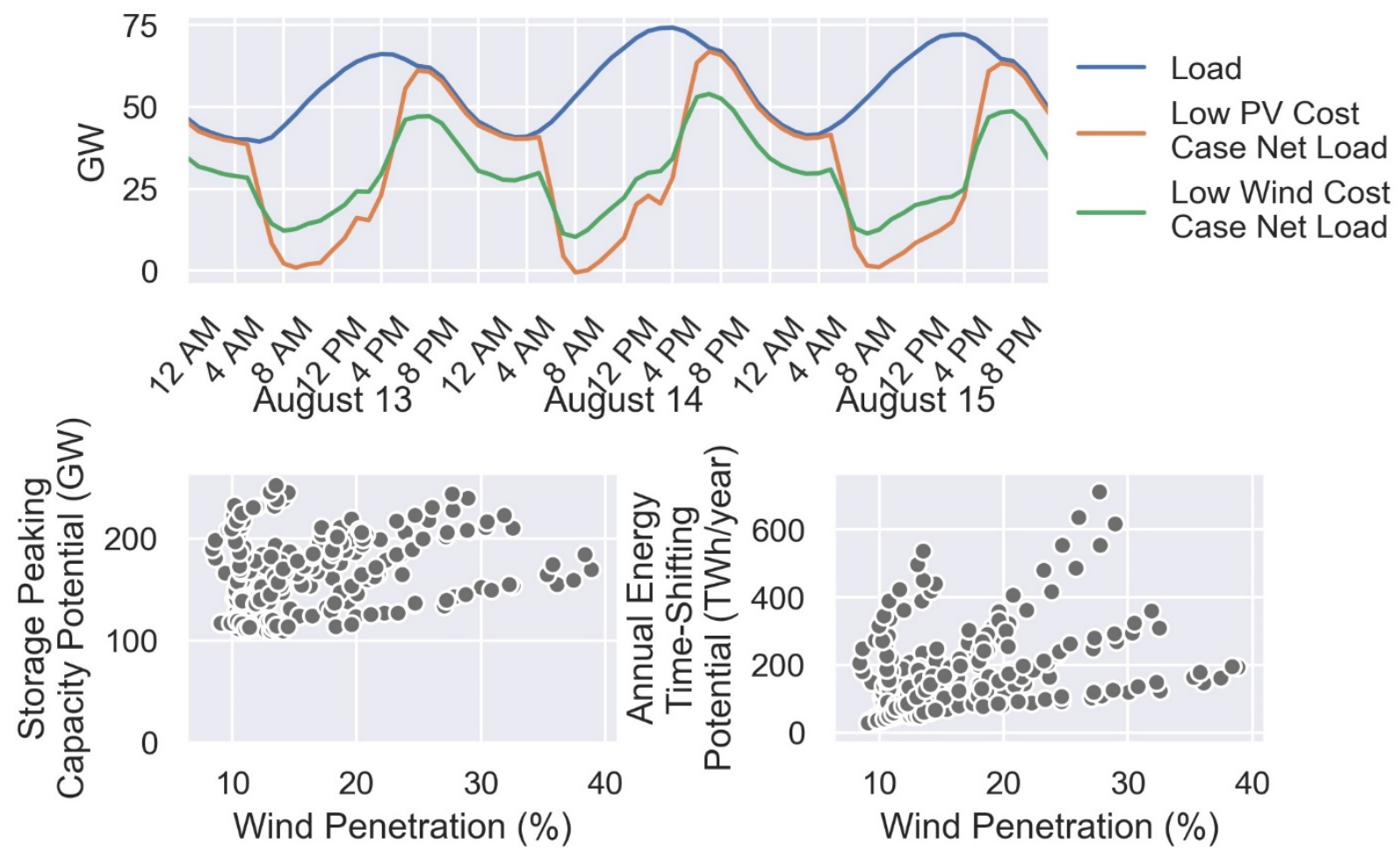

Figure A-6. Load and net load in 2050 in California for the Low PV Cost and Low Wind Cost Cases (top); national peaking capacity potential for diurnal storage (up to 12 hours) as a function of wind penetration (bottom left) and national diurnal energy time-shifting potential as a function of wind penetration (bottom right)

The bottom figures show all years in all scenarios (i.e., there is one point for each year in each scenario). 


\section{A.6 Regional Results}

The results up to this point focus on national-scale results. This section presents the results at a regional level. Results are aggregated to the 18 reliability assessment zones shown in Figure A-7. These zones approximately map to RTO/ISO regions. The remaining figures then present those regional values for storage.

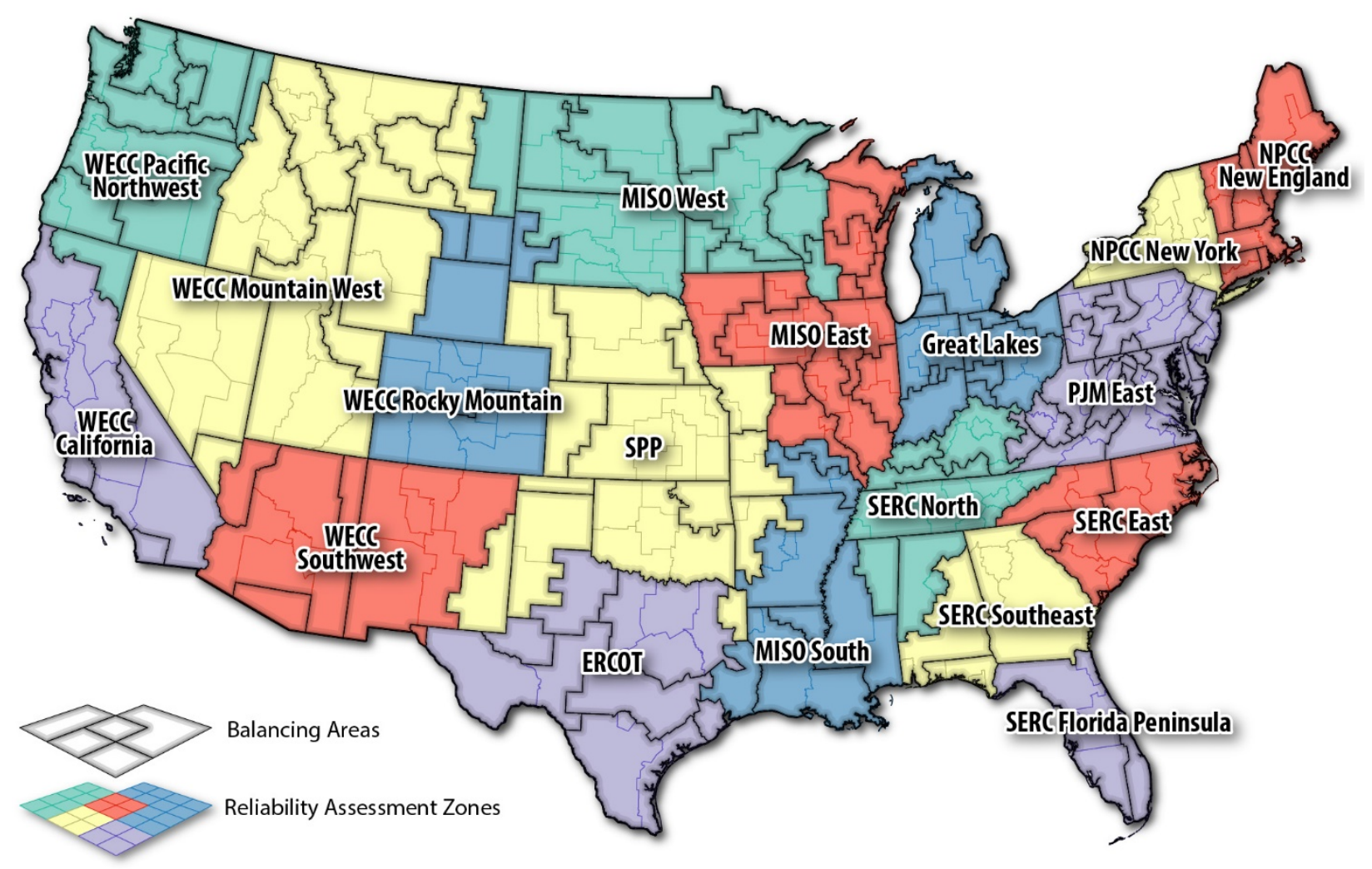

Figure A-7. Map of ReEDS reliability assessment zones

Storage peaking capacity potential is assessed at this regional level. 


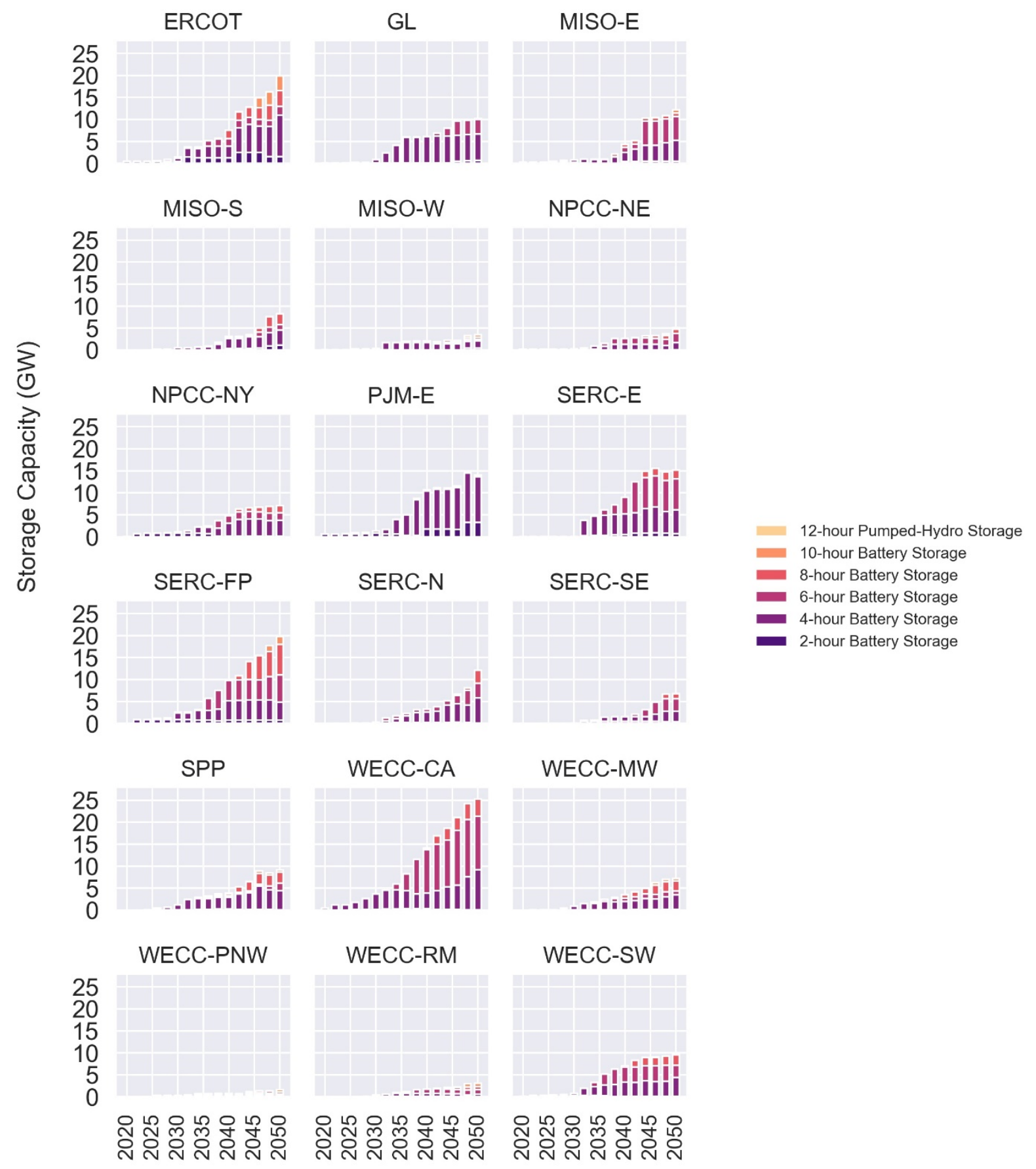

Figure A-8. Cumulative storage capacity by duration and year in each Reliability Assessment Zone (shown in Figure A-7) in the reference case 


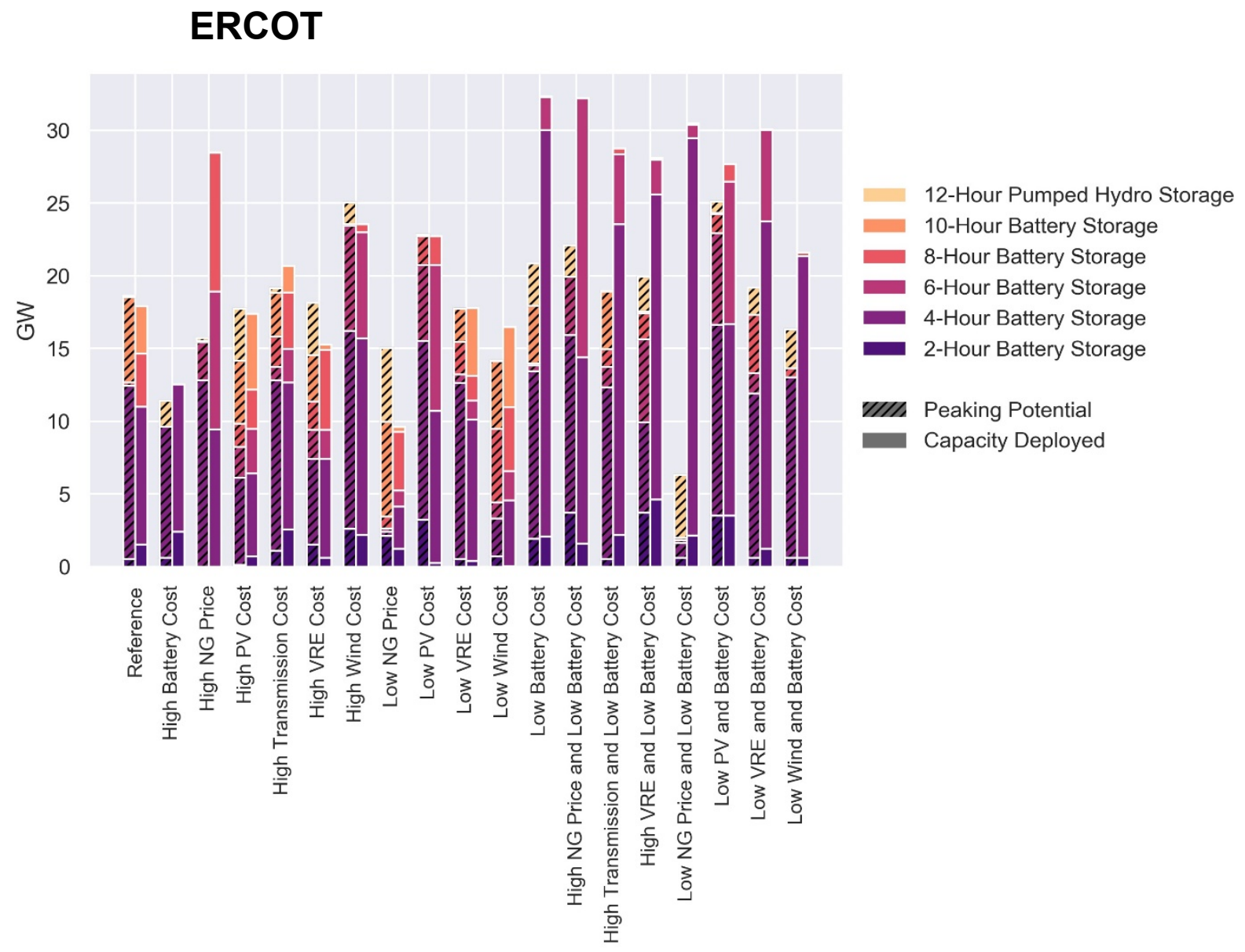

Figure A-9. Economic storage deployment and peaking capacity potential of storage in 2050 in all resource sensitivity scenarios in ERCOT (Figure A-7) 


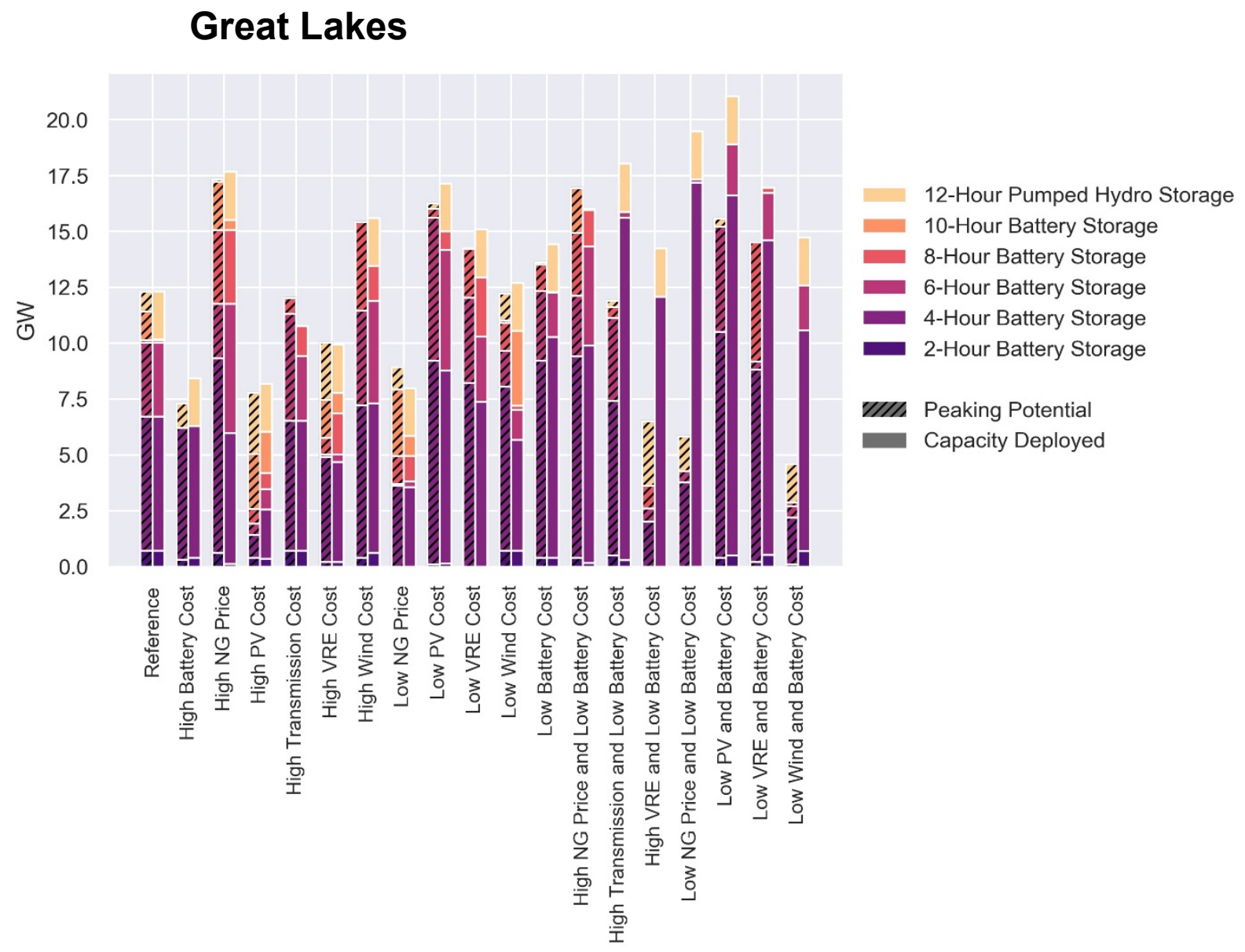

Figure A-10. Economic storage deployment and peaking capacity potential of storage in 2050 in all resource sensitivity scenarios in the Great Lakes zone (Figure A-7) 


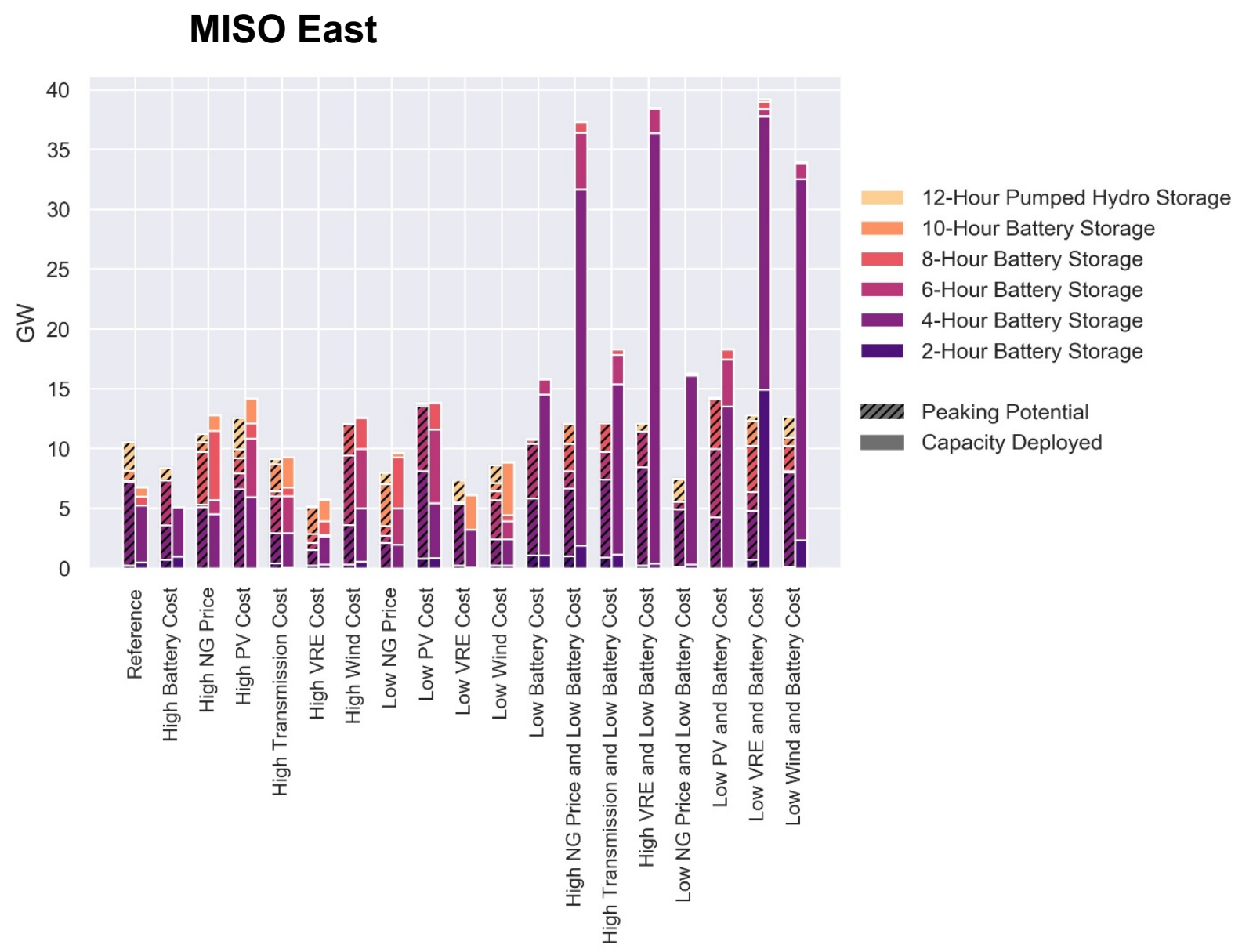

Figure A-11. Economic storage deployment and peaking capacity potential of storage in 2050 in all resource sensitivity scenarios in the MISO East zone (Figure A-7) 


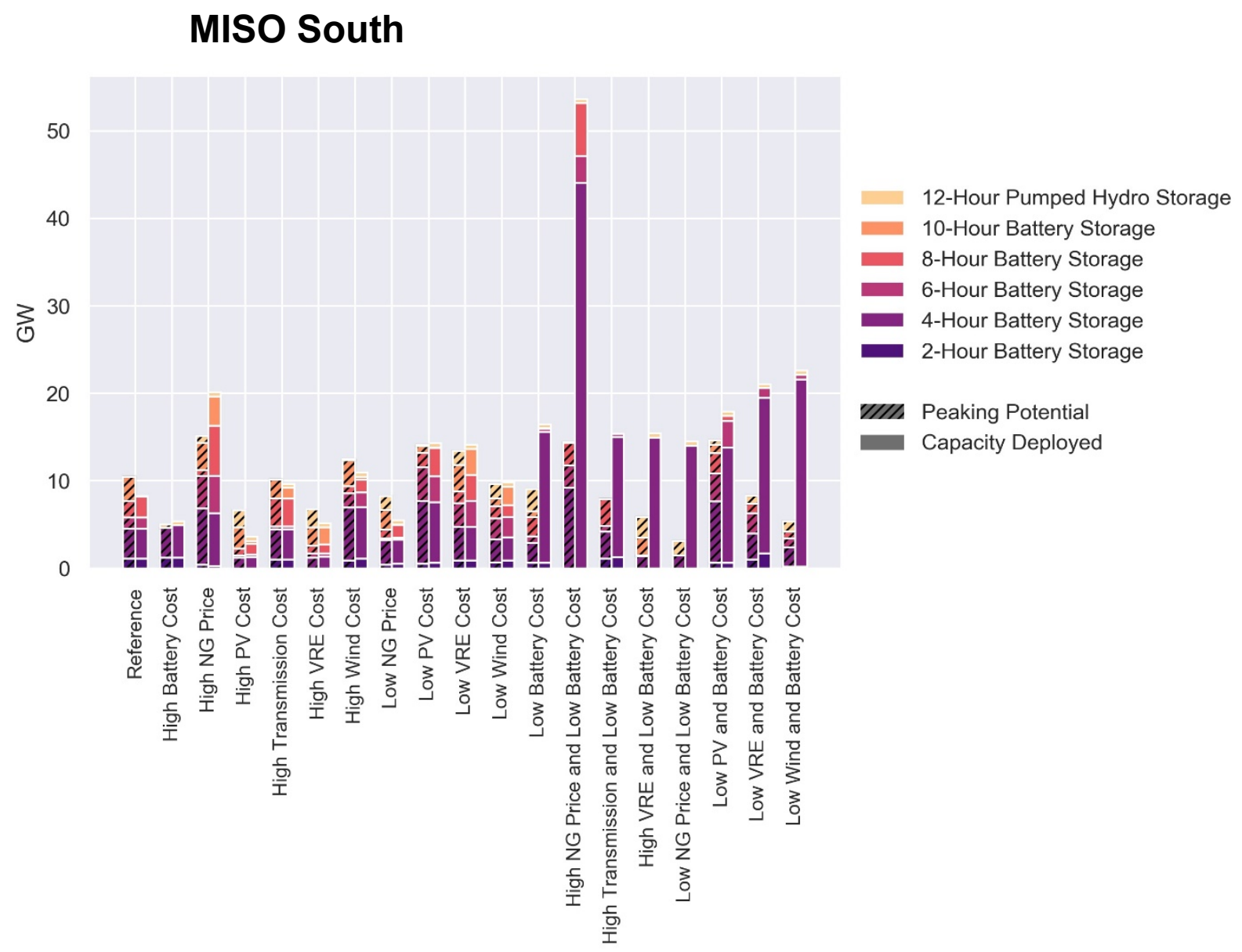

Figure A-12. Economic storage deployment and peaking capacity potential of storage in 2050 in all resource sensitivity scenarios in the MISO South zone (Figure A-7) 


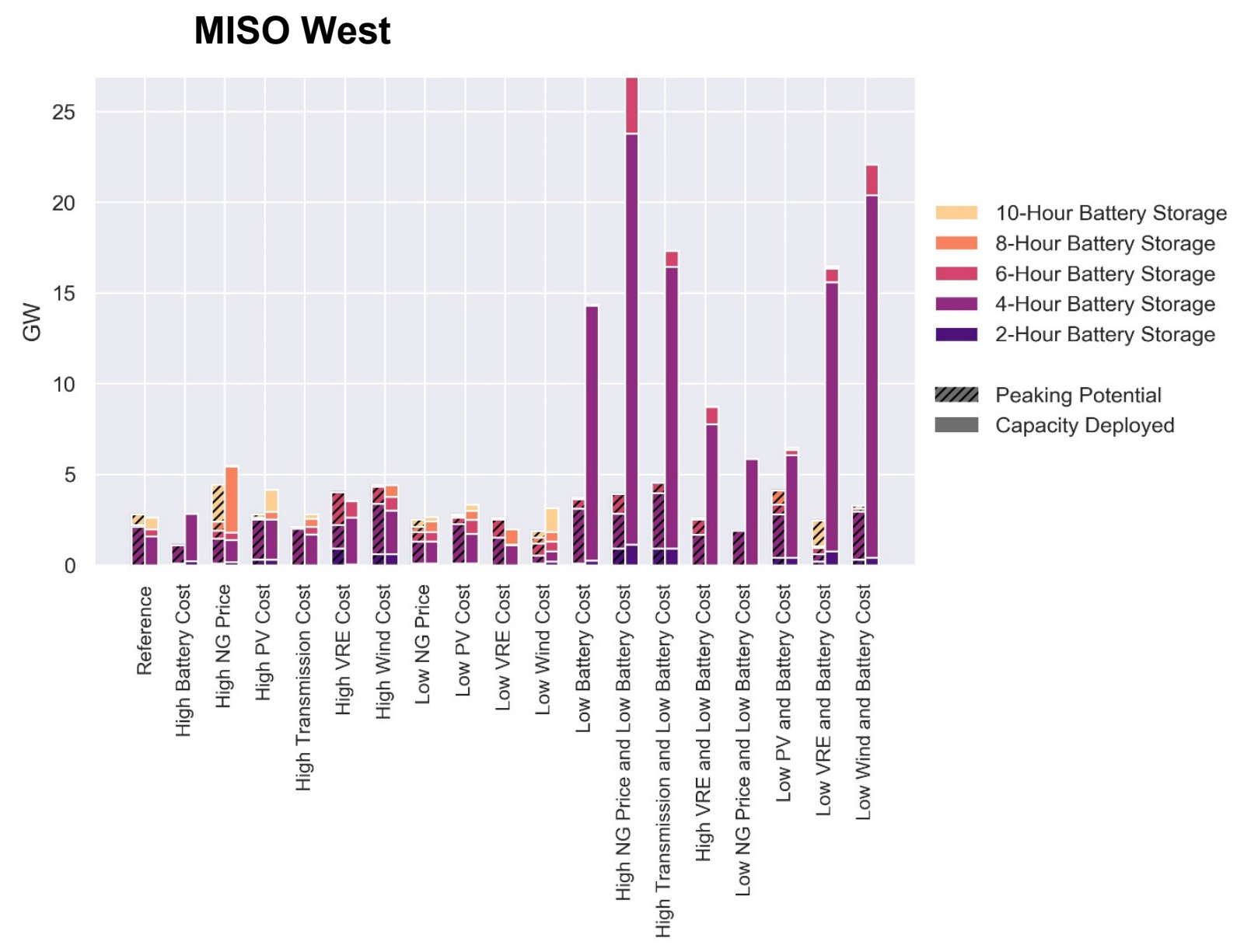

Figure A-13. Economic storage deployment and peaking capacity potential of storage in 2050 in all resource sensitivity scenarios in the MISO West zone (Figure A-7) 


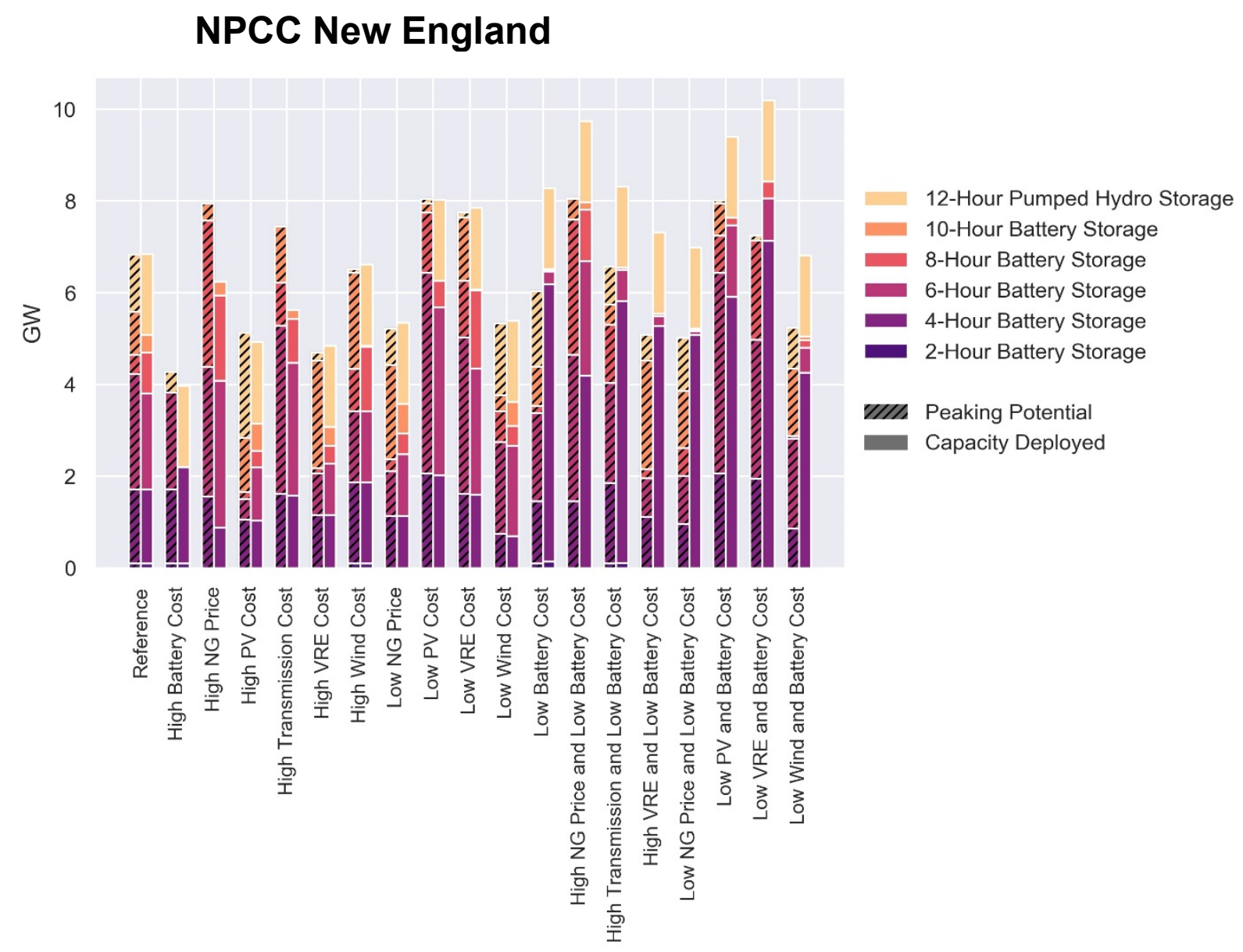

Figure A-14. Economic storage deployment and peaking capacity potential of storage in 2050 in all resource sensitivity scenarios in the NPCC New England zone (Figure A-7) 


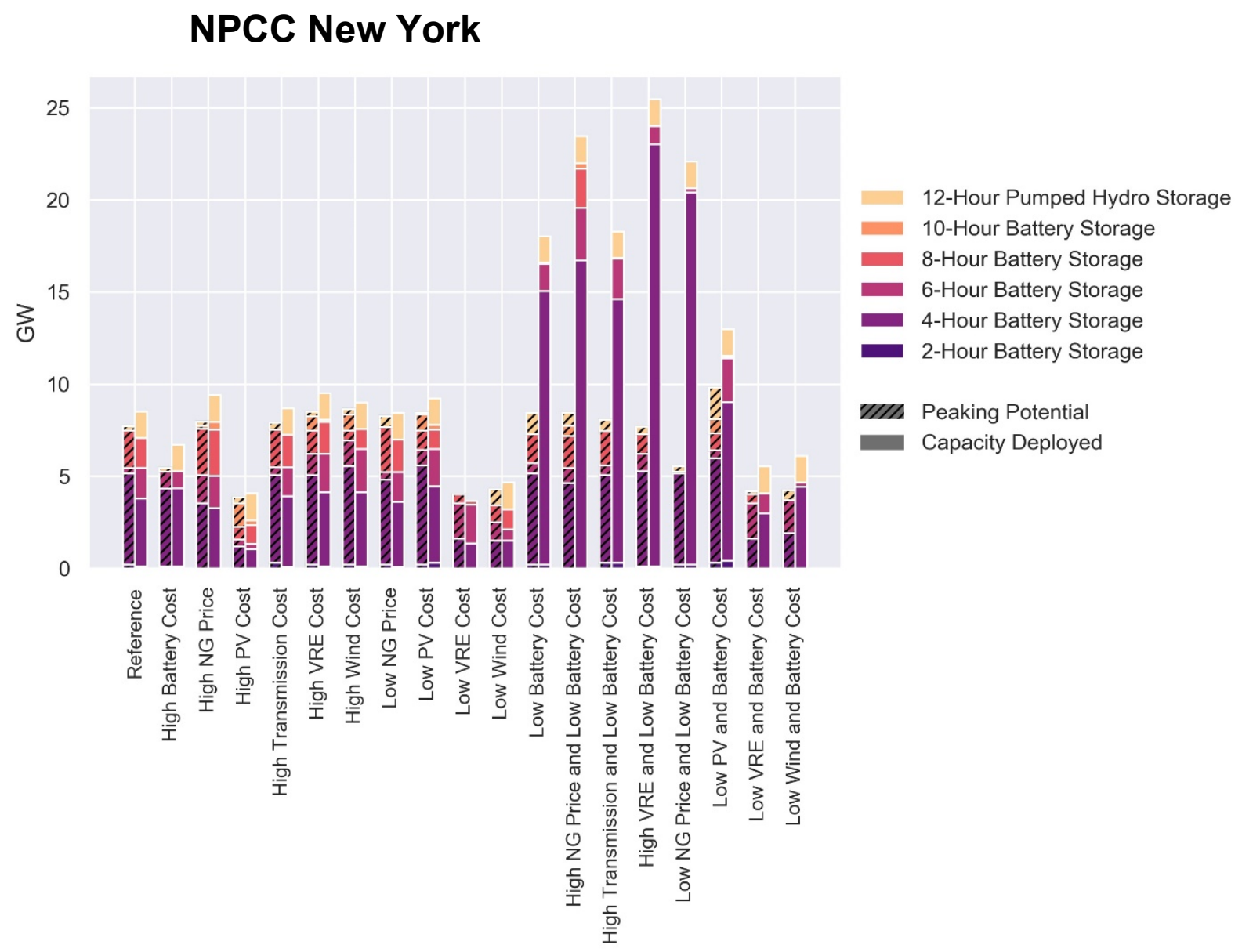

Figure A-15. Economic storage deployment and peaking capacity potential of storage in 2050 in all resource sensitivity scenarios in the NPCC New York zone (Figure A-7) 


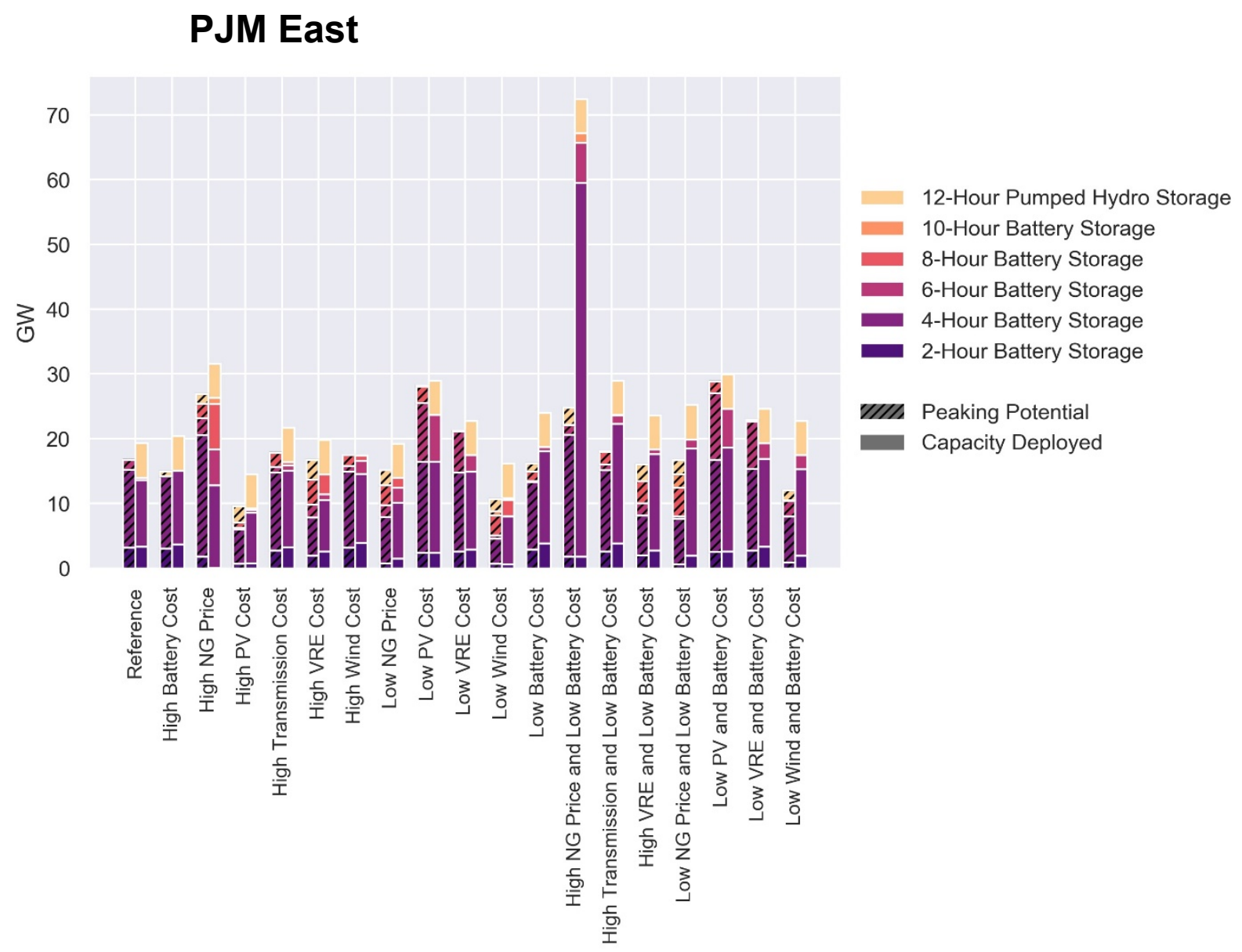

Figure A-16. Economic storage deployment and peaking capacity potential of storage in 2050 in all resource sensitivity scenarios in the PJM East zone (Figure A-7) 


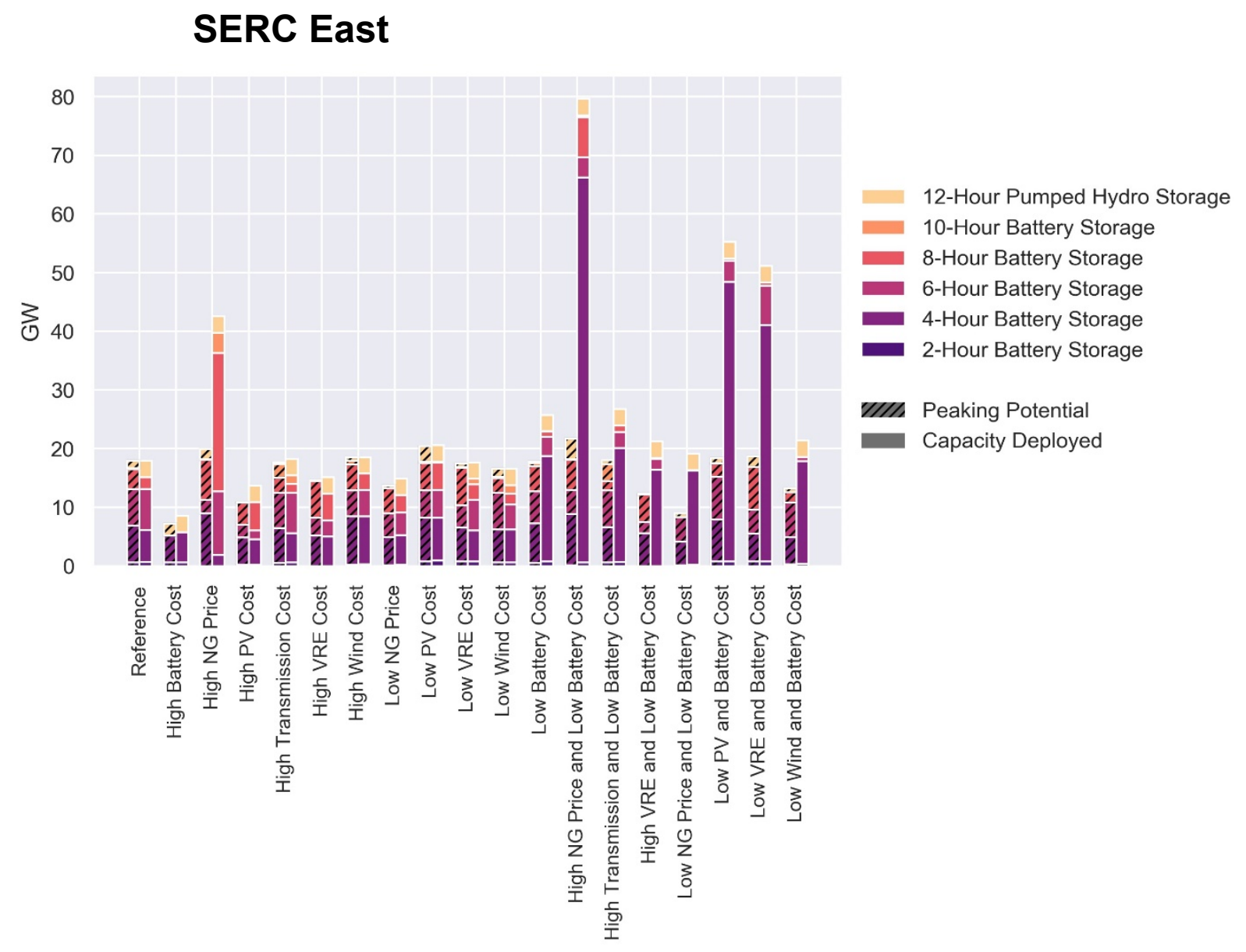

Figure A-17. Economic storage deployment and peaking capacity potential of storage in 2050 in all resource sensitivity scenarios in the SERC East zone (Figure A-7) 


\section{SERC Florida Peninsula}

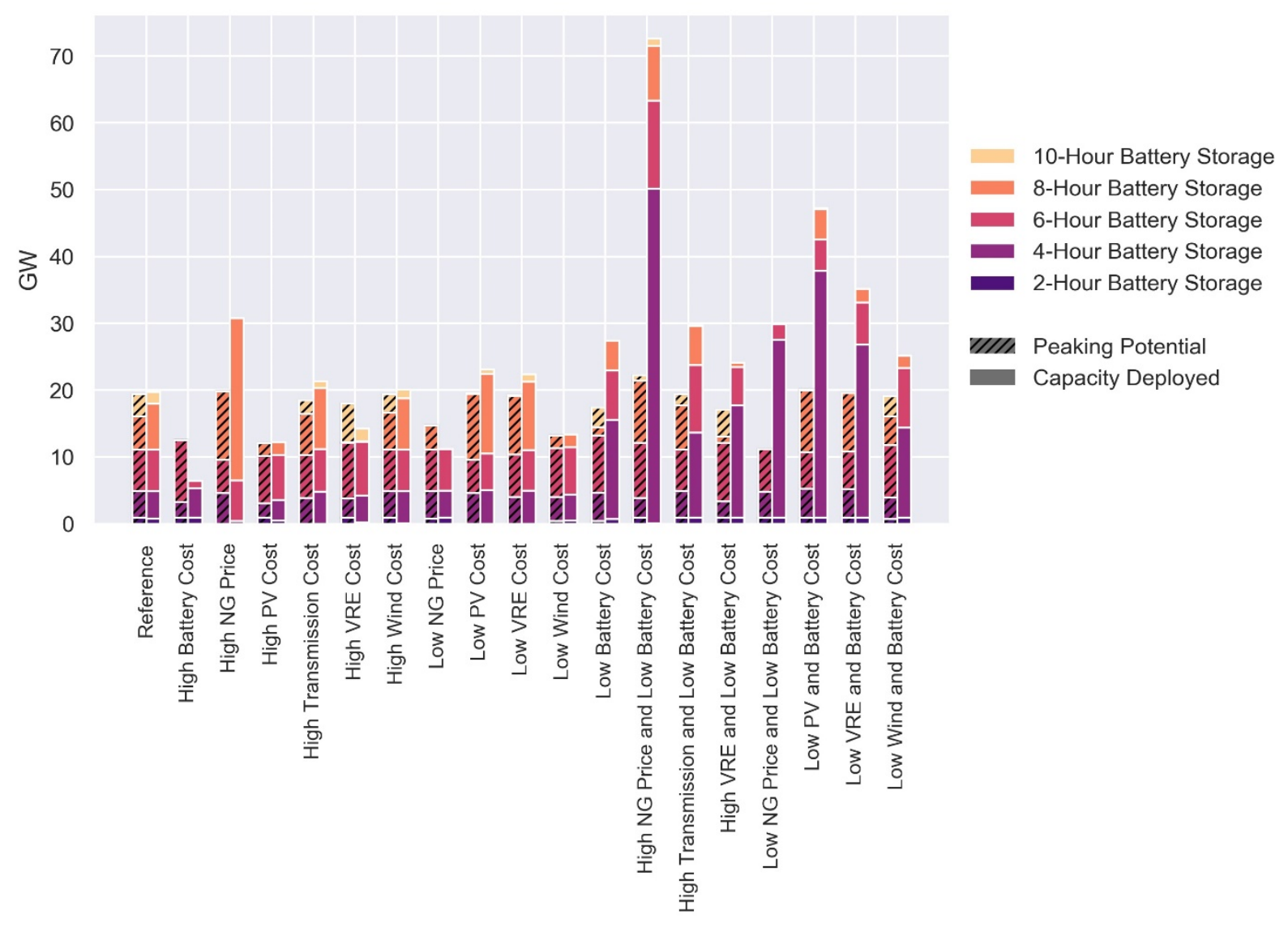

Figure A-18. Economic storage deployment and peaking capacity potential of storage in 2050 in all resource sensitivity scenarios in the SERC Florida Peninsula zone (Figure A-7) 


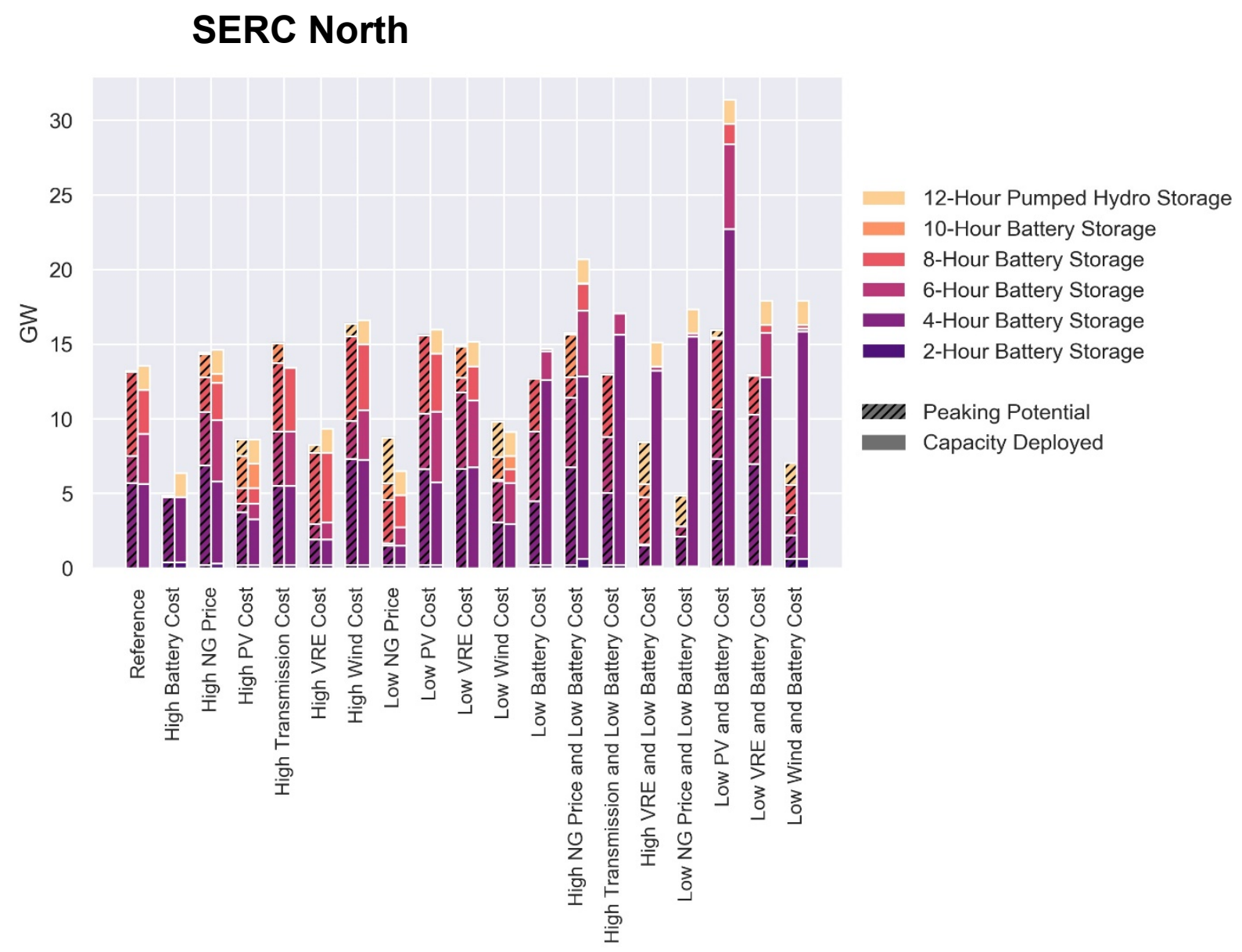

Figure A-19. Economic storage deployment and peaking capacity potential of storage in 2050 in all resource sensitivity scenarios in the SERC North zone (Figure A-7) 


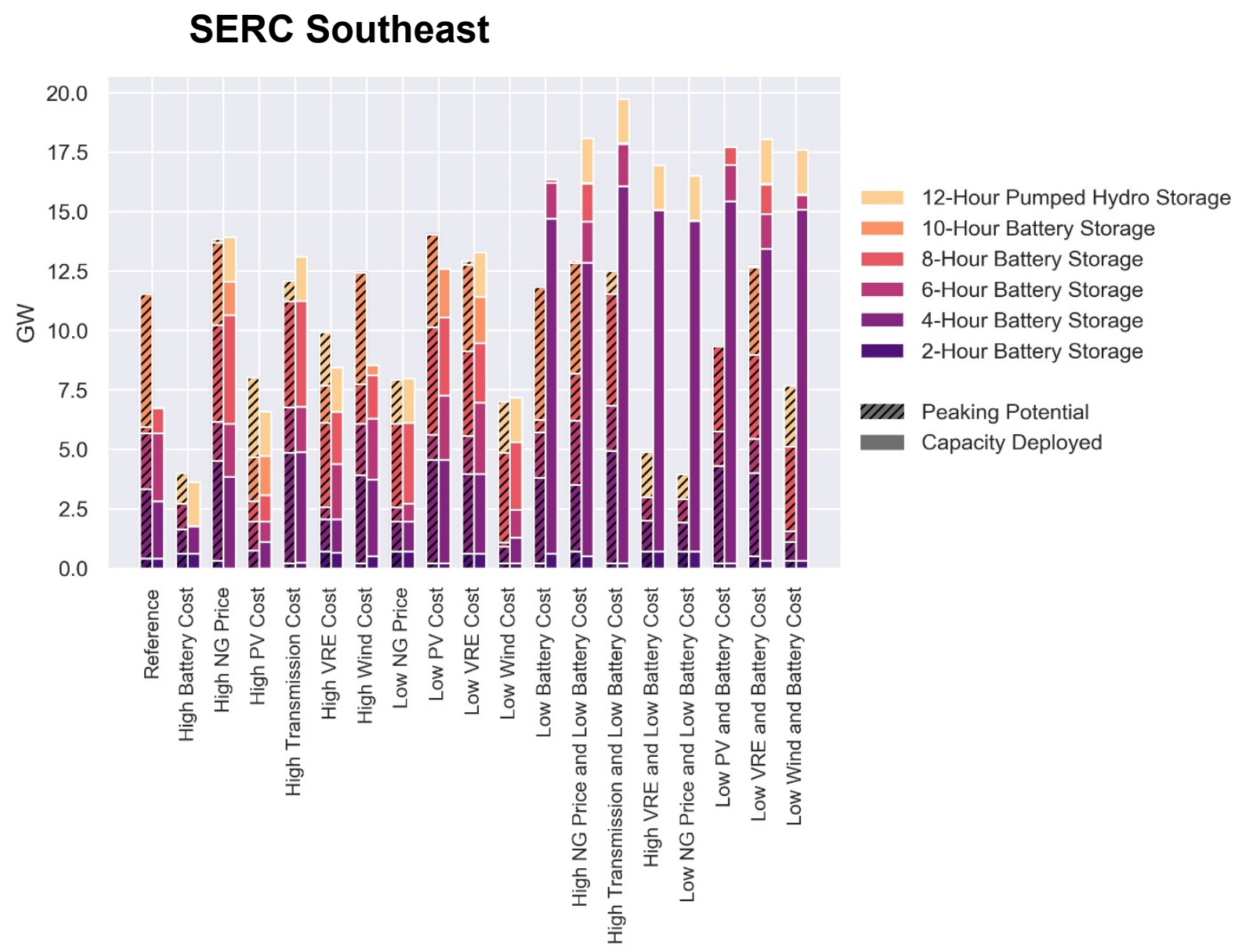

Figure A-20. Economic storage deployment and peaking capacity potential of storage in 2050 in all resource sensitivity scenarios in the SERC Southeast zone (Figure A-7) 


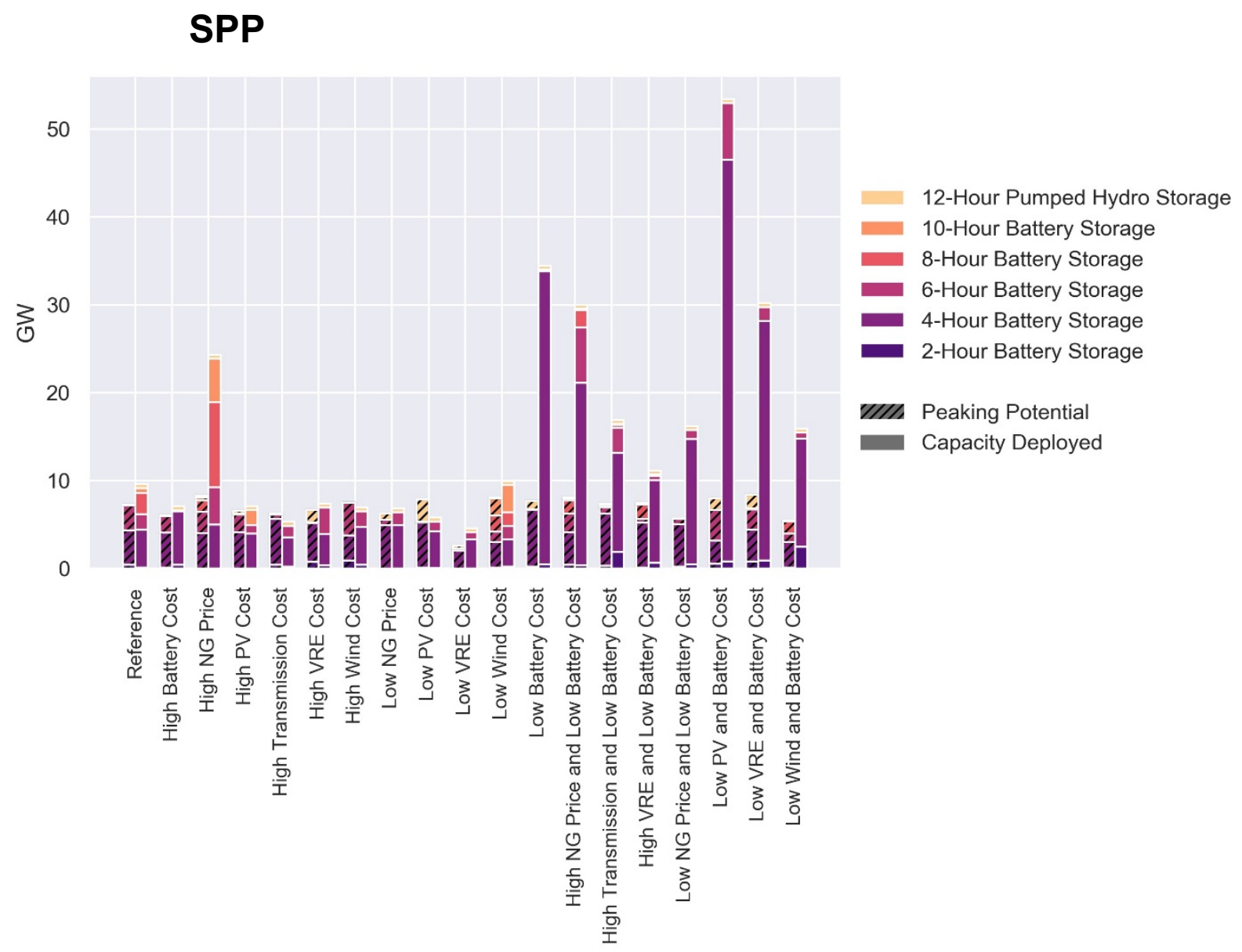

Figure A-21. Economic storage deployment and peaking capacity potential of storage in 2050 in all resource sensitivity scenarios in the SPP zone (Figure A-7) 


\section{WECC California}

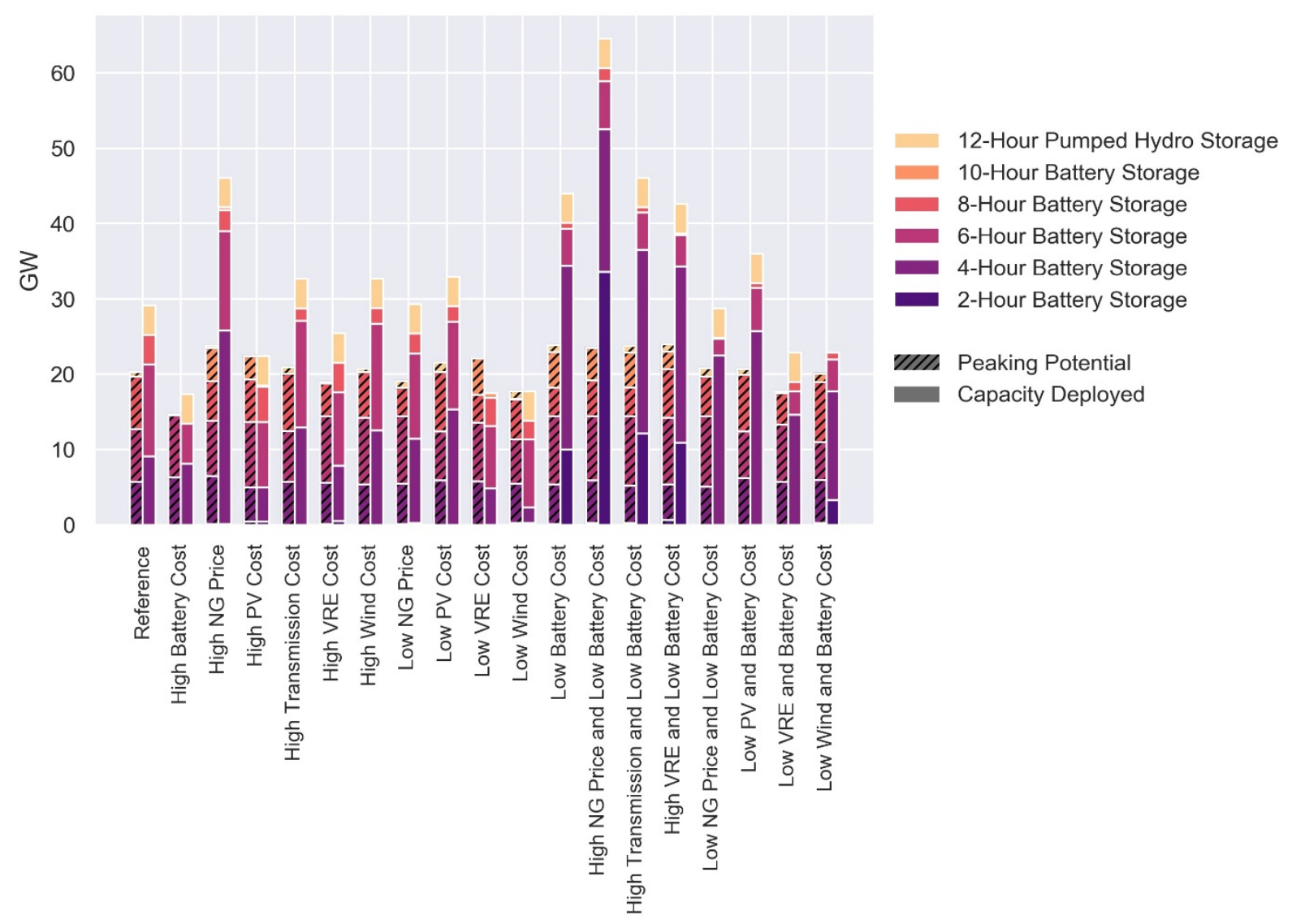

Figure A-22. Economic storage deployment and peaking capacity potential of storage in 2050 in all resource sensitivity scenarios in the WECC California zone (Figure A-7) 


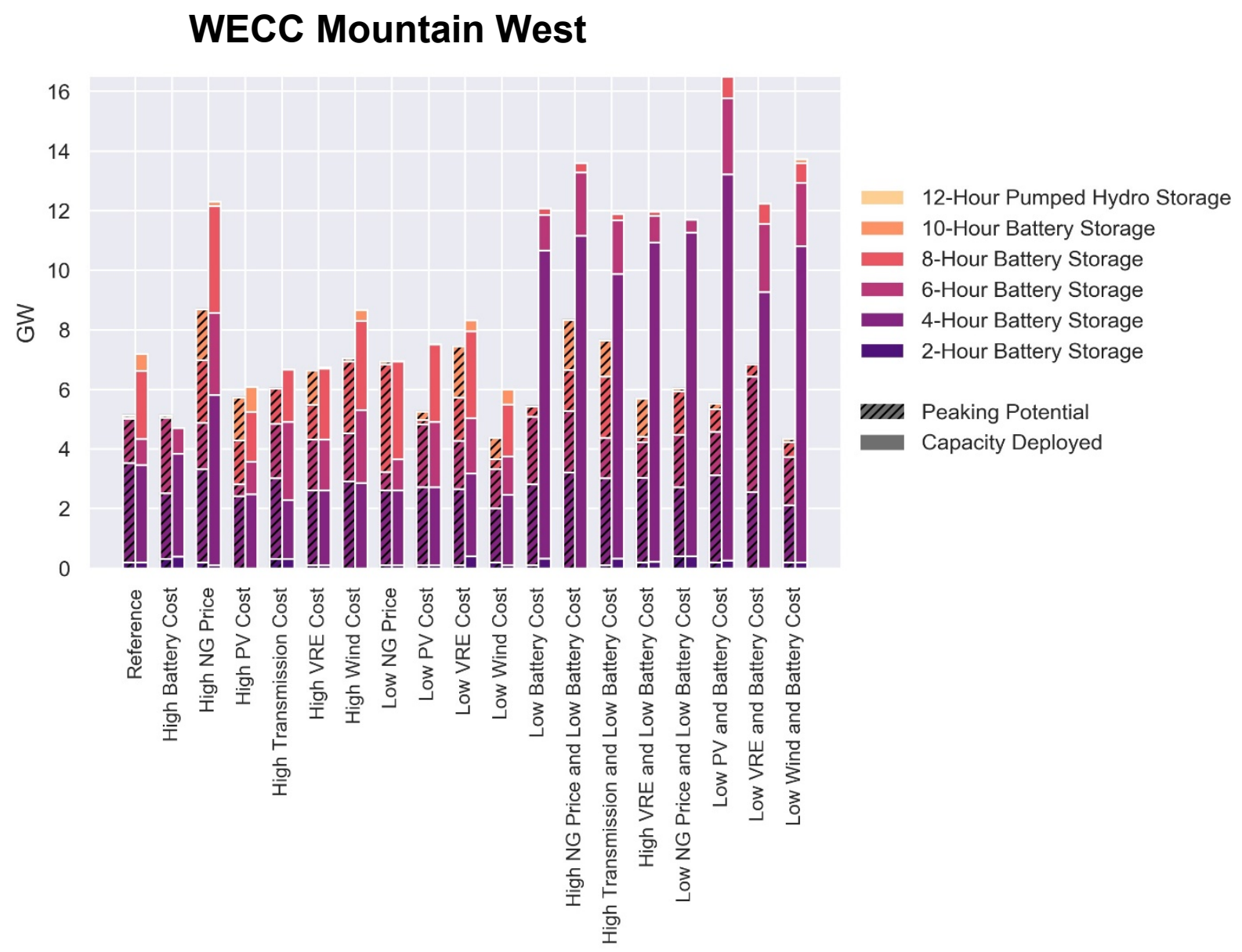

Figure A-23. Economic storage deployment and peaking capacity potential of storage in 2050 in all resource sensitivity scenarios in the WECC Mountain West zone (Figure A-7) 


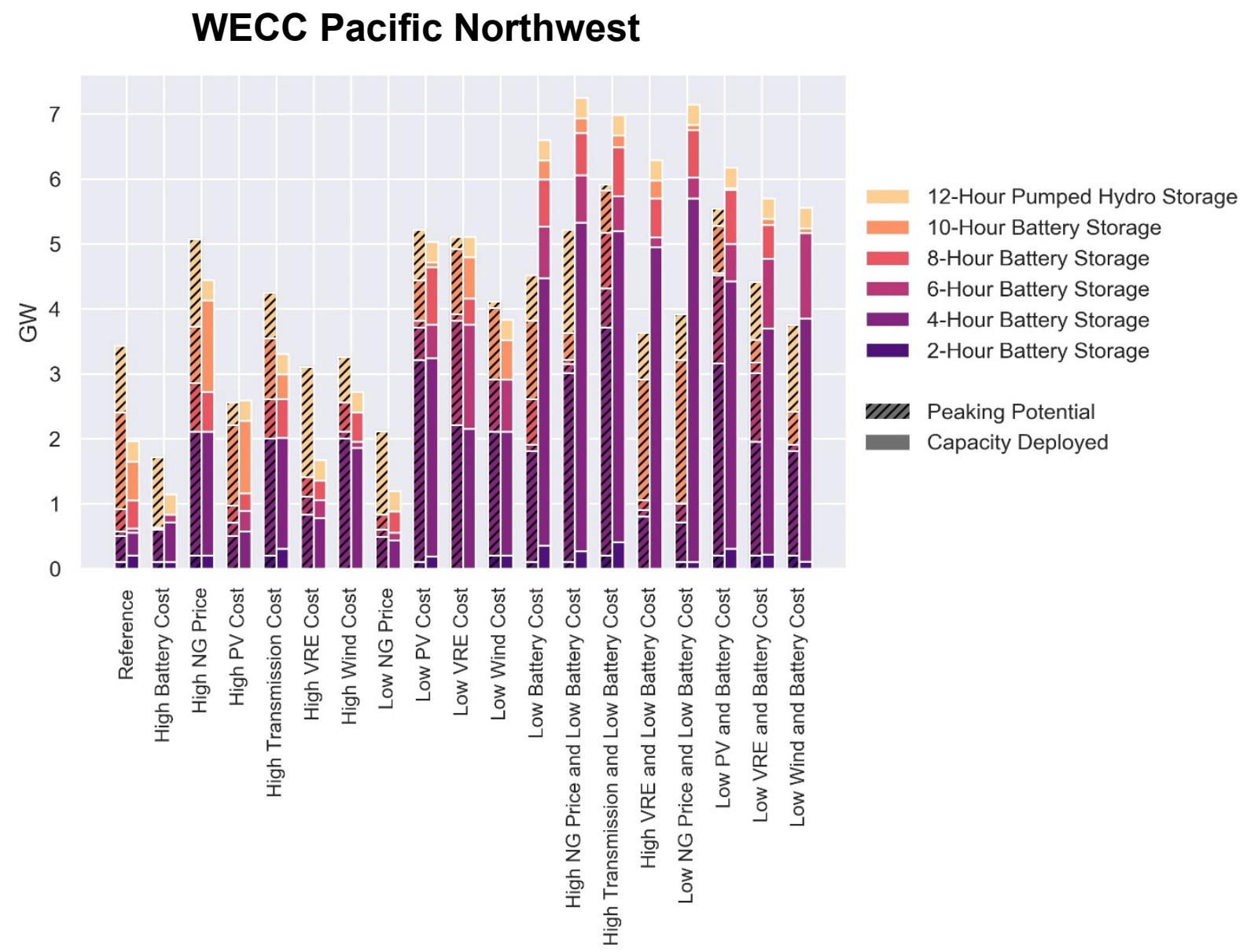

Figure A-24. Economic storage deployment and peaking capacity potential of storage in 2050 in all resource sensitivity scenarios in the WECC Pacific Northwest zone (Figure A-7) 


\section{WECC Rocky Mountain}

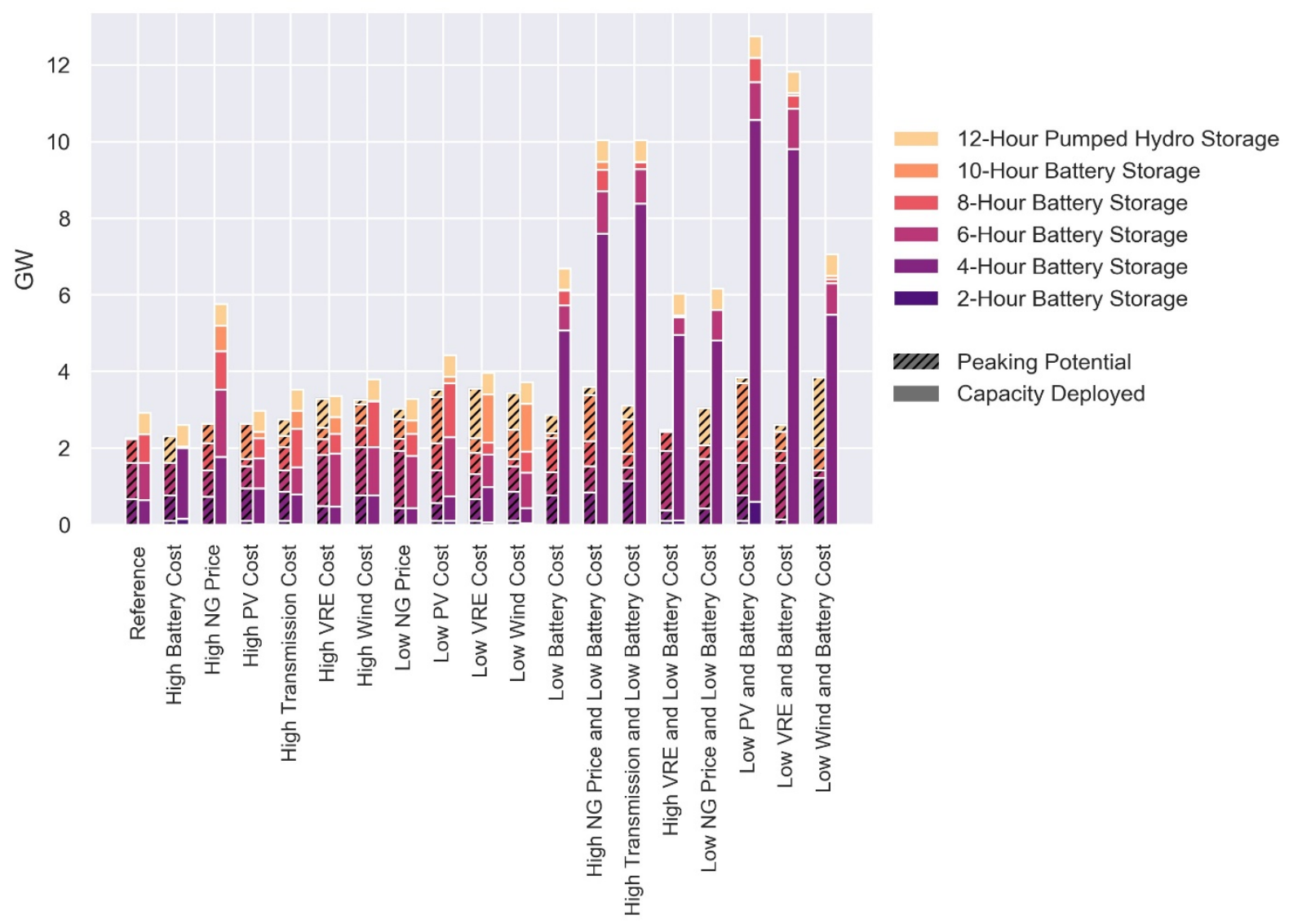

Figure A-25. Economic storage deployment and peaking capacity potential of storage in 2050 in all resource sensitivity scenarios in the WECC Rocky Mountain zone (Figure A-7) 


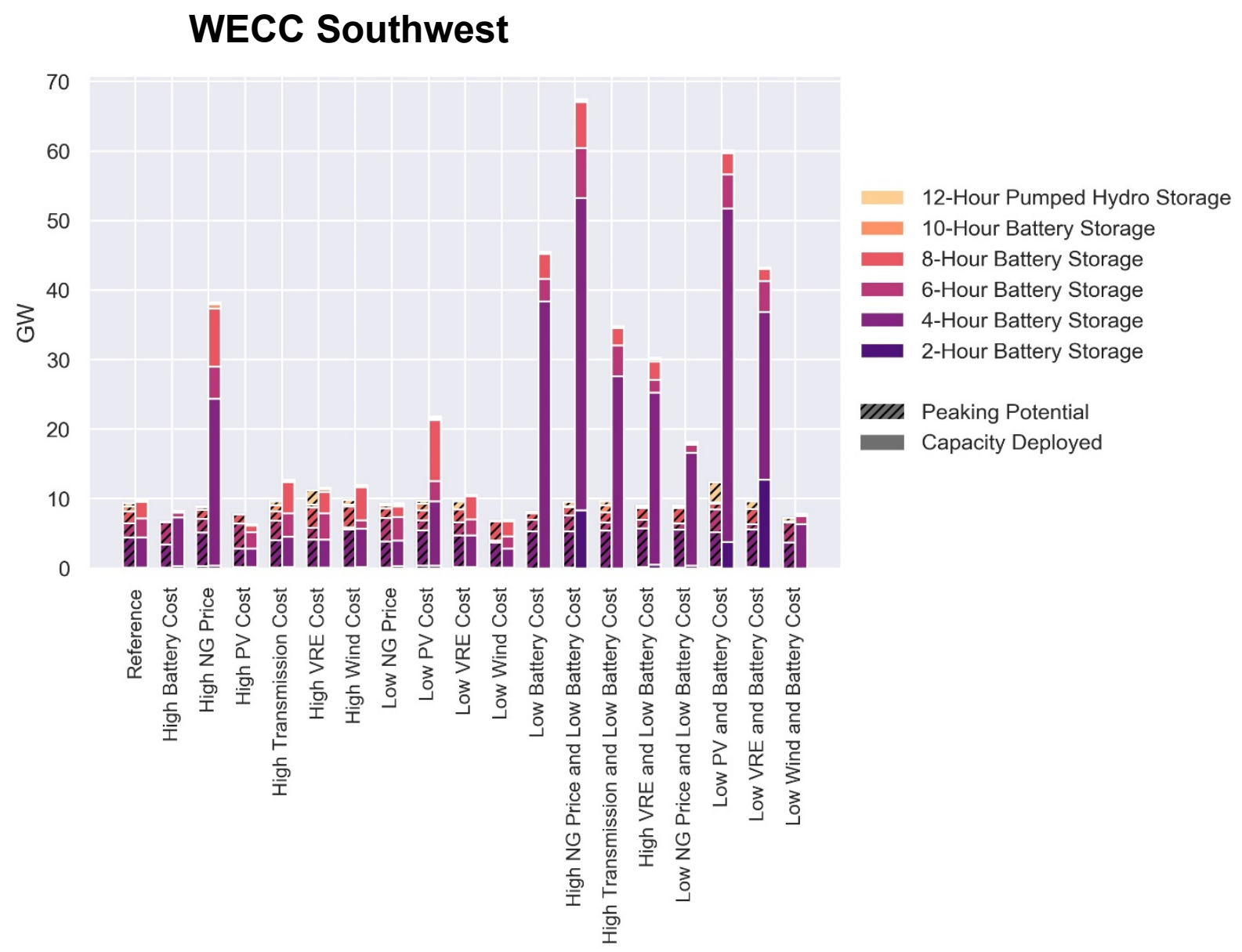

Figure A-26. Economic storage deployment and peaking capacity potential of storage in 2050 in all resource sensitivity scenarios in the WECC Southwest zone (Figure A-7) 


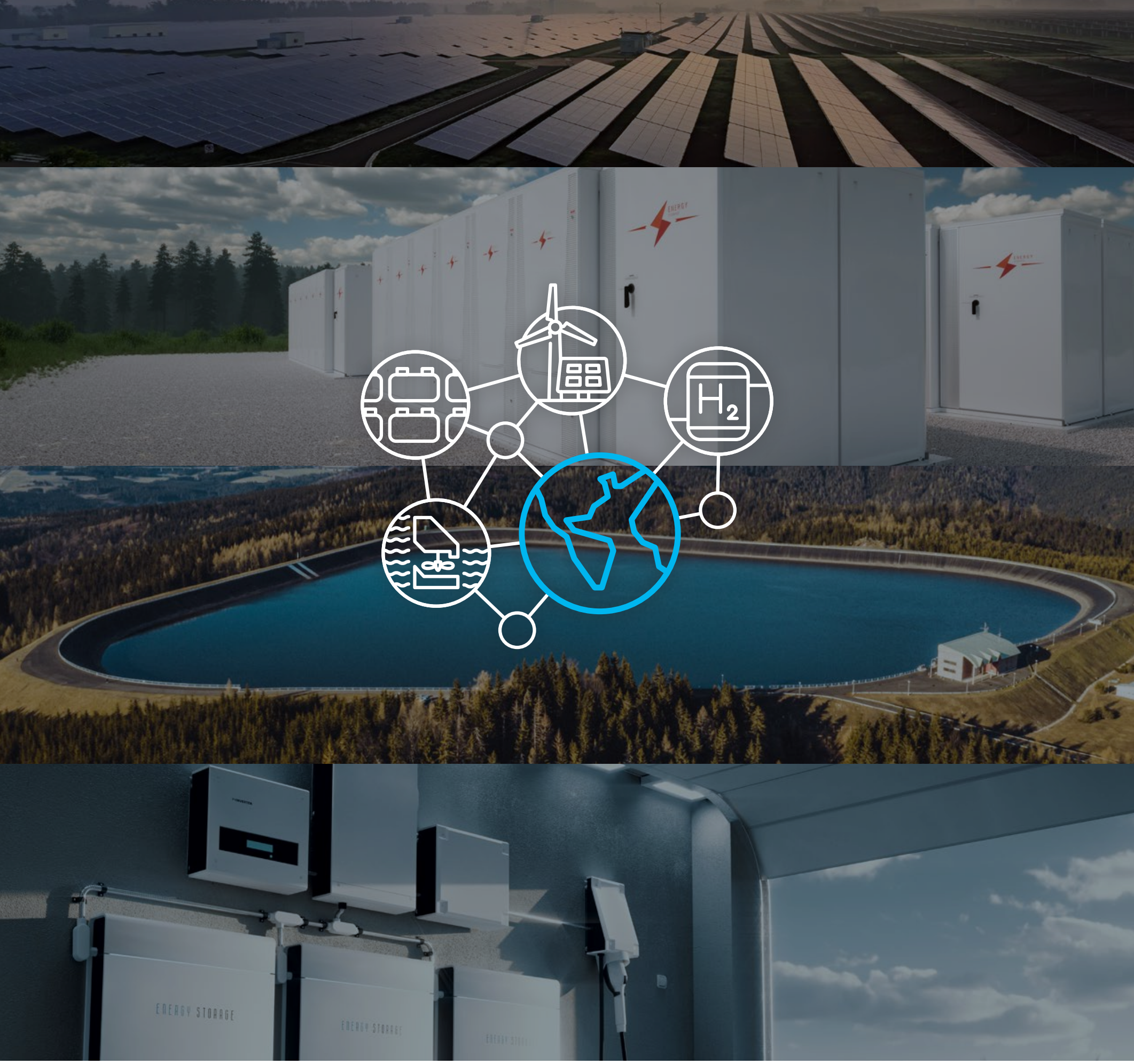

National Renewable Energy Laboratory

15013 Denver West Parkway, Golden, CO 80401 303-275-3000 • www.nrel.gov

NREL prints on paper that contains recycled content.
NREL is a national laboratory of the U.S. Department of Energy Office of Energy Efficiency and Renewable Energy Operated by the Alliance for Sustainable Energy, LLC NREL/TP-6A20-77449 • May 2021 